\title{
The RADARSAT-1
}

\section{Antarctic Mapping Project}
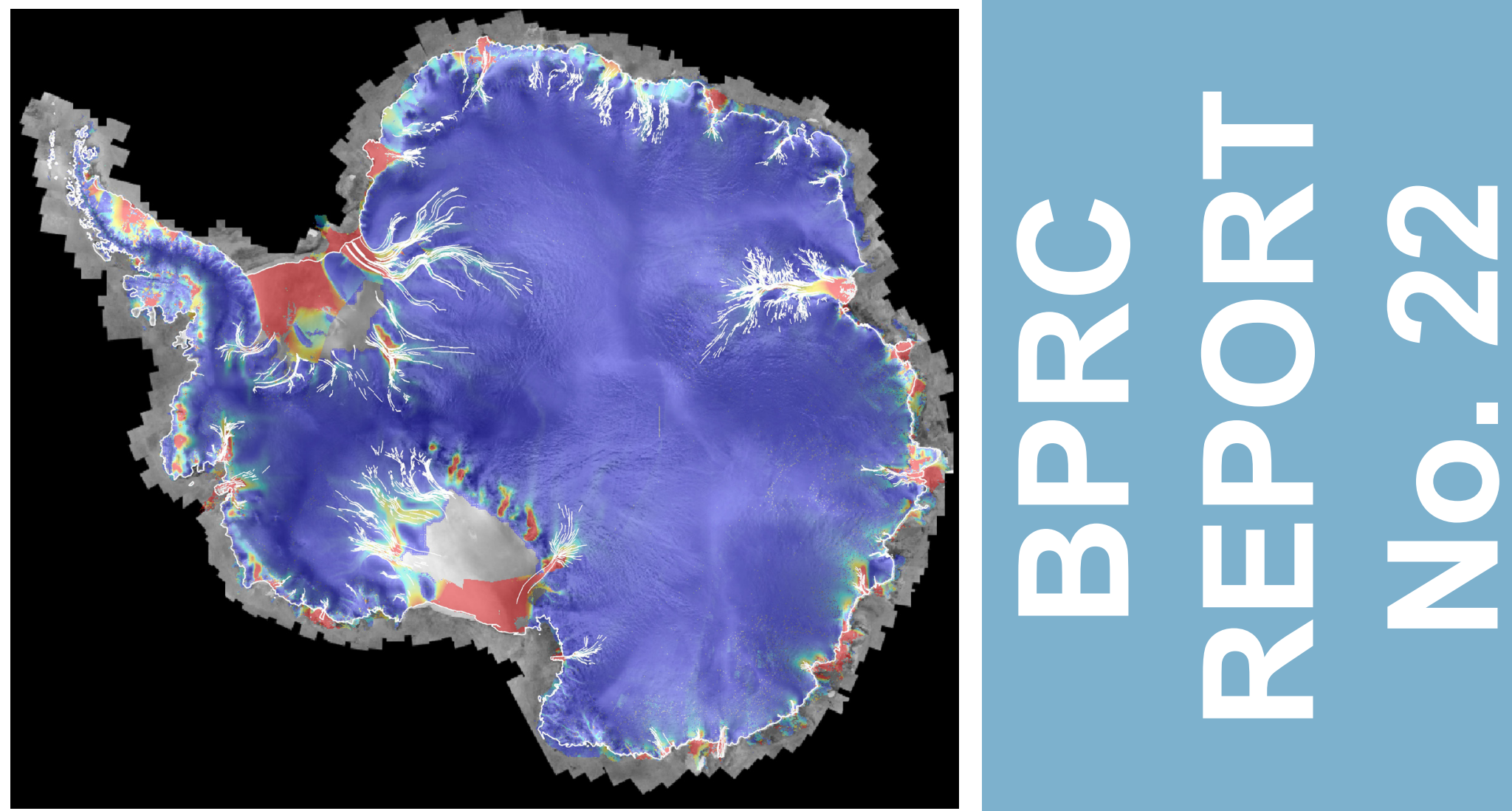


\section{BYRD POLAR RESEARCH CENTER}

Report No. 22

THE RADARSAT-1 ANTARCTIC MAPPING PROJECT

by

Kenneth C. Jezek

2008

ISSN: 0896-2472 


\section{Acknowledgements}

This work was supported by the NASA Pathfinder Program and by the NASA Polar Oceans and Ice Sheets Program. The project also received assistance from the Office of Polar Programs of the National Science Foundation. Of the many dedicated individuals involved in RAMP, Katy Farness and John Crawford merit special mention because of their many important contributions over the duration of the project. We are grateful to the Canadian Space Agency for its substantial support of the project.

Cover Image. Composite of RAMP project InSAR speeds, balance velocity speeds, flow stripes, coastline and SAR mosaic 
Published in 2008 by the

\title{
BYRD POLAR RESEARCH CENTER
}

This report may be cited as:

Jezek, Kenneth C. 2008. The RADARSAT-1 Antarctic Mapping Project. BPRC Report No. 22, Byrd Polar Research Center, The Ohio State University, Columbus, Ohio, 64 pages.

The Byrd Polar Research Center Report Series is edited by Lynn Tipton-Everett.

Copies of this and other publications of the Byrd Polar Research Center are available from:

\author{
Publication Distribution Program \\ Byrd Polar Research Center \\ The Ohio State University \\ 1090 Carmack Road \\ Columbus, Ohio 43210-1002 \\ Telephone: 614-292-6715
}




\section{Table of Contents}

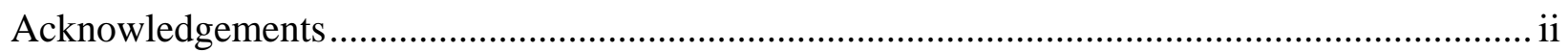

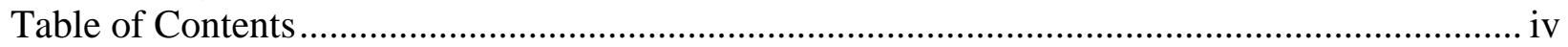

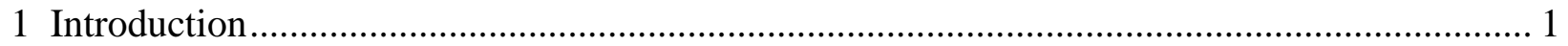

1.1 RAMP Program Development .................................................................................. 1

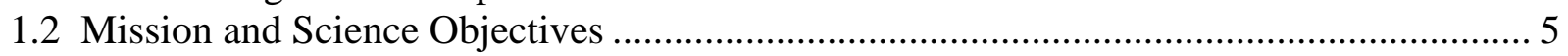

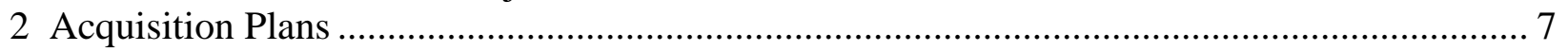

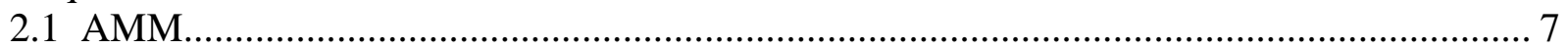

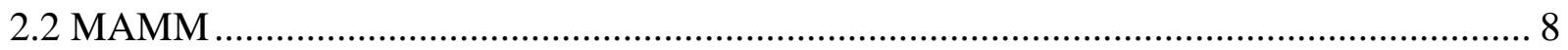

2.3 Mission Acquisition Statistics...................................................................................... 9

3 Image Processing Methodology and Map Products..................................................................... 10

3.1 Image Mosaic Processing Approach................................................................................. 10

3.1.1 Orthorectification and block processing overview ……........................................... 11

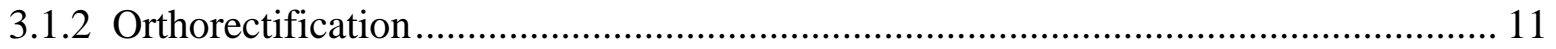

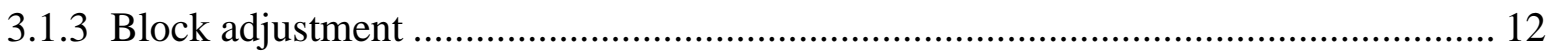

3.2 Mapping Ground Control Points...................................................................................... 13

3.3 AMM-1 and MAMM Image Mosaics and Derived Products.............................................. 13

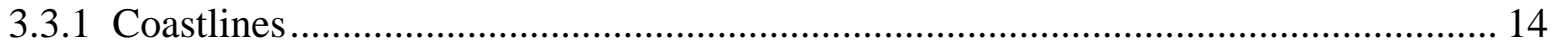

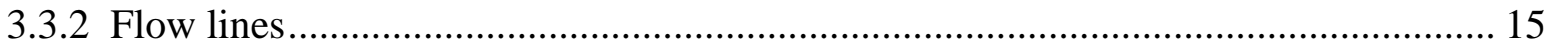

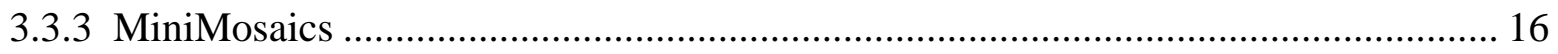

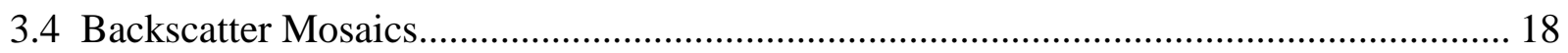

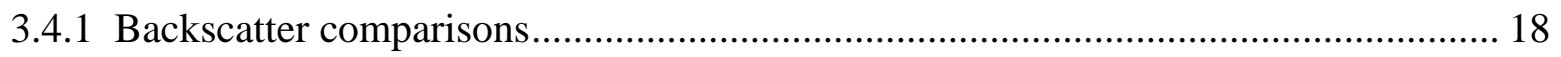

3.4.2 Validation calibration......................................................................................... 19

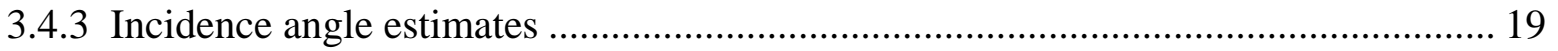

4 Interferometric Processing Methodology and Velocity Products ............................................... 20

4.1 MAMM InSAR Methodology ……………………..................................................... 20

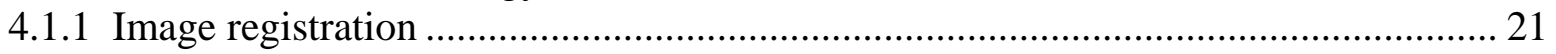

4.1.2 Interferogram and offset map mosaics........................................................................ 23

4.1.3 Missing line and azimuth streak removal .................................................................. 23

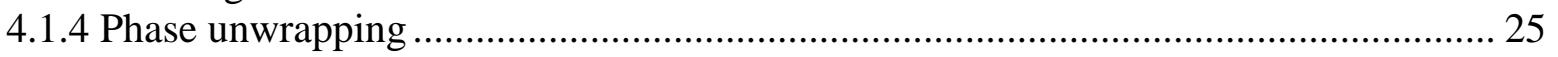

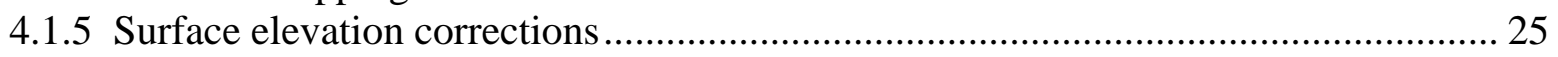

4.1.6 Velocity from a single interferogram........................................................................ 25

4.1.7 Velocity error sources .................................................................................................. 26

4.1.8 Velocity map from ascending and descending azimuth velocity component.............. 27

4.1.9 Velocity map from ascending and descending range velocity component.................. 27

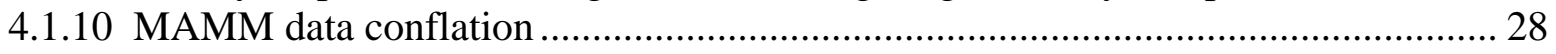

4.2 MAMM Velocity Control Points ............................................................................... 29

4.3 Balance Velocity Mosaic .......................................................................................... 30

4.4 Coherence Mosaics and Interferograms........................................................................... 31

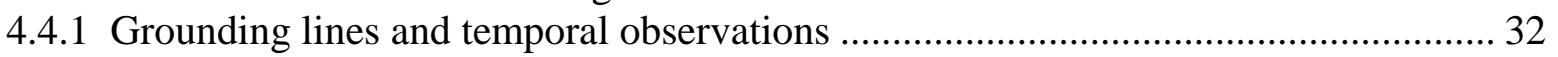

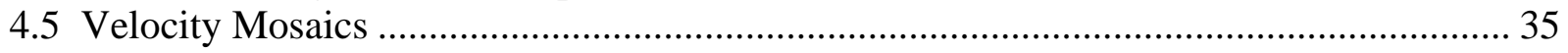

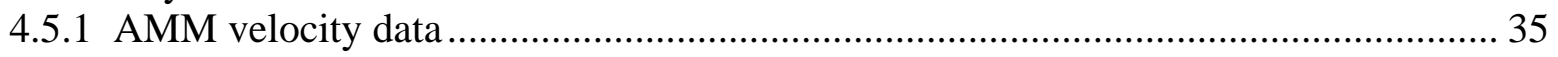

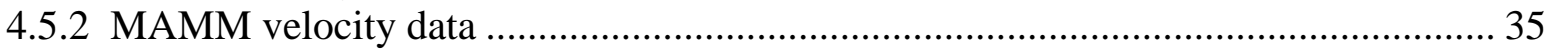




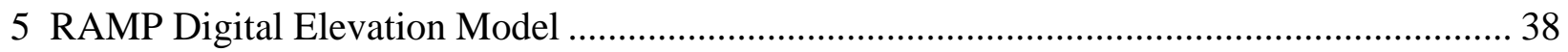

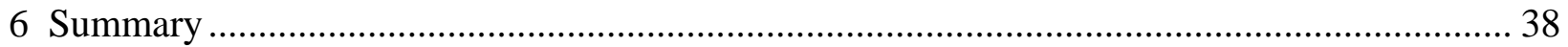

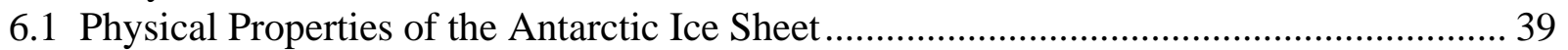

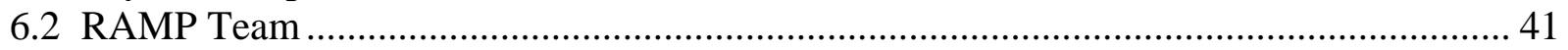

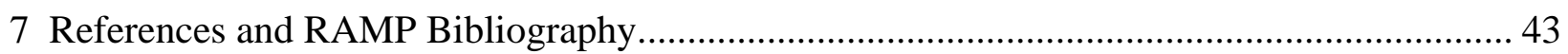

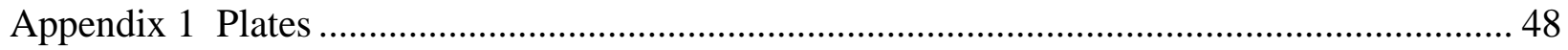

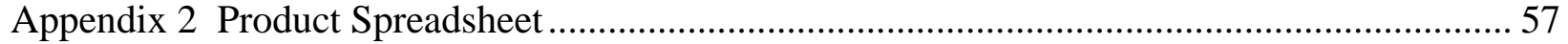

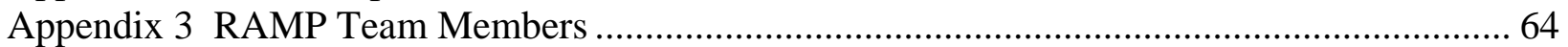




\section{Executive Summary}

This report summarizes the motivation, processing procedures and products that were part of the RADARSAT-1 Antarctic Mapping Project (RAMP). RAMP was a collaboration between NASA and the Canadian Space Agency to map Antarctica using the RADARSAT -1 Synthetic Aperture Radar. The project proceeded in two parts. The first part, called Antarctic Mapping Mission -1 that acquired data in 1997, resulted in the first high-resolution radar map of Antarctica. The second part, called the Modified Antarctic Mapping Mission which occurred in 2000, remapped the continent below $80^{\circ} \mathrm{S}$ latitude and exploited interferometric repeat-pass observations to estimate glacier surface velocities.

RAMP project goals and objectives are reviewed here along with several science highlights. These highlights include observations of ice sheet margin change using both RAMP and historical data sets, the discovery of large ice streams in Coates Land, observations of the ice sheet surface-velocity field and changes in the velocity field, and observations of surface change using radar coherence. RAMP data products are summarized and a tabulated list of data products is appended to this report. The appendix also lists all of the partner organizations, including the Alaska Satellite Facility (ASF) DAAC, who have received a copy of the complete data set. 


\section{Introduction}

Borne aloft by a NASA rocket launched from Vandenburg Air Force Base on November 4, 1995, the Canadian Radarsat-1 carried a C-band Synthetic Aperture Radar (SAR) capable of acquiring high resolution $(25 \mathrm{~m})$ images of Earth's surface day or night and under all weather conditions. The RADARSAT-1 SAR collected data using a variety of swath widths, incidence angles and resolutions. Most importantly, for observations of Antarctica, RADARSAT-1 maneuvered in orbit to rotate the normally right-looking SAR to a left-looking mode. This 'Antarctic Mode' provided capability for obtaining the first, nearly instantaneous, high-resolution views of the entirety of Antarctica in 1997. Satellite rotation occurred on September 10. Acquisitions began September 19 ending on October 19. This period was designated as the first Antarctic Mapping Mission (AMM-1). The second, Modified Antarctic Mapping Mission (MAMM) began on September 3, 2000 and was successfully concluded on November 17, 2000. For both projects, The Ohio State University (OSU) directed the overall project and scientific activities. OSU also computed the final products. The ASF acquired all data and processed AMM-1 signal data to images. ASF also transcribed MAMM signal data for later processing at OSU. The Jet Propulsion Laboratory (JPL) developed acquisition strategies and was responsible for early ASF data processing system development. Vexcel Corporation developed the RADARSAT-1 Antarctic Mapping System used by OSU to create final products. The Environmental Research Institute of Michigan (ERIM), along with many international participants who contributed via the Scientific Committee for Antarctic Research (SCAR), provided geodetic control for the final map and velocity products. NASA Goddard Space Flight Center (GSFC) and NASA Headquarters provided program management oversight. The Office of Polar Programs of the National Science Foundation provided operational support for the McMurdo Ground Station and field work by the RAMP team.

\subsection{RAMP Program Development}

The RADARSAT-1 Antarctic Mapping Project was conceived in the early 1980's by Stan Wilson, Bob Thomas and Bill Townsend of NASA Headquarters' Oceans Branch. The idea developed as part of negotiations over participation by NASA in the Canadian Space Agency's RADARSAT-1 project. Both Ed Langham at CSA and Shelby Tilford at NASA reacted favorably to the exciting concept, and two complete mappings of the Antarctic were included in the Memorandum of Understanding eventually signed by the agencies in about 1985.

Recognizing the importance of radar mapping of polar ice sheets, Frank Carsey and Ben Holt, both of the Jet Propulsion Laboratory, prepared a brief report entitled Mapping Antarctica and Greenland with Shuttle Imaging Radar (Carsey and Holt, 1985). The report sketched the scientific objectives for radar mapping of ice sheets and discussed a possible mapping campaign to be conducted as part of the SIR-B reflight. The advantage of the shuttle project was provision of data much sooner than any of several planned free-flying SARs. The key technical innovation was to launch the shuttle from Vandenburg Air Force Base so as to place the shuttle in an 88 degree inclination orbit. SIR-B was planned for launch in March 1987 and the crew was to include Kathy Sullivan, who worked with Carsey, Holt, Ken Jezek (who at the time was with 
NASA HQ) and the science team to prepare for the mission. With the report as background material, Carsey and Holt convened a meeting at JPL during October of 1985. The meeting was followed first by a late 1985 draft proposal and second, with help from NSF and Ian Whillans, the installation of several corner reflectors in Antarctica during that austral summer. Regrettably, the SIR-B reflight plans were abandoned when, after the catastrophic loss of the Challenger Space Shuttle in January of 1986, NASA designated the Kennedy Space Center as the sole location for future shuttle launches. That decision precluded launch of the shuttle into polar orbit. Nevertheless, Carsey and Holt's effort laid the foundation for understanding the operational constraints behind a future mission.

At about the same time, NASA was solidifying plans for the construction of a northern ground receiving station. After consideration of several sites, NASA selected the Geophysical Institute (GI) of the University of Alaska as the optimal site based on the station mask which stretched far out over the western basin of the Arctic Ocean. NASA also recognized the mutual benefits of co-locating a satellite station within the GI's already strong research environment. Much of the scientific focus of the ASF at that time was concentrated on Arctic sea ice as set forth by the Program for International Polar Oceans Research (PIPOR). The agencies continued background plans for mapping the polar ice sheets in anticipation of the early 1990's launch of the European Space Agency ERS-1 satellite, but with an eye toward the additional capabilities expected for Japan's JERS-1 and, in particular, Canada’s RADARSAT-1 (NRC, 1989).

In November 1990, The Byrd Polar Research Center (BPRC) hosted a conference to examine capabilities for collecting data over the southern continent and the surrounding ice covered waters. The main objectives of the meeting were to review potential science pay-off from a major SAR mapping campaign and to look at limitations associated with the planned instrument suite of that time. Participants concluded that given constraints on downlink capabilities (ERS-1 for example had no onboard recording for example) and limitations in expected on board tape recorder data volume, Antarctic coverage could be optimized by developing a ground receiving station at McMurdo Ground Station (MGS) Antarctica (Jezek and Carsey, 1991). They recommended that the station operations be modeled after the ASF and that data received at the MGS be transferred to ASF for processing, distribution and archival. The recommendation was accepted by NASA and NSF in 1992 and the MGS became operational in 1994.

With the successful launch of ERS-1 in 1991 and the beginning of routine operations at the ASF, the science community began to concentrate on plans for a complete mapping of Antarctica using RADARSAT-1. BPRC hosted a second meeting in March 1993 to prepare more detailed requirements for the proposed mission (Jezek and Carsey 1993). The meeting was attended by Martha Maiden who represented NASA's Pathfinder Project, members of the glaciological community, representatives from CSA and the 4 partners in the RAMP activity, namely BPRC, ASF, Vexcel and JPL. John Crawford from JPL and Ed Oshel from OSU provided the first estimates of acquisition duration at the meeting. They estimated that 24 days were required to fulfill all mapping and stereo mapping goals. They found that about 17 days were required to meet the mapping requirements. This estimate was later refined by Crawford who concluded that the acquisition period required a minimum of 18 days. 
Mission preparations intensified during the mid-1990's and detailed plans were developed during a series of meetings between the team members, NASA and CSA. The plan was refined to specify acquisitions at both ASF and MGS as well as at Canadian Ground Receiving Stations. ASF would be responsible for accumulating and for processing all the signal data to images using SAR processing systems developed by JPL. OSU would construct the image mosaics using software developed by John Curlander, Lynne Norikane and Bob Wilson from Vexcel. JPL would develop the mission plan, and together with OSU would be on hand to monitor and modify the acquisition plan as needed during the mission. With the successful launch of RADARSAT-1 in 1995, final responsibilities for each aspect of the mapping plan were formalized in a series of requirement documents in early 1996 and which aimed at a mapping mission during the fall of 1997.

In 1996, Erick Chiang of the Office of Polar Programs of the National Science Foundation arranged for Frank Carsey to visit the McMurdo Ground Station. The objective was to observe the overall operation of the facility but also to discuss preparations for a 1997 imaging campaign. Ken Jezek and Robert Onstott, from ERIM, joined Carsey on the trip partly to better understand operations at MGS but primarily to install radar transponders at McMurdo and South Pole Station. The NSF transponders and other ground control would be used to constrain the orbit ephemeris to be used in latter data processing.

Vanessa Griffin and Dick Monson, both from NASA, and Ken Jezek traveled to St. Hubert in January 1997 for the RADARSAT-1 Antarctic Imaging Campaign kick-off meeting. George Harris was identified as the CSA Project Manager under Dan Showalter. Ken Lord and Ken Ashworth discussed aspects of the imaging campaign implementation which required a rotation of the satellite for southerly observations. The objective of the meeting was the formal go-ahead subsequently received from Rolf Mamen and Ed Langham. In addition operational procedures were discussed for mission planning, rehearsals and contingencies.

Refinements of John Crawford's acquisition plan and project rehearsals continued throughout the 1997 summer. Crawford and Rejean Michaud with help from Nettie LaBelle-Hamer and Jean Muller assumed most of the responsibility for the mission planning preparations under the supervision of Ken Lord. Planning for receipt of data at ASF and MGS was organized by Carl Wales of ASF with much of the daily responsibility falling on Marc Forbes, Dick Harding, Greta Reynolds, and Nettie LaBelle-Hamer. Tom Bicknell, Dave Nichols, Pat Liggett and Dave Cuddy from JPL were responsible for SAR processor preparations. Jason Williams from ASF and Satish Srivastiva from CSA were responsible for calibration preparation and Jamie Marshner was responsible for simulations and testing of the end to end system at ASF. Verne Kaupp led the ASF science team preparations along with Ben Holt. Prasad Gogineni, then at NASA HQ, was responsible for overall program management of the effort and Paul Ondrus from GSFC was responsible for day-to-day crisis management.

Final preparations for the 1997 imaging campaign included positioning people at various stations across the northern hemisphere. Katy Farness and Biyan Li from OSU were stationed at the Gatineau and Prince Albert Ground Stations to monitor downlinks at those sites. Ben Holt, Rick Forster, Frank Carsey, Rick Guritz and Sue Digby were stationed at ASF for similar work and to conduct preliminary science analysis. Rick Austin joined the mission planning team to help with 
replanning work. Hong Xing Liu and Hong Gyoo Sohn remained at OSU to help with acquisition summaries and swath mapping.

Satellite rotation was successfully engineered on September 10 and acquisitions proceeded as planned a few days later (Jezek, 1998). Antarctic data acquisitions began September 19 and lasted until October 19 when orbit maintenance requirements dictated that the satellite operators prepare for the return to right-looking mode on October 23. Processed image data from the acquisition phase of the 1997 campaign (over 2170 minutes of SAR signal data) have been mosaicked to achieve the primary goal of producing the first, high-resolution SAR image map of the entire Antarctic continent (Plate 1). The project also acquired a sampling of 24-day exactrepeat observations because of the contingency pre- and post-nominal plan acquisitions. Those data have been analyzed to extract surface velocity and topography data using radar interferometric techniques. The resultant velocities are critically important for studying ice sheet dynamics and assessing ice-sheet mass-balance, which in turn is a key parameter influencing global sea level.

Several years of data processing followed the 1997 imaging campaign. By mid-1999 processing was sufficiently complete that the RAMP team began to inquire about the anticipated second mapping mission. Kim Partington, now at NASA HQ, endorsed the idea and project planning began in January 2000. The scope of the new project, deemed the Modified Antarctic Mapping Mission by Rolf Mamen, was different from the 1997 Antarctic Imaging Campaign. MAMM would focus on interferometric coverage north of 80 degrees south latitude. The complex mission plan was developed by John Crawford and Rick Austin from JPL. The mission plan was then handed off to Stephanie Ruel who led the CSA mission planners. Dick Monson from NASA HQ along with Ian Joughin and Ramachand Bhat from JPL provided guidance on interferometric constraints on orbit maintenance to Greg Hammel of CSA who was responsible for the difficult orbit maintenance maneuvers required for this mission. Richard Carande, Xiaoqing $\mathrm{Wu}$ and James Miller from Vexcel worked with Katy Farness from OSU to develop automated software for processing the huge volumes of interferometric data. Verne Kaupp, now the ASF director, added Jeremy Nicholl, Paul Brown, and Dave Fluetsch to the ASF team. Bill Potter from GSFC helped with crisis management. Ken Jezek at OSU continued to manage the project and the science team component. With the concurrence of NASA and of Surendra Parashar from CSA, the team prepared for a second acquisition plan starting in September 2000.

MAMM began on September 3, 2000 and lasted till November 14, 2000, an interval corresponding to three repeat cycles. Data were acquired so that, where possible, the position of features on the glacier (such as crevasses) could be compared between the 1997 and 2000 data sets to measure point velocities by feature retracking. Second, and the real challenge of MAMM, was to acquire interferometric data so as to estimate velocity fields. The second approach required the use of RADARSAT-1 fine and standard beams, and demanded unprecedented control of the spacecraft orbit and attitude. As the mission unfolded, CSA spacecraft engineers demonstrated their ability to navigate the satellite in the manner dictated by the science requirements. The outcomes of the MAMM effort are a second high resolution map of much of Antarctica (Plate 2) and extraordinary observations of glacier motion captured over three, 24 day, RADARSAT-1 cycles (Plate 9). These data provide an unprecedented opportunity to study many of Antarctica's fast glaciers, whose extent was first revealed through AMM-1 data. 
With mounting evidence for rapid changes in the polar regions, follow-on measurements were requested by the RAMP team and then approved by Waleed Abdalati at NASA HQ and Nettie LaBelle-Hamer, the current ASF director. These were scheduled in 2004 and designed to be coincident with the MAMM data over the target areas. The MiniMAMM mission was planned by Michele Harbin and Vicky Wolf of ASF. MiniMAMM acquired additional interferometric data over 4 fast glacier areas around Antarctica beginning September 4 and ending December 23, 2004. The interferometric results from this data set are of a very high quality because the acquisitions occurred between peaks in solar activity. This means there is less ionospheric distortion in the MiniMAMM data set than in the MAMM data set.

\subsection{Mission and Science Objectives}

The primary mission objective of AMM-1 was to obtain the first complete high resolution SAR mapping of Antarctica. Principal science themes addressable using the SAR map are listed in table 1 . Note that exploration was specifically called out as an AMM-1 theme because at that time, Antarctica remained to be mapped at high resolution. Indeed, successful conclusion of AMM-1 also completed the radar mapping of Earth.

Table 1. AMM-1 Science Themes.

\section{Glaciology}

Ice sheet/stream flow regimes (fast glacier flow, relict features, outlet glaciers Stability of West Antarctic Ice Sheet (grounding lines, surface velocities)

Ice sheet mass balance (calving rates, ice sheet margins, topography)

Surface melt regimes

\section{Geology}

Uplift of the Transantarctic Mountains (Fault and lineament mapping)

History of subduction beneath the Antarctic Peninsula

Geologic mapping (Sirius Formation)

Vulcanology

History of glaciation (moraines, raised beaches)

\section{Exploration}

The science themes and technical capabilities directed that the primary mission objective be a complete mapping of the entire continent using a combination of standard and extended beams during the "Antarctic Mode" of the RADARSAT-1 Mission. Secondary objectives included stereo coverage of the Transantarctic Mountains and coastal areas. The principle AMM- 1 product was a high resolution, map-quality mosaic of Antarctica.

Experience from AMM-1 and a shift in the technical capabilities available for the project redirected the focus of the MAMM. MAMM science questions are listed in table 2. 
Table 2. MAMM Science Questions.

\begin{tabular}{|l|}
\multicolumn{1}{|c|}{ Ice Sheet Kinematics and Mass Balance } \\
\hline How are the interior ice sheet and ice sheet margin changing? \\
\hline $\begin{array}{l}\text { What are the velocities and strain rates for different flow regimes (ice streams, interior ice sheet, } \\
\text { ice shelves)? }\end{array}$ \\
\hline What is the mass discharge from major drainage basins? \\
\hline Where are grounding lines located and have they moved? \\
\hline \multicolumn{1}{|c|}{ Ice Sheet Dynamics and Ice Streams } \\
\hline What are the morphologies and dynamic properties of Antarctic Ice Streams? \\
\hline What portion of the Antarctic Ice Sheet is drained by ice streams? \\
\hline How are ice sheet properties correlated with the glacier bed? \\
\hline
\end{tabular}

MAMM had two primary mission objectives.

1) Produce high-resolution image mosaics of Antarctica north of -80 degrees latitude for change detection measurements and studies to understand the response of the ice sheet to climate change.

2) Measure the surface velocity field over coherent and/or traceable areas of the ice sheet north of -80 degrees latitude for ice dynamics studies and for exploring the time varying nature of dynamical processes.

The project specified primary products for delivery to the science community. These were:

1) Production of a $25 \mathrm{~m}$ image map of the viewable area.

2) Production of $200 \mathrm{~m}$ coherence maps of the viewable area.

3) Production of $5 \mathrm{~km}$ post spacing velocity field of coherent or trackable areas.

4) Production of $1 \mathrm{~km}$ post spacing velocity field of coherent or trackable areas of fast glaciers.

5) Production of $500 \mathrm{~m}$ post spacing velocity field along the grounding line.

6) Delivery of products to the DAACs.

A secondary set of products was also prepared. These were:

1) Production of ascending and descending image mosaics of the viewable area.

2) Production of high resolution, F1 ascending and descending image mosaics of fast glaciers.

3) Production of ascending and descending coherence maps of the viewable area.

4) Production of F1 ascending and descending coherence maps of fast glaciers. 


\section{Acquisition Plans}

AMM-1 and MAMM acquisition plans were constrained by the following operational guidelines:

1) Minimize the total mission duration.

2) Minimize the total data volume in the context of the science objectives.

3) Maximize the use of real time downlinks.

\section{1 АMМ}

The first Antarctic Imaging Campaign (AIC-1) was made possible by the unique capabilities of RADARSAT-1 including an electronically steerable antenna array that provided a range of selectable beam pointing angles. This capability was essential for maximizing the range of the acquisition swaths away from the satellite nadir track. The satellite also could maneuver in orbit enabling it to change the look direction of the SAR. These two capabilities permitted acquisitions to the Earth's South Pole and represent technical abilities afforded by no other civilian spaceborne radar.

AIC-1 acquisitions began with a pre-nominal plan on September 19, seven days earlier then the anticipated start of the nominal plan on September 26 (figure 1). The early data constituted an important contingency against anomalies encountered later in the mission. The nominal plan was designed to obtain complete mapping coverage within 18 days. The nominal plan proceeded nearly flawlessly through completion on October 13. It was executed in parallel with acquisition plans for other RADARSAT-1 users and with CSA's Background Mission. An additional opportunity was realized because of the early start on September 19. Radar data collected after the conclusion of the nominal mission were acquired exactly 24 days after the beginning of the early start data. This schedule repositioned the spacecraft to within a few hundred meters of its position 24 days earlier. Consequently the data are suitable for interferometric analysis - a demonstrated technique for estimating ice sheet surface displacement. Exact repeat data collections started on October 14 and continued through October 19.

Preparations to return the satellite to normal operations began on October 20. Arctic mode operations resumed on October 23. Acquisitions for customers resumed on October 26. This occurred 9 days ahead of the planned schedule. 


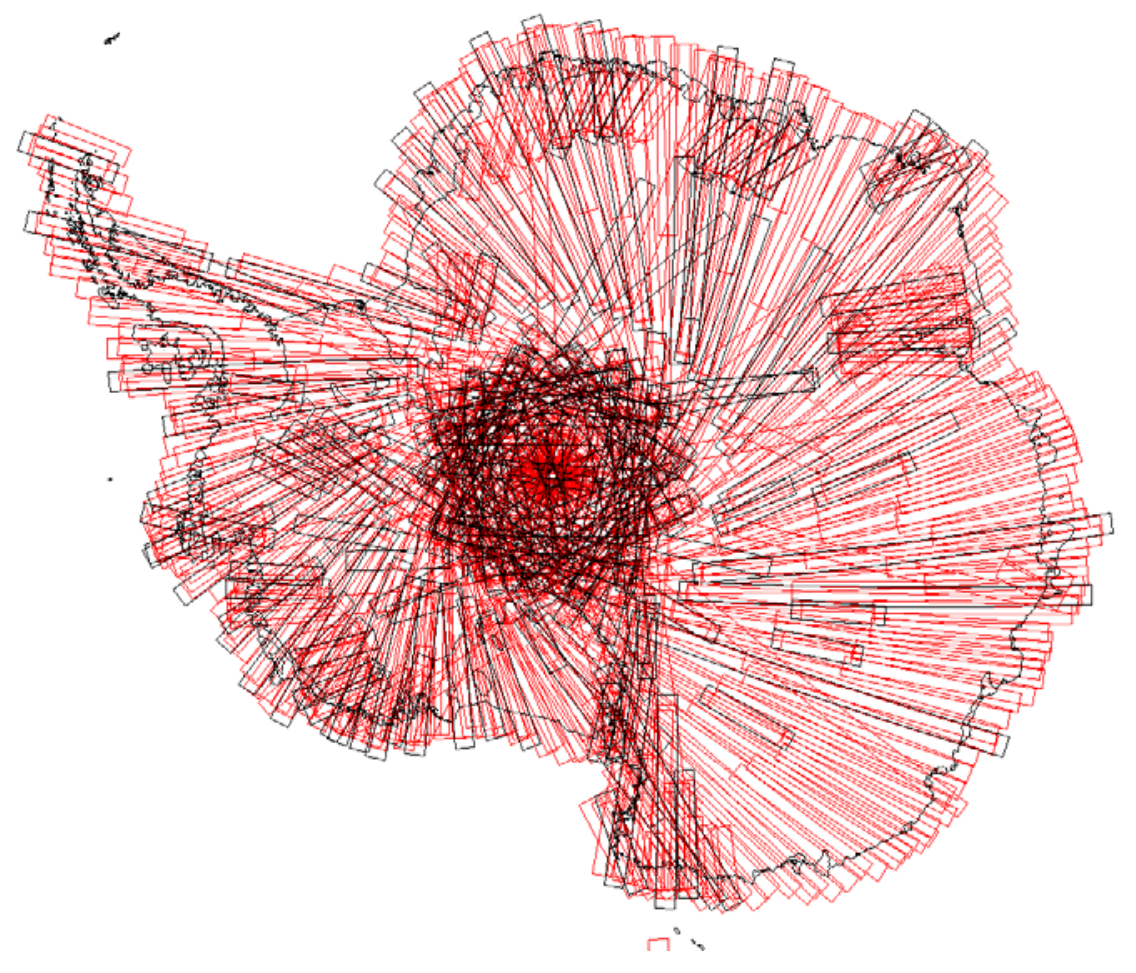

Figure 1. AMM-1 swath coverage. Red swaths are the nominal acquisitions. Black swaths show 24-day repeat passes suitable for interferometry.

\section{2 МАMМ}

Acquisitions were planned with two constraints necessary to reach the mission goals. First, data were acquired so that, where possible, the position of structures on the glacier could be compared between the 1997 and 2000 data sets so as to measure point velocities. Second, and the real challenge of MAMM, was to acquire interferometric data so as to estimate velocity fields. The second approach required the use of RADARSAT-1 fine and standard beams, and the unprecedented control of the spacecraft orbit and attitude.

MAMM acquired data from about 80 degrees South Latitude to the Antarctic Coast. Interferometric SAR calculations required that this area be imaged 6 times during the mission (three times in descending orbit mode and three times in ascending orbit modes) (figure 2). The number and orientation of acquisitions then enabled measurements of two components of the surface velocity vector and to remove the effects of surface topography. 

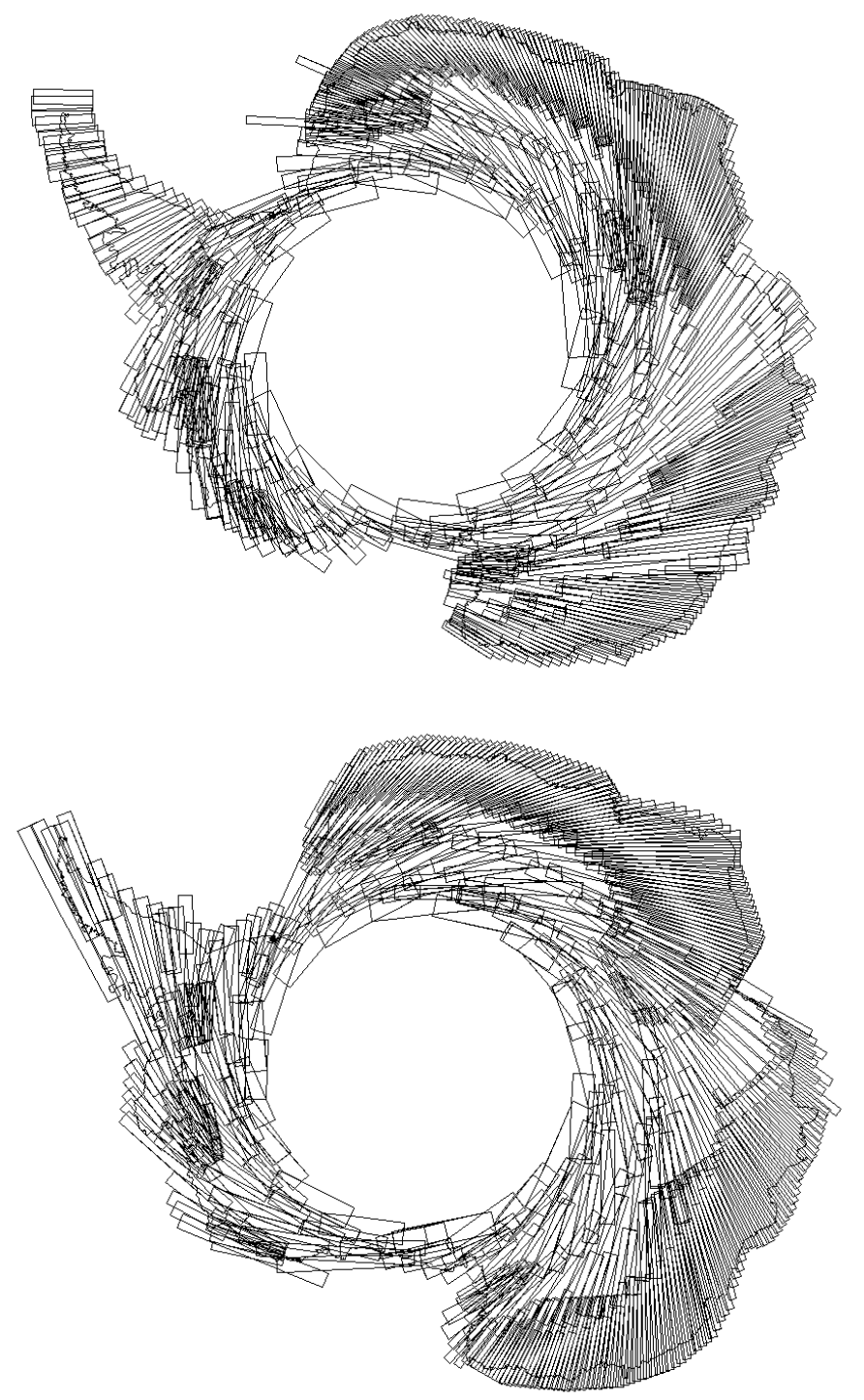

Figure 2. Ascending (top) and descending (bottom) cumulative coverage maps for the three MAMM acquisition cycles. Maximum southerly coverage is $80.1^{\circ}$ S latitude.

\subsection{Mission Acquisition Statistics}

Mission statistics are compiled in figure 3. The activity imaged more of the Antarctic in 1997. Interferometry, which requires multiple passes, was only a measurement of opportunity during AMM-1. Interferometric coverage was only attempted after the conclusion of the nominal plan and solely based on the pre-nominal collections. The activity imaged less area in 2000. However, three cycles of acquisitions with each cycle consisting of ascending and descending data takes required substantially more total time to complete. Because of unexpected failures at the McMurdo Ground Receiving Station, much of the data were captured on the on-board tape recorder and downlinked in the northern hemisphere. The figure illustrates roughly the SAR ontime allocation supported by NASA and CSA respectively. 


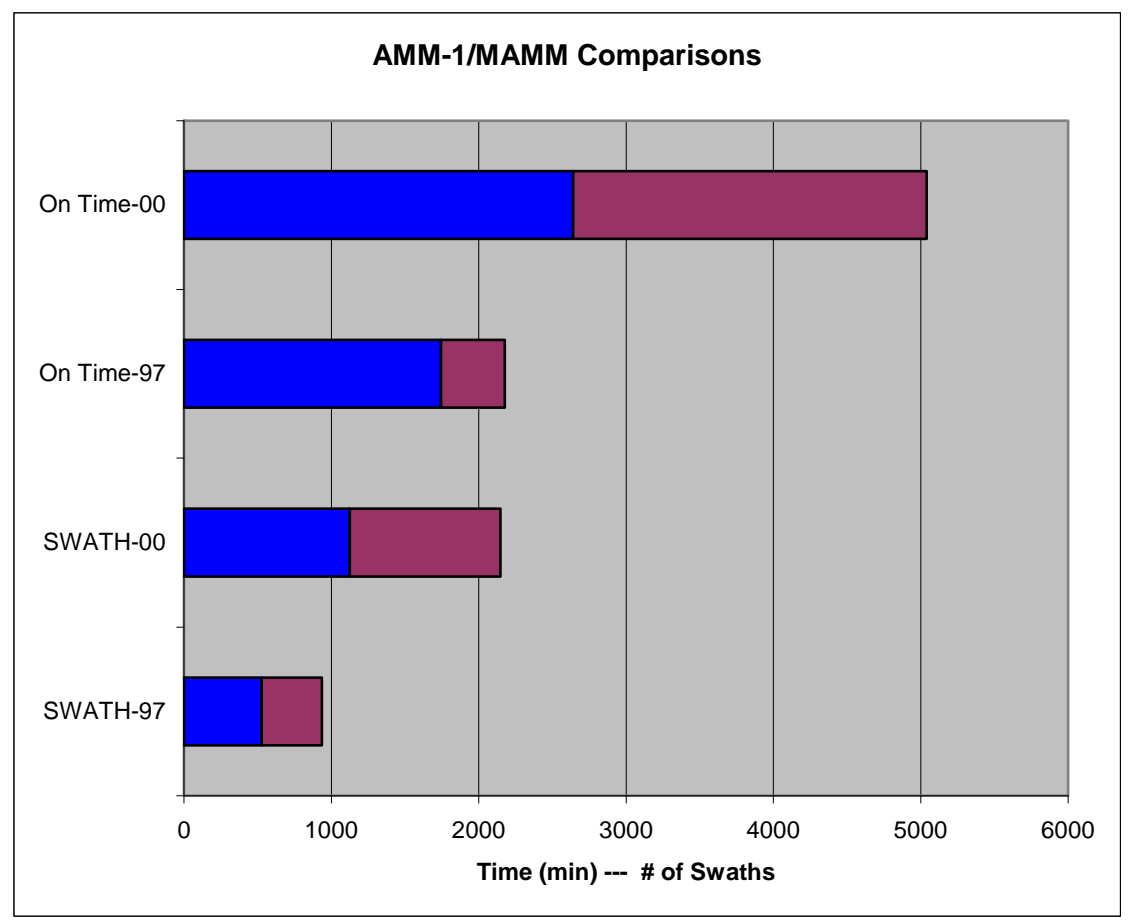

Figure 3. Mission statistics by number of swaths and SAR on time. The 1997 AMM-1 data are divided by nominal (blue) and pre and post (red) acquisitions. The later are related to interferometry opportunities. The 2000 MAMM data are divided by the rough proportions of time allocated by NASA (blue) and CSA (red) to the project.

\section{Image Processing Methodology and Map Products}

This section describes RAMP mapping products. The products are available in a variety of formats including raster and vector data sets as well as tile products unique to the RAMP project. All of the products have been submitted to the ASF DAAC and to several of the RAMP international partners for distribution to the science community (see appendix). Several of the smaller products and ancillary data sets are also available on the BPRC web site.

\subsection{Image Mosaic Processing Approach}

High resolution, map quality image mosaics were a primary objective of the project. Once the data were collected and processed into slant range images, further manipulation as well as ancillary data sets (such as a digital elevation model) were required to construct the map products. The steps are outlined in the following sections. 


\subsubsection{Orthorectification and block processing overview}

Mosaic formation proceeds in two stages. These are the block processing stage and the tile formation stage. Briefly, the steps in each stage are;

Block Processing Stage:

Ingest of Level 1 products (i.e. frames)

Ground control points located

Tie points collected between images

Block adjustment (to correct relative and absolute errors in state vectors)

Orthorectification (terrain distortion removal and, optionally, radiometric corrections for pixel size)

Tie points collected between orthorectified images

Radiometric balancing (for radiometric seam removal)

Geometric warp (optional, for residual geometric seam removal)

Block mosaic formation

Reset shadow / layover areas to no-data

Mosaic fill-in with shadow / layover imagery

Extraction of image chips around block boundaries for block-to-block tie point computation in the Tile Processing Stage.

Tile Processing Stage:

Grand Adjustment (after all blocks in the mosaic have been processed): The purpose of the adjustment is to remove block-to-block geometric and radiometric seams.

Seam removal requires the computation of tie points from the image chips extracted from each block.

Final tiles are then produced from block data by applying the geometric adjustment, seam removal and radiometric equations derived from the block-to-block tie points.

\subsubsection{Orthorectification}

In order for RAMP data products to be geographically comparable to other Antarctic mapping products, the individual SAR frames need to be first orthorectified and then mosaicked. The process of orthorectification shifts image pixels from their natural SAR image locations (slant range and azimuth) to their proper geographic locations (e.g. Easting, Northing or even simply ground range and azimuth). When the assumed Earth model differs significantly from the actual terrain, a SAR image will appear distorted and sometimes exhibits a phenomenon called layover wherein the top of a mountain appears closer to the radar than the bottom. It is also possible to be unable to image the back side of a mountain when a radar "shadow" exists. 
The orthorectification approach used for RAMP consisted of exploiting the known imaging geometry, an Antarctic elevation model, and the locations of ground control points. The orbital geometry (spacecraft ephemeris), SAR imaging parameters (range, Doppler, and whether the radar was left or right looking), and Earth model (Earth ellipsoid model plus terrain model) are simultaneously intersected to determine what patch of Earth corresponds to a particular SAR image pixel. Any errors in this intersection are assumed to come from errors in the spacecraft ephemeris and are removed using ground control points on a per orbit basis. As there are fewer ground control points than orbits, an approach called a block adjustment is used to make corrections to one orbit based on an adjacent orbit. This step is described later. The block adjustment yields a cross- track, along-track, and altitude adjustment for each orbit used during the mapping mission.

After orthorectification, the images should be properly geolocated and can then be mosaicked to form larger data products.

\subsubsection{Block adjustment}

The RAMS orbital adjustment system accommodates the requirement to adjust a large number of orbits using a sparse distribution of ground control. The ground control in the Antarctic is primarily located near the coast and at the South Pole station where a transponder was erected for the AMM acquisitions.

The entire map formation process requires that an overall processing plan be formulated. The primary purpose of this planning is to divide the map into blocks (groups of overlapping images) and to choose the order in which blocks will be processed.

A good block is considered to having the following characteristics. At least two radar-visible ground control points must be contained within its boundaries. Blocks should consist of long contiguous swaths of data, overlapping each other in the cross-track direction.

Ground control points (GCPs) must be manually located in the SAR image. GCPs were derived from available maps and photographs graciously provided by members of the SCAR community and from RAMP-specific tie points (section 3.2). Tie points are collected in both an automated fashion and a manual fashion. Tie points are collected in the along-track direction through an automated process. Crosstrack tie points (i.e. tie points collected between frames in different orbits) are also collected in an automated fashion using estimates on locations of overlap regions and an image automatcher.

Given a sufficient number of tie points and located ground control points within the block, the block adjustment may be computed. The orbit adjustment for a given block of data is first done on all orbits that contain one or more ground control points. The remaining frames in the block are then adjusted to those already controlled. All orbits are corrected within the block such that tie points and GCPs are reconciled as closely as possible. The approach surpassed the design goal of 300 meter geolocation accuracy for the maps. 


\subsection{Mapping Ground Control Points}

Geodetic quality of the final AMM-1 and MAMM map products is primarily determined by our knowledge of spacecraft position and instrument pointing directions. Navigational data for RADARSAT-1 are acquired by the Canadian Space Agency using a facility in western Canada, which then uses those observations to estimate satellite position along the entire orbit. Prior to the mapping missions, the quality of the position and pointing data over the Antarctic were uncertain. Consequently, ground control points were needed to refine position knowledge over the Antarctic and to act as a validation of the final map products. Many control points were needed about the continent and several were required in the interior. Such a data set was unavailable prior to RAMP and a solution had to be found.

Based on discussions with colleagues at the Environmental Research Institute of Michigan and with the assistance of many organizations which participate in the Scientific Committee for Antarctic Research we compiled a data base from which associated the latitude, longitude and elevation information for places in Antarctica with points on RADARSAT-1 image chips. Integration of the data (figure 4) into the mapping calculation resulted in at least a two-fold increase in map accuracy. As importantly, the control points withheld from the calculation represented an important validation of the map accuracy and convinced cartographers of the quality of the map product.
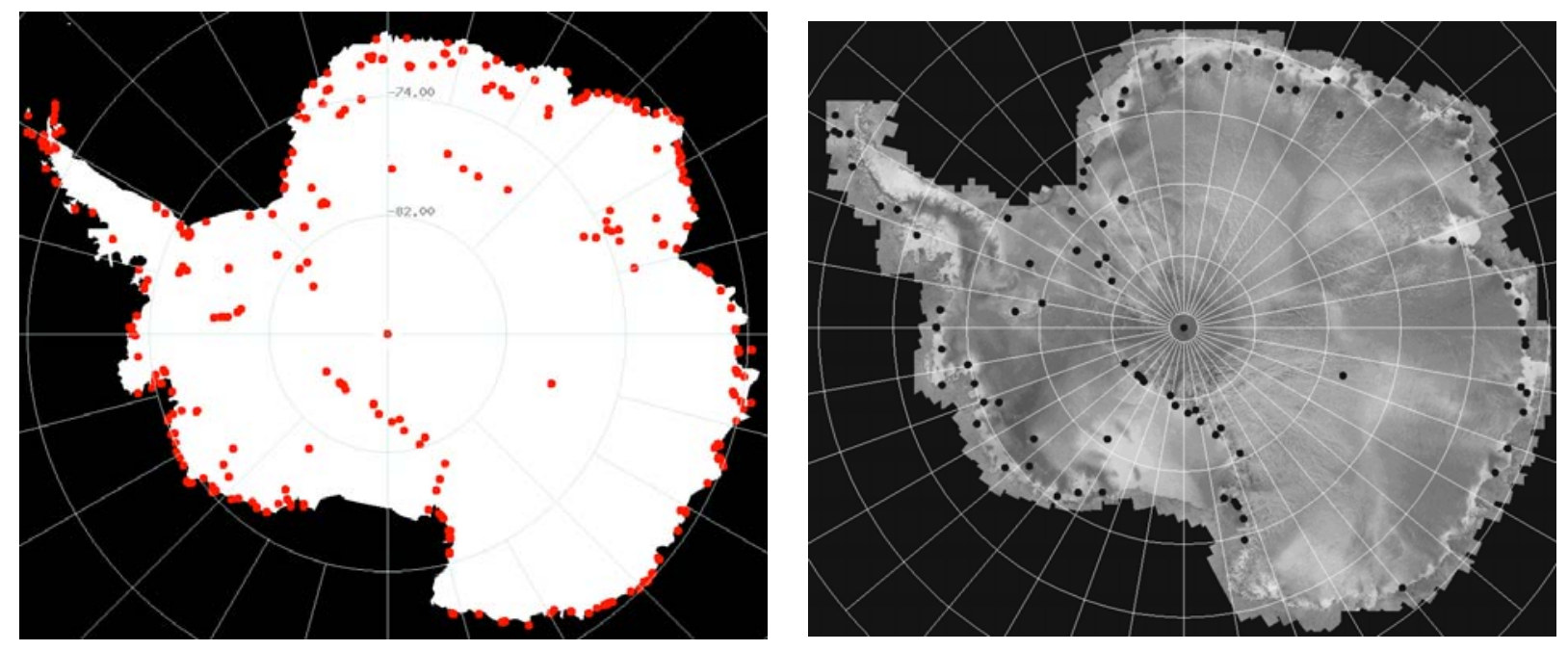

Figure 4. Distribution of ground control points used to constrain the AMM-1 mosaic. AMM-1 control points and tie points from the AMM-1 mosaic are used to control the MAMM image geometries. Left image shows all GCPs used by RAMP including GCPs identified from photos and maps. Right image shows GCPs acquired specifically for the RAMP project.

\subsection{AMM-1 and MAMM Image Mosaics and Derived Products}

The RAMP mosaics remain a unique view of Antarctica (Plates 1, 2, and 3 of Appendix 1). Large-scale spatial variations in radar brightness are evident across the continent. The bright 
portion of Marie Byrd Land and the eastern sector of the Ross Ice Shelf probably represent the region where significant melting and refreezing occurred during an early 1990's melt event. Most of the coastal areas and much of the Antarctic Peninsula also appear bright because of summer melt. But unlike Greenland, where most of the large-scale brightness patterns are associated with firn melt facies, the remaining, strong variations in radar brightness are poorly understood. At a somewhat smaller scale, thousands-of-kilometer long curvilinear features snake across East Antarctica. These appear to follow ice divides separating the large catchment areas. The reason why the ice divides appear so prominently in the radar imagery is unknown.

On an intermediate scale, the East Antarctic Ice Sheet appears to be very 'rough'. The texturing is probably due to the flow of the ice sheet over a rough glacier bed. Textures are particularly strong paralleling the flanks of the Transantarctic Mountains and extending deep into adjacent portions of the East Antarctic Plateau. Long linear patterns are strongly suggestive of subglacial geology and may indicate that the ice sheet in this area is resting on relatively resistant basement rocks. The texture changes abruptly across the northernmost section of the Wilkes Subglacial Basin located in George V Land. There the imagery shows remarkable, subtle rounded shapes similar in appearance to the signature of subglacial lakes such as Lake Vostok.

Most intriguing are ice stream and ice stream like features in Queen Maud Land that were partly described in previous research using optical imagery. Ice streams are made visible by the intense crevassing along the shear margins where chaotic surface roughness results in a strong radar echo. Fast, channeled flow, which are two of the diagnostic characteristics of ice streams, are evident in the surface velocity field computed from repeat pass interferometry (described in the next section). Slessor Glacier is located on the northeastern margin of the Filchner Ice Shelf. The upper reaches of the glacier consist of a network of tributaries that feed a funnel shaped midsection. Patches of crevasses punctuate the interior of the funnel. The ice stream is about $450 \mathrm{~km}$ long from the grounding line to the upstream area.

An enormous ice stream, reaching at least $800 \mathrm{~km}$ into East Antarctica, feeds Recovery Glacier. It too is fed by a funnel shaped catchment. Down-glacier, crevasses cascade across the ice stream at several locations suggesting that strong variations in basal topography modulate the flow. The confluence of a thin, elongated, $280 \mathrm{~km}$-long tributary ice stream with Recovery Glacier is located approximately $250 \mathrm{~km}$ from the constriction where Recovery Glacier enters the Filchner Ice Shelf. The central body of the pipe-like tributary is crevasse free indicating that shear stresses are concentrated only at the margins. The tributary is an enigma in that there is little evidence for ice flow into the tributary from the adjacent ice sheet and there is little if any indication as to the source of ice from the up-glacier catchment region.

The AMM-1 mosaic has captured the interest of scientists and the public. It has been published by the National Geographic Society (2001) and by the U.S. Geological Survey.

\subsubsection{Coastlines}

The 1997 coastline of Antarctica was automatically mapped using a thresholding algorithm applied to the AMM-1 mosaic (Liu and Jezek, 2004). After further refinement by manual 
inspection, the 1997 coastline was compared with the 1963 coastline mapped from orthorectified Argon satellite images. Using the Antarctic Digital Data Base grounding line as reference, ice shelf extent decreased by about $0.8 \%$ over the 34 year period.

Shortly after the completion of the MAMM ascending mosaic a 2000 coastline was mapped using the same technique. Additional coastline comparisons between the AMM-1 and MAMM data (Plates 1, and 2) show that fragile, composite ice shelves along the southeastern flank of the Antarctic Peninsula disintegrated sometime during the 3 years between observations. Figure 5 shows that the composite ice shelf in New Bedford Inlet receded by $1200 \mathrm{~km}^{2}$, or about the amount of ice cover lost by the collapse of Larsen A ice shelf (Jezek and Liu, 2005).
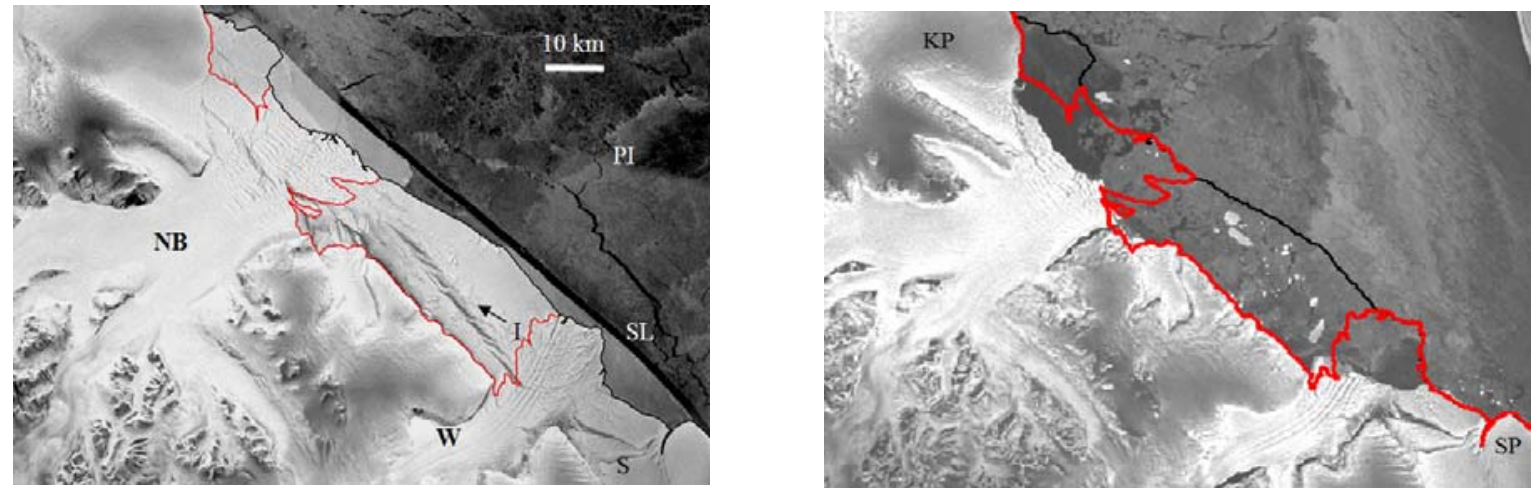

Figure 5. Retreat of composite ice shelves along the Antarctic Peninsula (1997 AMM-1 image, left; 2000 MAMM image right). Kemp (KP) and Smith (SP) Peninsulas are identified in the right image. New Bedford and Wright Inlets are identified in the left image. Pack ice (PI), shore leads (SL) and small icebergs (I) are also identified on the right image.

\subsubsection{Flow lines}

The flow stripe map in figure 6 was constructed by manual interpretation of lineaments observed on the AMM-1 image. Slessor, Bailey, and Recovery Glaciers extend hundreds of kilometers into East Antarctica (Wu and Jezek, 2005). Previously unknown RAMP and Blackwall Ice Streams are long narrow tributaries that feed into Recovery Glacier. 


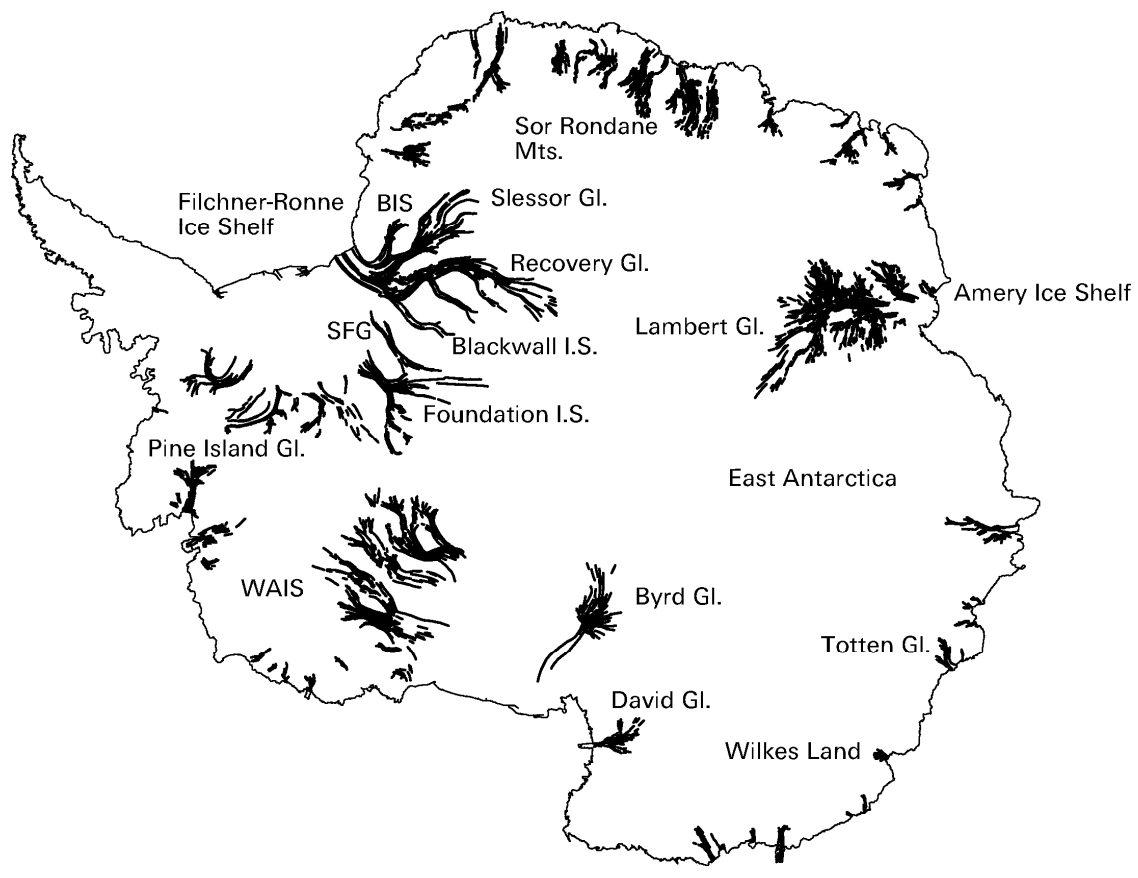

Figure 6. Flow stripes of fast glaciers interpreted from the AMM-1 mosaic.

\subsubsection{MiniMosaics}

MiniMosaics are derived from Fine-1 beam MAMM data and compiled into $10 \mathrm{~m}$, single look imagery. They are intended to enable maximum enlargement of small-scale features associated with fast glaciers identified from the AMM-1 mosaic. Figure 7 shows the location of all the minimosaics.

MAMM Fine-1 beam $25 \mathrm{~m}$ data, Fine-1 $10 \mathrm{~m}$ data, and AMM-1 $25 \mathrm{~m}$ data are compared in figure 8. The geocoding between each image is comparable to within two pixels. Discrepancies of less than two pixels arise because a grand block adjustment was not applied to the MiniMosaic data. As expected the MiniMosaic frame is more specklely than the $25 \mathrm{~m}$ multilook data. Interestingly the MAMM $25 \mathrm{~m}$ data is visually improved over the AMM-1 $25 \mathrm{~m}$ data. This is because more Fine- 1 beam looks (5) are used to create the MAMM $25 \mathrm{~m}$ data as opposed to the 3-looks used to form the AMM-1 image from standard beam data. 


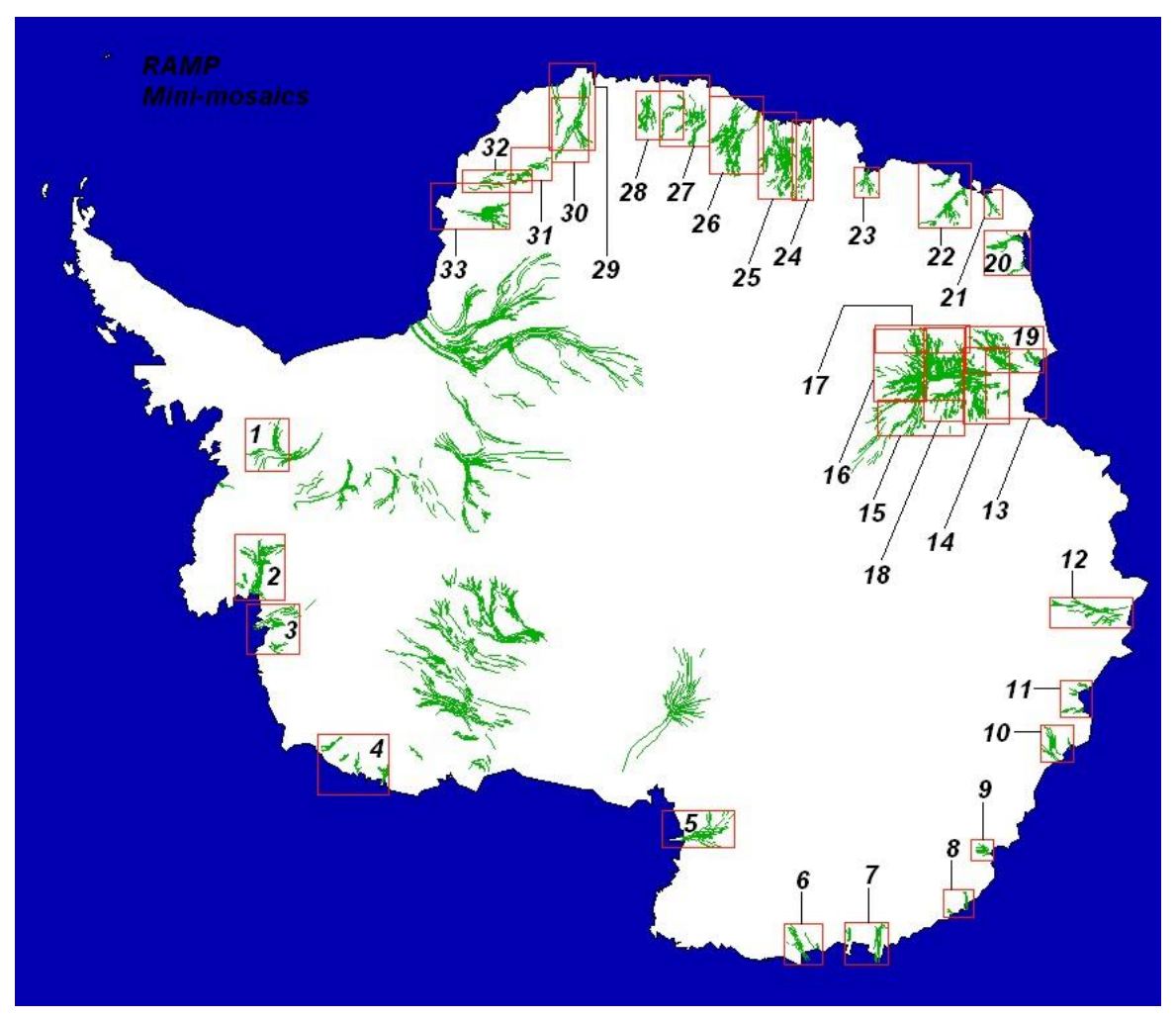

Figure 7. Coverage map of MiniMosaics showing relationships to fast glaciers.
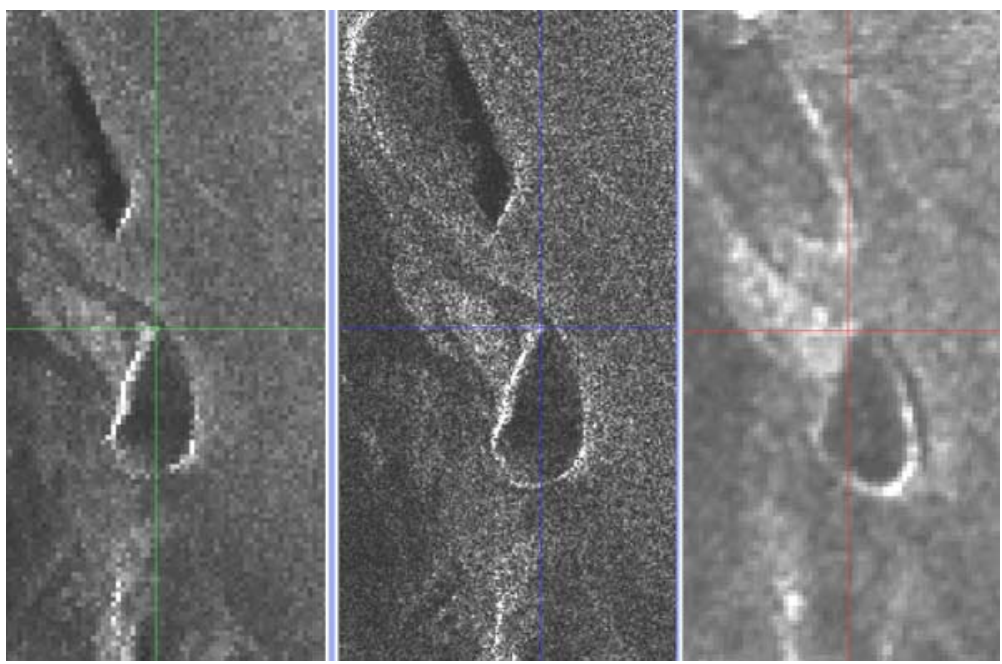

Figure 8. MAMM 25 image (left), MAMM 10 m image (center) and AMM-1 25 m image (right). Note the good geolocation comparison and the improved quality of the MAMM $25 \mathrm{~m}$ data over the AMM-1 25 m data. 
The improved, small-scale resolution achievable in the MiniMosaic is further demonstrated in figure 9 which compares 10-m and $25 \mathrm{~m}$ processed MAMM data over a highly crevassed area. The improved resolution can be an aid in feature retracking analyses.

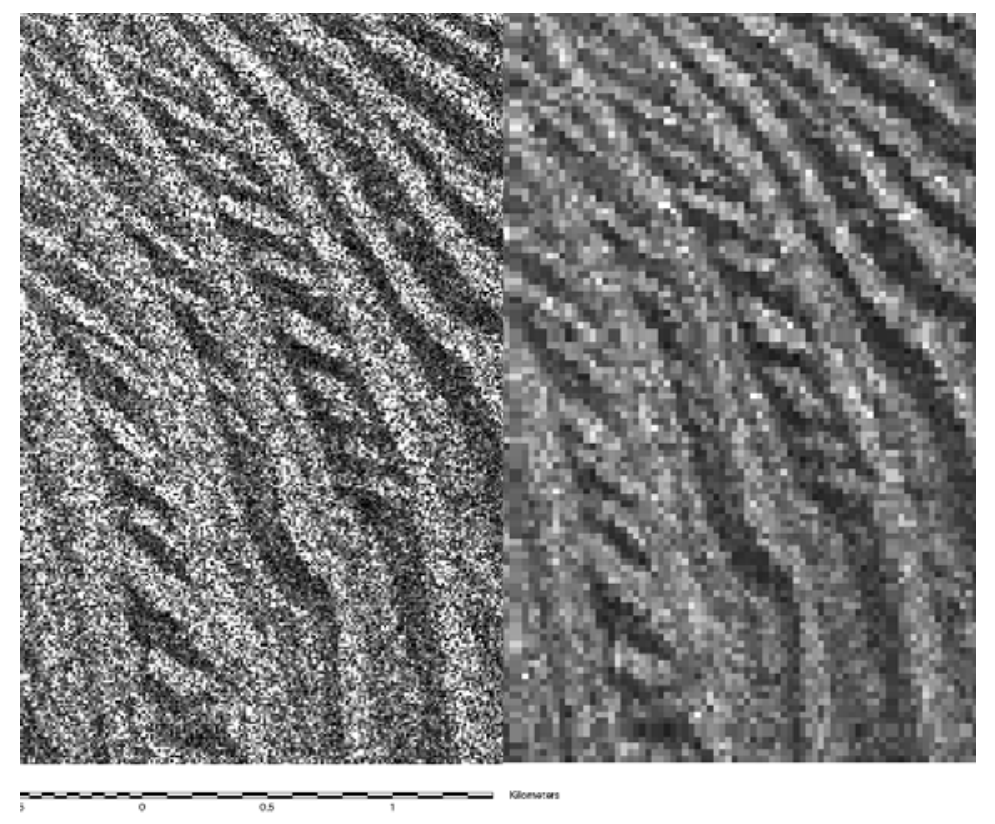

Figure 9. $10 \mathrm{~m}$ (left) and $25 \mathrm{~m}$ (right) MAMM data of a highly crevassed region. The image is about $2 \mathrm{~km}$ wide.

\subsection{Backscatter Mosaics}

The RAMP image mosaics are distributed as tile products. Each tile contains several data sets including image files, elevation data, incidence angle data, beam type and information for extracting the backscatter from the radiometrically adjusted products. Because the task is time consuming, and because there is advantage in averaging the backscatter estimates over eight, 25 $\mathrm{m}$ pixels, we created separate mosaics in which the digital numbers represent the backscatter coefficient in $\mathrm{dB}$. The AMM-1, MAMM ascending and MAMM descending backscatter mosaic products are shown in plates 4,5 , and 6 . The cross swath fall off in backscatter coefficient is noticeable as is the difference in backscatter coefficient with beam angle.

\subsubsection{Backscatter comparisons}

Backscatter coefficients vary by incidence angle and viewing azimuth. Resulting differences between AMM-1 Standard beam 2, MAMM ascending standard beam 6 and MAMM descending standard beam 6 measured over the Larsen Ice Shelf (figure 10) are illustrated in (figure 11). 

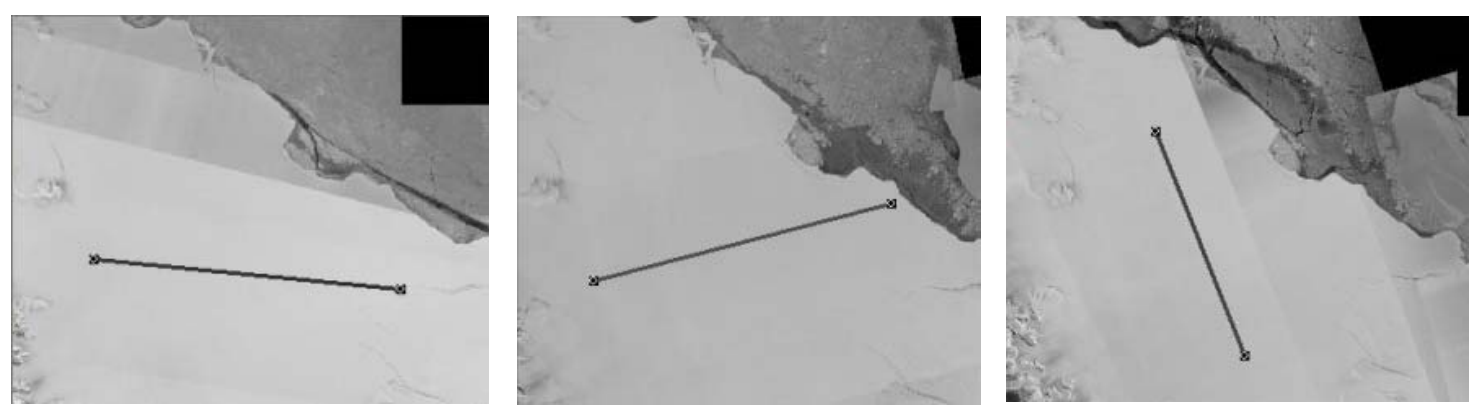

Figure 10. Profile lines along swath centers for AMM-1 (left), MAMM ascending (middle) and MAMM descending (right). Examples avoid regions affected by automatic gain control artifacts.
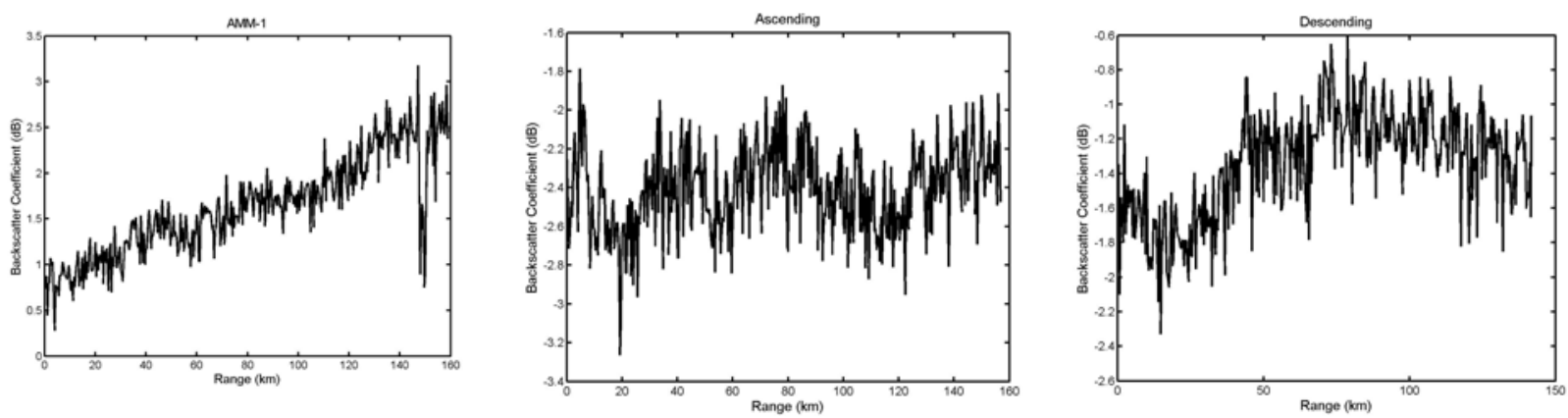

Figure 11. Backscatter coefficients along profiles. $1 \mathrm{db}$ mean difference between MAMM ascending (middle) and MAMM descending (right) are probably due to azimuthal anisotropy in the scattering coefficient. $3 \mathrm{~dB}$ differences between AMM-1 and MAMM data are attributable to differences in incidence angles.

\subsubsection{Validation calibration}

The ASF in cooperation with CSA radiometrically calibrated the RAMP data sets. The calibration procedures and results are documented in two ASF reports provided with the data sets (see Appendix 2).

\subsubsection{Incidence angle estimates}

Backscatter data are best interpreted with knowledge of incidence angle. Local incidence angles are estimated using the satellite viewing geometry and the surface elevation data. Incidence angle data are provided on individual tiles. The data have been composited into mosaics for both the AMM-1 1997 and the MAMM 2000 data sets. Figure 12 shows a gray scale representation of the incidence angles. Large tonal variations are associated with different beams. Textured variations are associated with topography. Gradients across the swath direction show local variations associated with swath position. 

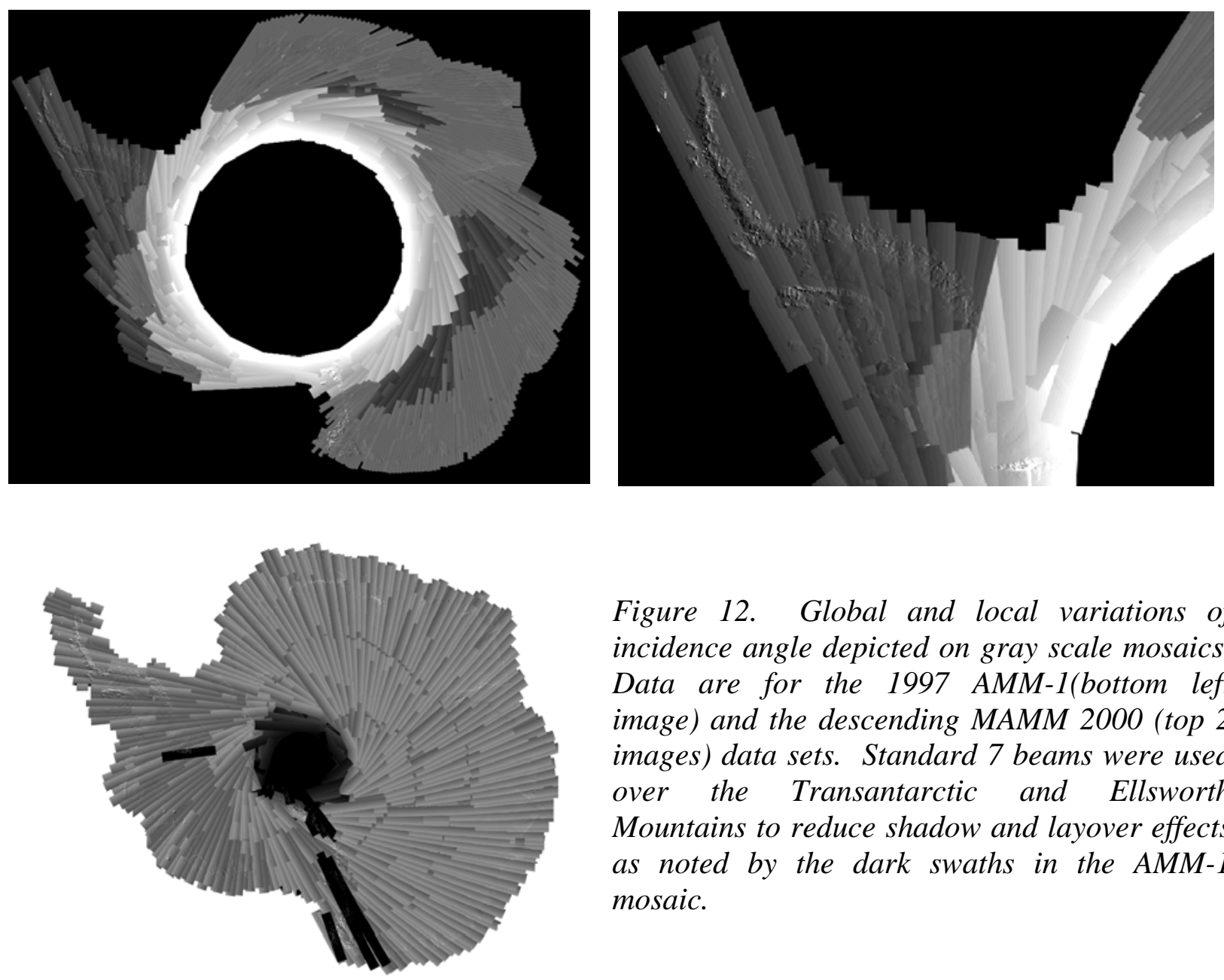

Figure 12. Global and local variations of incidence angle depicted on gray scale mosaics. Data are for the 1997 AMM-1(bottom left image) and the descending MAMM 2000 (top 2 images) data sets. Standard 7 beams were used over the Transantarctic and Ellsworth Mountains to reduce shadow and layover effects as noted by the dark swaths in the AMM-1 mosaic.

\section{Interferometric Processing Methodology and Velocity Products}

Interferometric data were collected during AMM-1 and MAMM. The following sections describe how these data were processed into velocity and coherence maps. Sections are compiled from various unpublished project reports by X. Wu, R. Carande and K. Jezek.

\subsection{MAMM InSAR Methodology}

The RAMP data processing system automates the mosaicking and velocity calculations as much as possible in order to manage and process the voluminous data set. The block diagram in figure 13 shows the major procedures for processing the RADARSAT- 1 InSAR data. The image mosaicking production is handled in the RAMS-1 system. The mosaicking steps were outlined in section 3.1. Velocity products are computed using the additional RAMS-2 system. The RAMS-2 process from ingesting the raw data to producing the final velocity products consists of three phases. Phase one processing, shown in the second column of figure 13, is frame-based and includes data ingest and automatic interferogram generation. This phase produces an archive of 
interferograms, coherence images and registration offsets for each frame of data. Phase two processing is data take based. The data take time varies and could be as long as 4 to 5 minutes. A typical data take could cover $1000 \mathrm{~km}$ in the along track direction of the satellite. Phase two processing includes interferogram and offsets mosaic creation from the frame-based results, interferogram filtering to reduce speckle noise, phase unwrapping to get the relative phase values with respect to a reference point, baseline estimation by using available Velocity Ground Control Points (VGCPs), removing the phase component of the DEM, creating velocity maps and merging ascending/descending velocities. This processing phase creates an archive of data take based velocity map products for each data take. The third phase of the processing chain creates velocity metadata for the velocity map products.

\section{RADARSAT-1 Antarctic Mapping System}

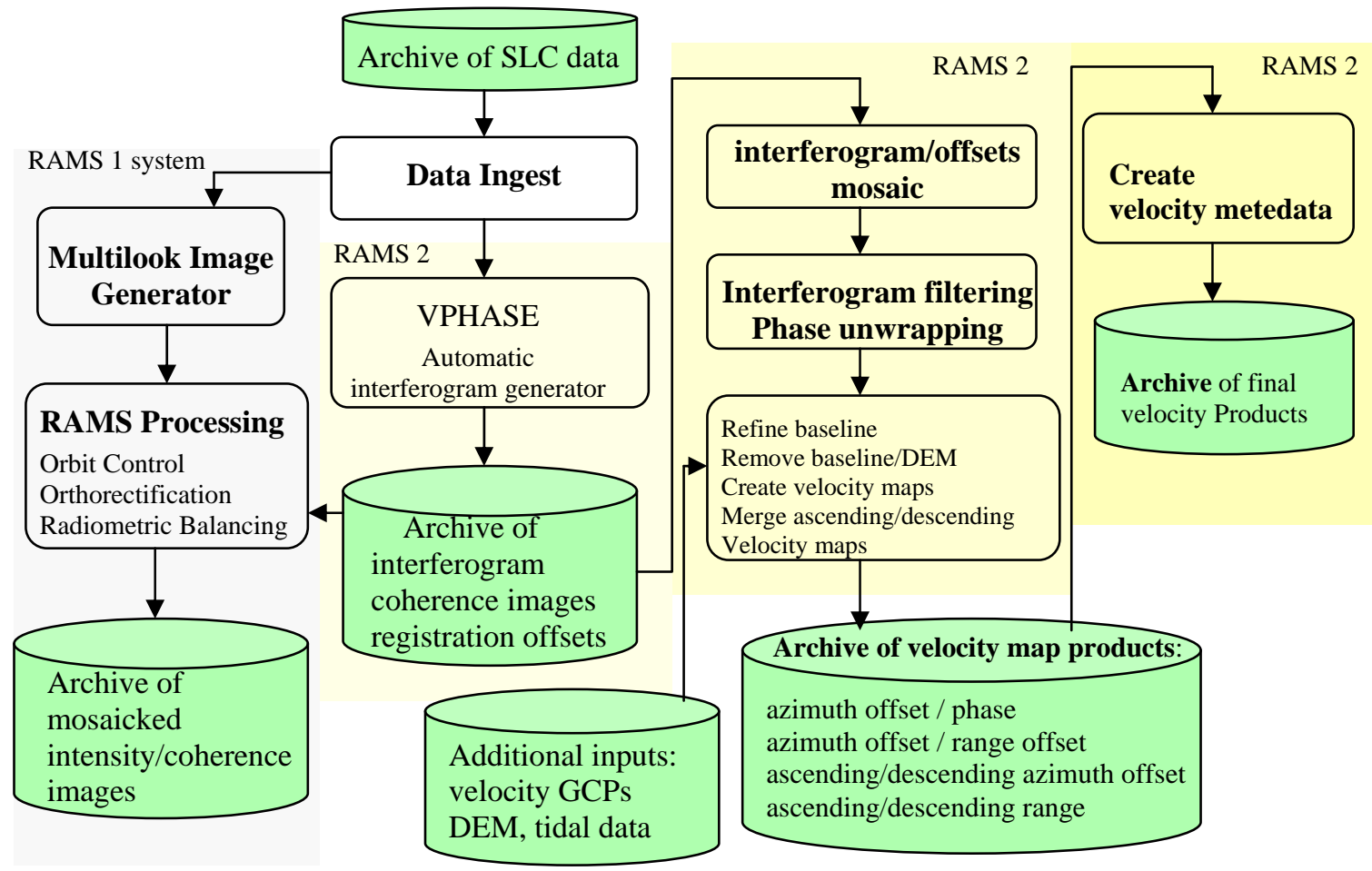

Figure 13. MAMM data processing system.

\subsubsection{Image registration}

Image registration begins simply by registering the data using the published ephemeris. The next refinement proceeds by selecting a small number of tie points and computing an affine transformation to roughly align the images. A hierarchy of correlation methods is subsequently applied to compute the precise registration and offset maps. The approach first tries to use the interferogram spectrum method (discussed below) because it yields the most accurate registration results. If the spectral method fails, the well known amplitude correlation method, 
which only uses the magnitude of the SLC data, is used. The correlation peak is computed by fitting a quadratic function to the correlation data. The computed offset of the correlation peak can be used to obtain either a speckle retracking or feature retracking result depending on the size of the correlation chips.

The interferogram spectral method begins by selecting a small chip of SLC data from both reference and secondary images and then multiplying the reference SLC with the conjugated secondary SLC to form the interferogram of this small chip. To calculate the magnitude of the correlation coefficient, we first multiply pixel by pixel the primary image chip with the complex conjugate of the secondary chip. We multiply this product by two terms that are local estimates of the linearly phase gradients in the range $\left(f_{r}\right)$ and azimuth $\left(f_{a}\right)$ directions associated with the satellite viewing geometry and for example, gently sloping topography or systematic displacements. We sum over the number of lines (l) and pixels (p) and take the absolute value of the normalized result. This procedure is summarized in equation 1:

$$
\gamma=\frac{\left|\sum_{l, p} f_{1}(l, p) \cdot f_{2}(l, p) \cdot \exp \left(-j 2 \pi f_{a} l\right) \cdot \exp \left(-j 2 \pi f_{r} p\right)\right|}{\sqrt{\sum_{l, p}\left|f_{1}(l, p)\right|^{2}} \sqrt{\sum_{l, p}\left|f_{2}(l, p)\right|^{2}}}
$$

where $\gamma$ is the magnitude value of the complex correlation coefficient, $\mathrm{f}_{1}$ is the reference SLC image and $f_{2}$ is the secondary SLC image. If the fringe rates $f_{a}$ and $f_{r}$ are known, the correlation coefficient can be calculated using (1). We find the maximum correlation coefficient by using the reference image chip to search across the secondary chip. Note that if we do not remove the linear gradients which result from the spacecraft imaging geometry from the calculation, we will not find the peak value of the correlation coefficient.

We must estimate the fringe rates in azimuth and range directions to calculate the correlation coefficient (1). In cases where the surface is relatively flat and stationary, baseline information can be used to accurately estimate the fringe rate. For more typical areas, displacement and topography can significantly contribute to the fringe pattern. For C band ERS1/2 and RADARSAT-1 data, a surface change of half a wavelength $(0.028 \mathrm{~m})$ between two acquisitions corresponds to one fringe, so ignoring the fringes related with surface changes will produce large errors in fringe rate estimates. However, such information is usually unknown or not sufficiently accurate.

The interferogram spectrum method uses the discrete Fourier transform to estimate the local fringe rate. This method generates an interferogram by multiplying the co-registered reference SLC image chip $\mathrm{f}_{1}(\mathrm{l}, \mathrm{p})$ with conjugate secondary SLC image chip $\mathrm{f}_{2}(\mathrm{l}, \mathrm{p})$ :

$$
f_{\text {int }}(l, p)=f_{1}(l, p) \cdot f_{2} *(l, p)
$$


Next the discrete Fourier transform is used to compute the spectrum of the interferogram:

$$
F_{\text {int }}\left(k_{l}, k_{p}\right)=\sum_{l, p} f_{1}(l, p) \cdot f_{2}^{*}(l, p) \cdot \exp \left(-j 2 \pi \frac{k_{l}}{N} l\right) \cdot \exp \left(-j 2 \pi \frac{k_{p}}{M} p\right)
$$

The fringe (frequency) indexes $\mathrm{k}_{\mathrm{l}}$ and $\mathrm{k}_{\mathrm{p}}$ are integers. $\mathrm{N}$ and $\mathrm{M}$ are the numbers of azimuth lines and range pixels of the image chip, respectively. The peak of the spectrum corresponds to the best estimation of the fringe rates $\mathrm{k}_{\mathrm{l}} / \mathrm{N}$ (line or azimuth fringe rate) and $\mathrm{k}_{\mathrm{p}} / \mathrm{M}$ (pixel or range fringe rate). Comparing (3) with (1) we see that the correlation coefficient in (1) is actually the magnitude of the normalized peak spectrum. There is an important difference between (1) and (3). In (1) the fringe rate is a real number taken to be known precisely. In (3) the accuracy of the estimated fringe rate depends on the size of the image chips. The resolution is limited to $1 / \mathrm{N}$ fringes per line and 1/M fringes per pixel and these estimates are susceptible to round-off error. Round-off error can be reduced by overcoming the resolution limit imposed by the data chip size, which is typically a power of 2 in each dimension. A simple way to overcome the resolution limit is to calculate (3) with finer grids. The method is implemented by zero-padding the interferogram and then doing the FFT or by calculating (3) directly in the image domain. A quadratic function can be used to fit the correlation coefficients as a function of the fringe rate to further reduce the fringe rate round-off error.

After the offset map refinement, good tie points are selected based on local coherence, offset variations between neighboring points, and fringe rate variations between neighboring points. Offset information from the acceptable tie points are propagated to all of the points in the grid using Delauny triangulation. The resulting offset map is smoothed using a moving window average and the final offsets are used to resample the secondary SLC. The primary and secondary SLCs are filtered to a common Doppler bandwidth and the interferogram and coherence map are computed. Interferograms are multilooked by averaging $3 \times 3$ pixels for fine beams and $8 \times 2$ pixels for standard beams. Coherence maps are multilooked first by averaging 3 x 3 complex pixels. A $200 \mathrm{~m}$, low resolution coherence map is created by averaging the magnitude of the fine scale coherence mosaic.

\subsubsection{Interferogram and offset map mosaics}

We divide each data take into smaller frames to accommodate changing Doppler centroids. Once we have computed the interferograms and offsets for each frame, we mosaic the data back into strips to improve baseline estimation and phase unwrapping.

\subsubsection{Missing line and azimuth streak removal}

Missing lines can occur when the return signal is weak. To compensate for the missing line in the offset data, we locate the position of the missing lines by examining the along track offset for abrupt jumps. We use tie points were available to refine the location and number of missing lines. 
Changing ionospheric disturbances distort the along track measurements of surface position and hence repeat pass estimates of the along track component of surface velocity. We used two methods to minimize ionospheric azimuth streaks in the data. First, we calculate the azimuth offset profile along the track by averaging offsets on all the range pixels for each azimuth line. We smooth the profile using a moving window average. We remove the smoothed azimuth offset profile from the azimuth offset image. Assuming the slope angle of the streaks is $\theta$, we can express a streak starting from an azimuth position y as:

$$
f(x, y+x \cdot \tan (\theta))
$$

where $\mathrm{x}$ is the range coordinate and $\mathrm{y}$ is the azimuth coordinate and $\mathrm{f}($.$) is the azimuth offset. By$ averaging the azimuth offset along the streak, we get the streak profile along the azimuth direction:

$$
f_{p}(y ; \theta)=\frac{1}{N} \sum_{x=0}^{N-1} f(x, y+x \cdot \tan (\theta))
$$

where $\mathrm{N}$ is the number of offset measurements in range direction. To estimate the slope angle $\theta$ we do a search for $\theta$ to minimize the residues between the streak profile $f_{p}(y ; \theta)$ and the azimuth streaks $f(x, y+x \cdot \tan (\theta))$ :

$$
\min [\theta] \sum_{x} \sum_{y}\left|f(x, y+x \cdot \tan (\theta))-f_{p}(y ; \theta)\right|^{2}
$$

After the slope angle $\theta$ is estimated using (6) we can approximate the streaks using the streak profile:

$$
f_{\text {streak }}(x, y) \approx f_{p}(y-x \cdot \tan (\theta) ; \theta)
$$

It is more desirable to compute velocities without resorting to azimuth offset data. This is possible for some MAMM data where the intersection of ascending and descending orbits makes possible a velocity estimate using range data alone. Two range measurements are possible: range offset; and interferometric phase. After the baseline and local topography related components are removed from these two measurements only the movement component is contained in the measurements. This method works well so long as the crossing angle between orbits is sufficiently large (greater than 20 degrees). 


\subsubsection{Phase unwrapping}

The interferogram is filtered using the Goldstein $\alpha$ filter. Two algorithms are then used for MAMM phase unwrapping of numerous, long interferograms. These are the miniMax method and a combination of miniMax and the minimum cost flow (MCF) method. The miniMax method utilizes the regional clustering property of residues and groups residues into different clusters with zero net residues under the criterion of minimizing the maximal cut length. It is optimal in the sense that it minimizes the maximum length of cut lines. The MCF is optimal in the sense that it minimizes the total length (or weighted length) of cut lines. It is however computationally inefficient. The perfect combination of miniMax method and the MCF method minimizes the maximum cut length and also minimizes the total cut length for each cluster and thus provides a good compromise between quality and efficiency.

\subsubsection{Surface elevation corrections}

The interferograms are corrected for the local elevation and, seaward of the grounding line, for the tide. Tide corrections are estimated using the tide model by L. Padman.

\subsubsection{Velocity from a single interferogram}

Two velocity map products can be created from a single interferogram. In one case, the azimuth offset and the unwrapped phase are used to derive the surface movement assuming the ice is moving along the surface. In the other, the same azimuth offset is used but the range offset is used instead of the unwrapped phase.

The algorithm for both the velocity products is the same. Assuming the velocity vector is parallel to the local surface slope:

$$
\begin{aligned}
& \mathbf{M} \cdot \mathbf{v}_{\mathbf{a}}=\Delta \mathbf{a} \\
& \left(\mathbf{M}+\text { tide } \cdot \mathbf{v}_{\mathbf{z}}\right) \cdot \mathbf{v}_{\mathbf{s}}=\Delta \mathbf{r} \\
& \mathbf{M} \cdot \mathbf{n}=0
\end{aligned}
$$

Where $\mathbf{M}$ is the surface velocity vector, $\mathbf{v}_{\mathbf{a}}$ is the unit vector in azimuth direction, $\Delta \mathrm{a}$ is the azimuth offset, tide is the tidal change between the reference and secondary acquisition, $\mathbf{v}_{\mathbf{z}}$ is the height unit vector, $\mathbf{v}_{\mathbf{s}}$ is the slant range unit vector, $\Delta \mathbf{r}$ is the range movement component and $\mathbf{n}$ is the unit vector of the surface normal.

The only unknown vector is $\mathbf{M}$, which has three known components that can be determined from the three equations (8). 


\subsubsection{Velocity error sources}

There are 6 different error sources included in the velocity estimate: VCP error; imperfect fitting between the baseline; offsets, and the VCPs; DEM error; phase unwrapping seed errors; offset error caused by misregistration and phase uncertainty. The total speed error of each velocity measurement is the sum of all the 6 speed error sources.

VCP error: The speed error of a VCP contributes directly to the total speed error.

Fitting error: The fitting error is standard deviation of the velocity differences between the VCP and the fitted velocity measurements after the baseline and offset are refined using the VCPs.

DEM speed error: DEM elevation error results in a speed error. The slant range projection of DEM speed error is calculated as:

$$
\text { dem_speed_error }=B_{\text {per }} * \text { dem_error } / \text { range } / \text { Sin(incidenceAngle) }
$$

Offset error: We assume there is a registration error for all the tie points. Because velocity is only measured on good tie points (higher coherence), we set the minimum offset error as 0.01 (line or pixel) and maximum offset error as 0.1 from experience. We calculate the offset speed error as:

$$
\text { offset_speed_error }=\max _{-} \text {error }-\frac{\text { max_error }-\min \_ \text {error }}{\text { good_error }- \text { coh_th }}(\text { coherence }- \text { coh_th })
$$

where max_error $=0.1$, min_error $=0.01$, good_coherence $=0.5$, coh_th is the coherence threshold set by user and it has a default value of 0.12 , the coherence is the coherence value of the tie point. If offset_speed_error is smaller than min_error, it will be set to min_error and if it is bigger than max_error it will be set to max_error.

Seed speed error: Because the isolated phase islands will rely on the seed to unwrap the whole interferogram any error in the seed will directly cause phase error and thus a velocity error. Suppose the total number of tie points is L, then the seed speed error will be

$$
\text { Seed_speed_error }=\frac{\sqrt{\frac{1}{L} \sum_{i} \text { offset_speed_error }{ }_{i}^{2}}}{\sqrt{L}}
$$

where offset_speed_error ${ }_{i}$ is the speed error of tie point i caused by offset error and

$$
\sqrt{\frac{1}{L} \sum_{i} \text { offset_speed_error }{ }_{i}^{2}}
$$

is actually the average of the offset speed error of the phase island. 
Phase error: We use the standard estimate given by

$$
\text { phase_error }=\sqrt{\frac{1-\gamma^{2}}{2 L \gamma}}
$$

where $\gamma$ is the coherence and $\mathrm{L}$ is the looks number for the interferogram. Finally, the total speed error can be calculated assuming all the sources are independent:

$$
\begin{array}{r}
\text { total_speed_error }=\text { sqrt }\left(\text { vcp_error }{ }^{2}+\text { fitting_error }^{2}+\text { dem_error }^{2}+\text { offset_error }^{2}\right. \\
+ \text { seed_error }
\end{array}
$$

\subsubsection{Velocity map from ascending and descending azimuth velocity component}

The velocity vector $\mathbf{M}$ can be derived from azimuth velocity measurements of ascending and descending offset measurements. The following equations are the basis for the derivation:

$$
\begin{aligned}
& \mathbf{M} \cdot \mathbf{v a 1}=\Delta \mathrm{a} 1 \\
& \mathbf{M} \cdot \mathbf{V a 2}=\Delta \mathrm{a} 2 \\
& \mathbf{M} \cdot \mathbf{n}=0
\end{aligned}
$$

where va1 is the unit azimuth velocity vector of the reference offset data set, va2 is the unit azimuth vector of the secondary offset data set, $\Delta \mathrm{a} 1$ is the azimuth offset measurement from the reference data, $\Delta \mathrm{a} 2$ is the azimuth offset measurement from the second data set and $\mathbf{n}$ is the local normal unit vector.

\subsubsection{Velocity map from ascending and descending range velocity component}

The velocity vector $\mathbf{M}$ can also be derived by using the range velocity measurements of ascending and descending interferogram. The following equations are the basis for the derivation:

$$
\begin{aligned}
& \mathbf{M} \cdot \mathbf{v}_{\mathbf{r} 1}=\Delta r \mathbf{r} \\
& \mathbf{M} \cdot \mathbf{v}_{\mathbf{r} 2}=\Delta \mathrm{r} 2 \\
& \mathbf{M} \cdot \mathbf{n}=0
\end{aligned}
$$

where $\mathbf{v r} \mathbf{1}$ is the unit slant range vector of the reference interferogram, $\mathbf{v r} \mathbf{2}$ is the unit slant range vector of the secondary interferogram, $\Delta \mathrm{r} 1$ is the range velocity measurement from the reference interferogram, $\Delta \mathrm{r} 2$ is the slant range velocity measurement from the secondary interferogram and $\mathbf{n}$ is the local normal unit vector. Range speckle or feature retracking offsets can be used equivalently. 


\subsubsection{MAMM data conflation}

The final velocity computation utilizes the several possible combinations of observations and the DEM. All or some of these can be used to estimate the velocity vector.

The possible combinations are:
azimuth offset, range phase;
azimuth offset, range offset;
ascending and descending range phase;
ascending and descending azimuth offsets

The conflation method is provided in the velocity index files.

In general, we maximized the use of velocities computed from ascending and descending range phase. We supplemented that with azimuth offset and range phase data along with azimuth offset and range offset data. We generally did not use ascending and descending azimuth offsets as these are the poorest quality estimates.

Where more than one observation of a particular measurement type was available, we also had the option to conflate the data via a simple average:

$$
\mu_{0}=\frac{\sum_{k=1}^{N} w_{k} x_{x}}{\sum_{k=1}^{N} w_{k}} \quad w_{k}=\frac{1}{\sigma_{k}^{2}}
$$

and

$$
\mu=\mu_{o} \pm\left(\sum w_{k}\right)^{-1 / 2}
$$

As noted above, ionospheric variability causes velocities estimated using azimuth offsets to have magnitude 'streaks' and inconsistent velocity directions. Two approaches were implemented to minimize this effect. In one case, the azimuth offsets in the vicinity of streaks are averaged across the disturbed zone and taking into account the slope of the offsets in the range direction. A better solution comes about because of the MAMM ascending and descending acquisitions. The ionospheric effects are almost absent in the range direction. So in cases where phase data are available from both 'scendings, and where there is a suitable crossing angle between orbits (greater than 20 degrees), the streaks can be avoided.

The final data product contains the following information for each velocity point:

- PS coordinates (8 bytes)

- Elevation (4 bytes)

- Slope (8 bytes) 
- Velocity Vector (12 bytes)

- Speed error (4 bytes)

- Direction error (4 bytes)

- Tide (4 bytes)

- Index for conflation data file (4 bytes), which includes (variable length with minimum 10 bytes)

o Number of measurements (1 bytes)

o Methods for velocity estimation (1 bytes)

o Speed error

o Index for data take dependent information, index data file (4 bytes), which includes (variable length)

- Beam name (4 bytes)

- Reference orbit number (4 bytes)

- Reference acquisition date (4 bytes)

- Secondary orbit number (4 bytes)

- Secondary acquisition date (4 bytes)

- Perpendicular baseline (4 bytes)

- Doppler overlap (4 bytes)

- Number of VCPs (4 bytes)

- List of VCPs (variable length with minimum 16 bytes)

- PS coordinates (8 bytes)

- Velocity (4 bytes)

- Direction (4 bytes)

\subsection{MAMM Velocity Control Points}

Interferometry only yields relative displacements across a scene. These then have to be adjusted by knowledge of absolute motion for several points in each radar image. Once again, data from a variety of sources including SCAR have been able to provide the required information. Information on individual velocity ground control points (VGCPs) are included in the velocity product index files (figure 14). Information on VGCPs collected specifically for the RAMP project is also provided in the data set. 

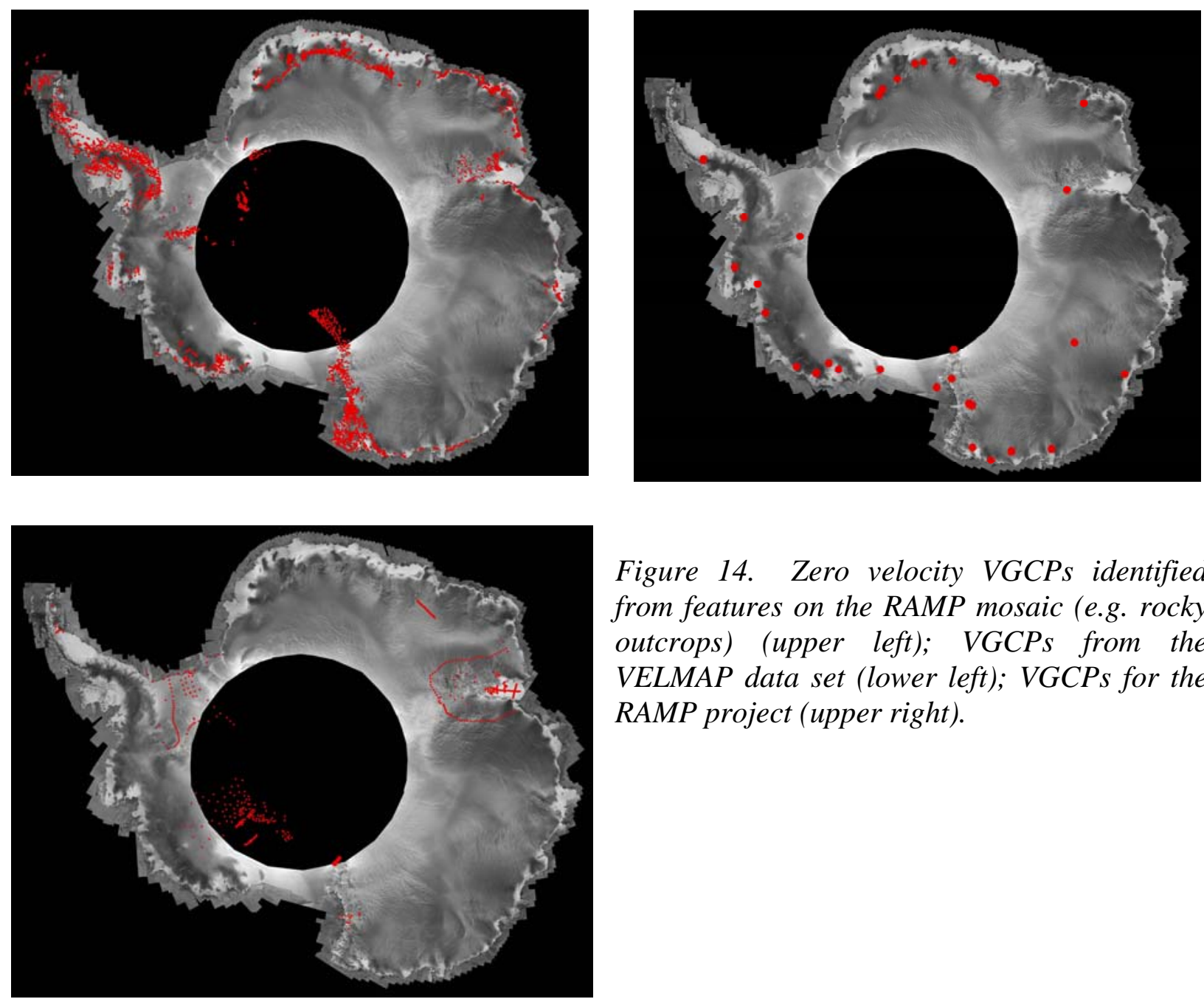

Figure 14. Zero velocity VGCPs identified from features on the RAMP mosaic (e.g. rocky outcrops) (upper left); VGCPs from the VELMAP data set (lower left); VGCPs for the RAMP project (upper right).

\subsection{Balance Velocity Mosaic}

OSU created a balance velocity model using the RAMP DEM, BEDMAP ice thickness data, and accumulation rate information compiled from the literature. The model, shown in figure 15, was used as a preliminary check on velocities estimated from InSAR. In regions near the ice divides where motion is low, balance velocities were also used as control points on the InSAR data. 


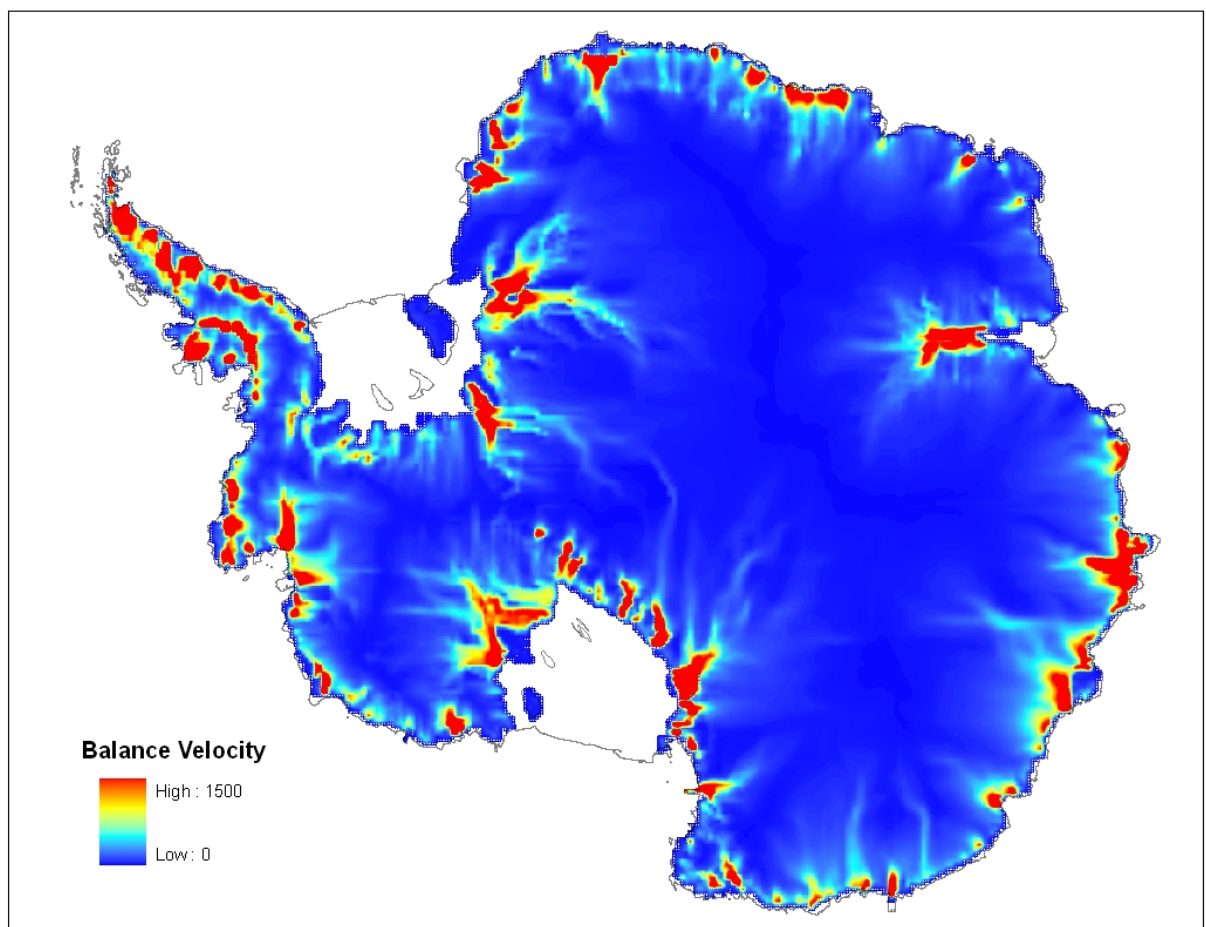

Figure 15. Balance velocity model (Wu and Jezek, 2005).

\subsection{Coherence Mosaics and Interferograms}

Coherence is calculated by cross correlating two repeat pass images. Cross correlation is an early step in the interferometric analysis and the coherence value provides a measure of interferogram quality. The coherence value is used in the interferometric velocity analysis as a filter for rejecting low quality observations.

Coherence is a function of the observing geometry (baseline), material properties (volume decorrelation in this case), thermal noise, and temporal changes in the surface. While it is possible to estimate the first parameter, the remaining terms are inextricably convolved. Nevertheless, coherence patterns appear throughout the data set and the spatial patterns can be interpreted in terms of geophysical properties. As a start of that analysis, the first, continental scale coherence maps are presented in Plates 7 and 8. Swath to swath variations have been smoothed slightly, though the individual swaths remain strongly represented in the mosaics. The geophysical information available in the smoothed coherence maps is illustrated in figure 16 which is a coherence map of the Amery Ice Shelf and Lambert Glacier. Shear margins bounding the various tributary glaciers are identifiable in the image as the black curvilinear segments of low coherence. 


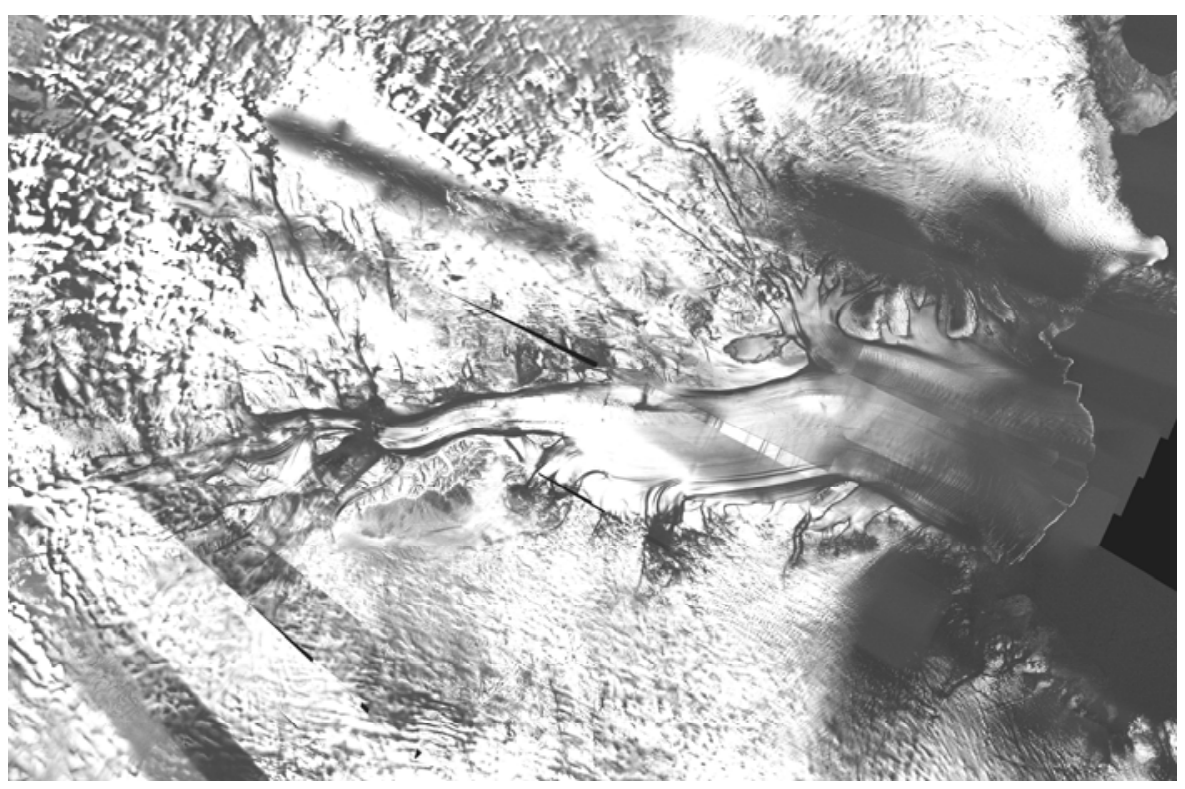

Figure 16. Coherence map of the Amery Ice Shelf and Lambert Glacier.

\subsubsection{Grounding lines and temporal observations}

As noted by Gray and others (2001) and by Zhao (2001), the grounding line is strongly depicted in coherence data. Figure 17 shows coherence across the Filchner Ronne Ice Shelf. Grounding lines around ice rises and ice rumples appear as distinct heavy bands of low (dark) coherence. Repeat pass interferometric data were collected in AMM-1 and MAMM over the Coates Land Ice Streams (figure 18). This enables a temporal comparison between coherence maps of the areas. Here, differences are probably attributable to slightly different registration algorithms rather than geophysical changes over time. 


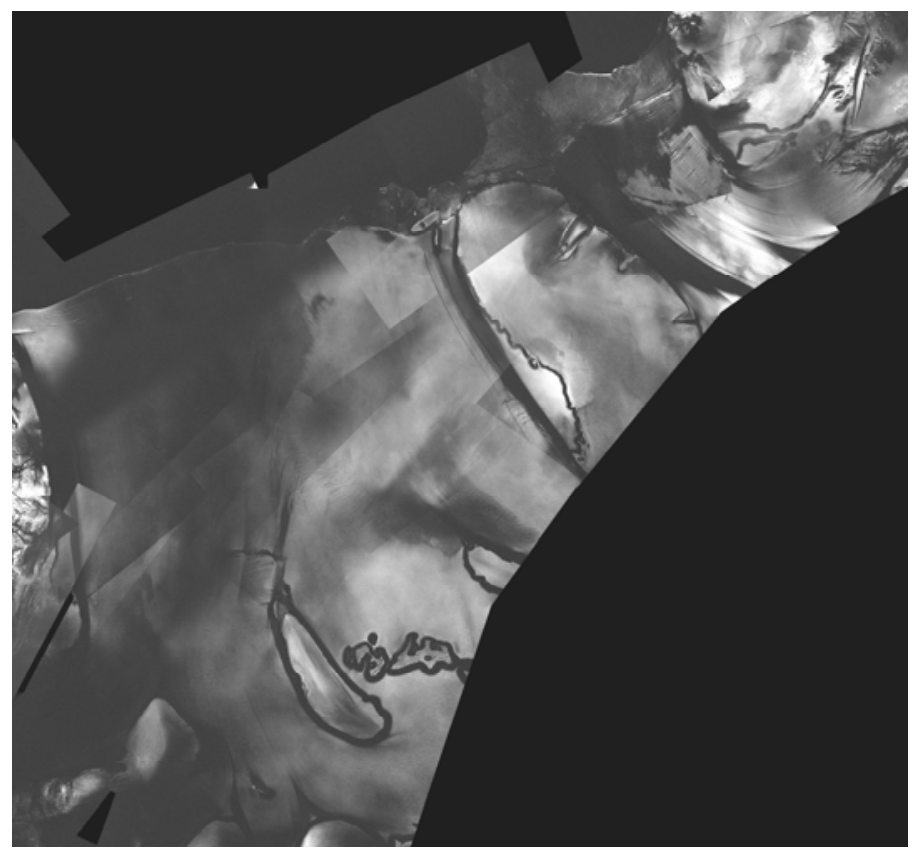

Figure 17. Coherence map of the Filchner and Ronne Ice Shelves. Thick bands of low coherence (dark) generally indicate the position of the grounding line in this region.
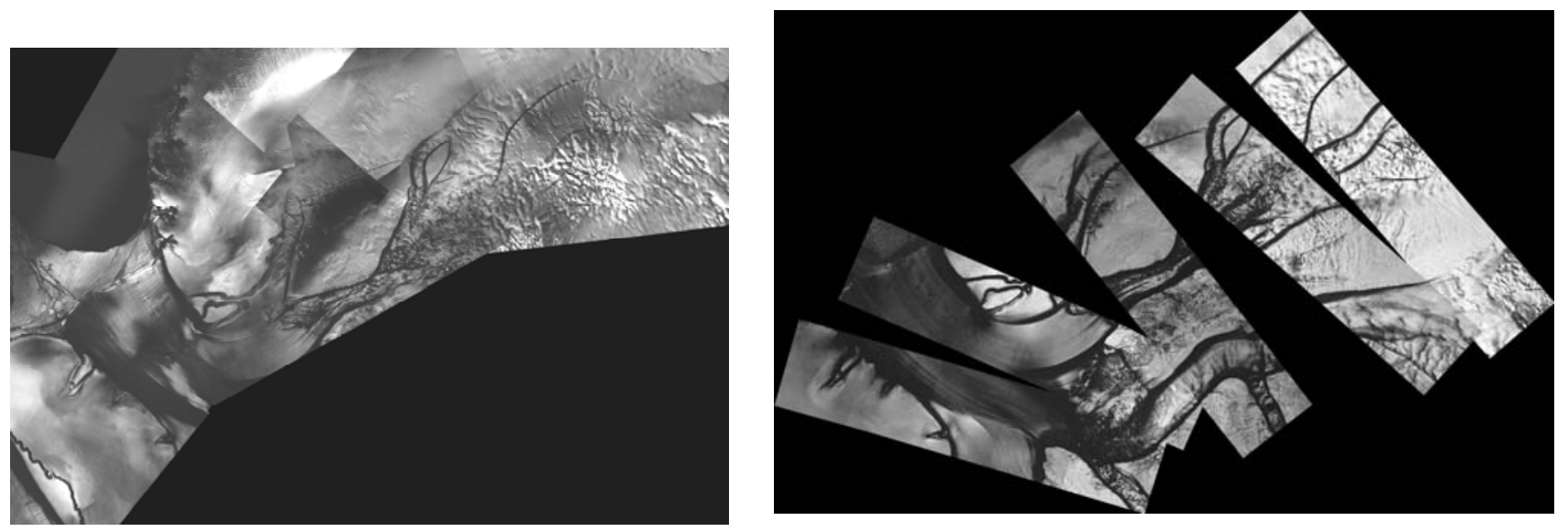

Figure 18. 1997 (right) and 2000 (left) coherence maps of ice streams in Coates Land.

Surface details appear in the coherence data at scales less than a kilometer. Figure 19 shows AMM-1 and MAMM coherence images near Dome C. Snow megadunes trend across the scene from upper left to lower right. Fine scale stripes cut orthogonal to the megadunes and are evident in both the AMM-1 and MAMM data. The stripe directions, which can be mapped in both the coherence and amplitude image correspond closely to the direction of the modeled katabatic wind field (figure 20). This suggests that a detailed map of the coherence stripes can be used to refine prevailing wind field directions. 

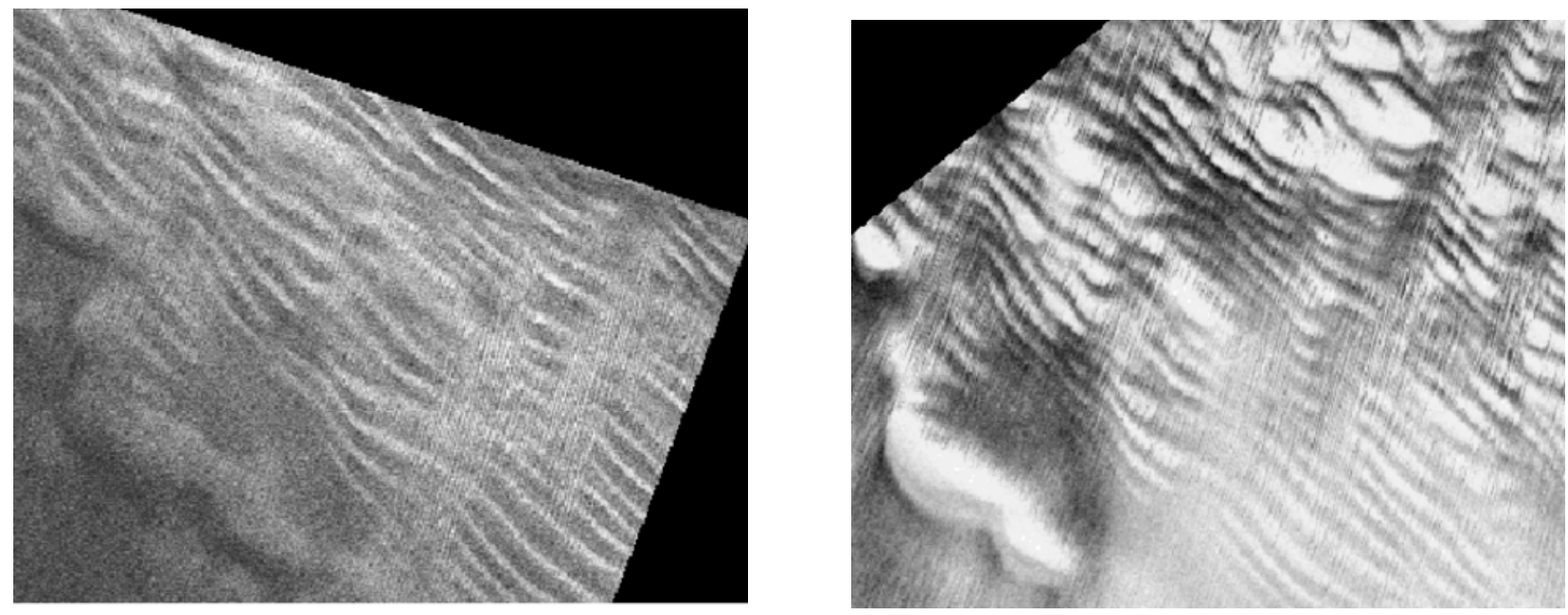

Figure 19. AMM-1 standard beam 2 data (left) and MAMM standard beam 2 coherence data collected near Dome C. The images are about $70 \mathrm{~km}$ across.

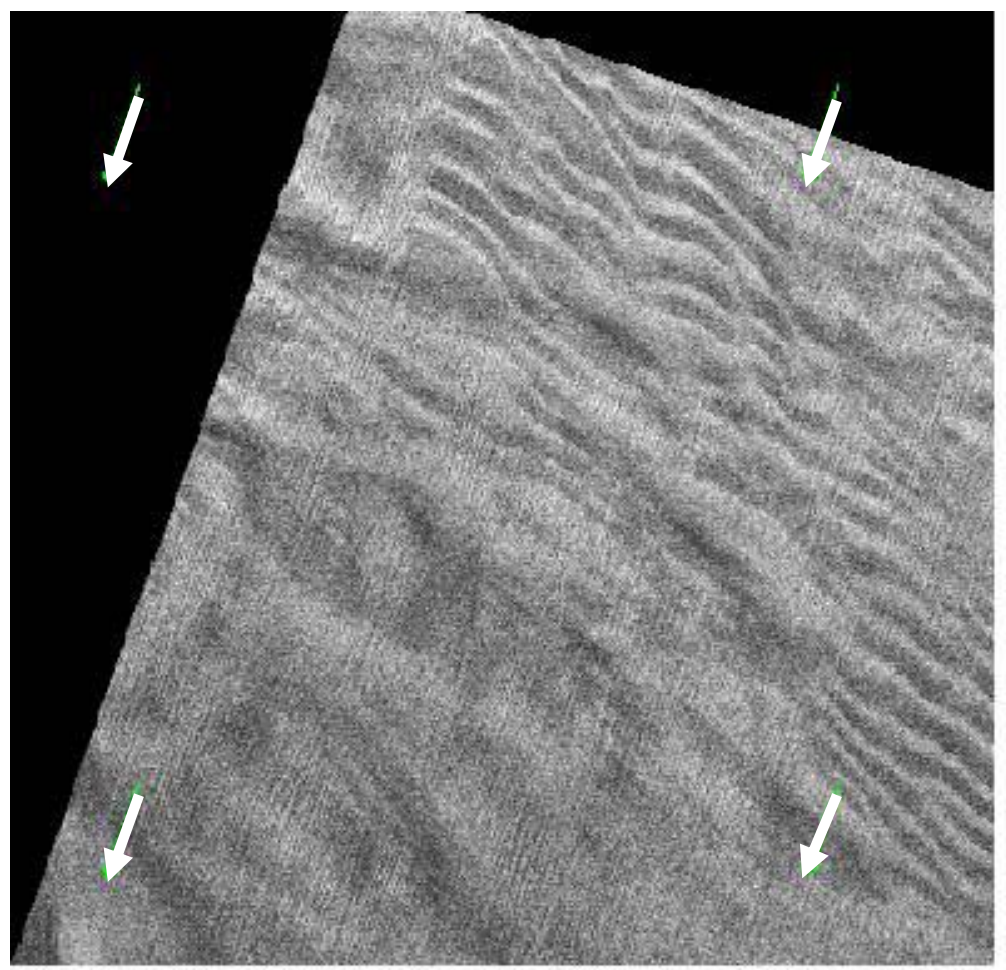

Figure 20. Katabatic wind field directions calculated by D. Bromwich and AMM-1 coherence stripes. 


\subsection{Velocity Mosaics}

Local velocity estimates were derived from exploratory interferometric data collected during AMM-1. Velocity estimates about the continent were derived from dedicated interferometric acquisitions that were part of MAMM.

\subsubsection{AMM velocity data}

AMM velocity data were processed using code developed at OSU (Zhao, 2001). Velocities were estimated over portions of the Coates Land glaciers and ice streams. The results are shown in figure 21. The results provide further evidence for the existence of the RAMP Ice Stream and Blackwall Glacier.

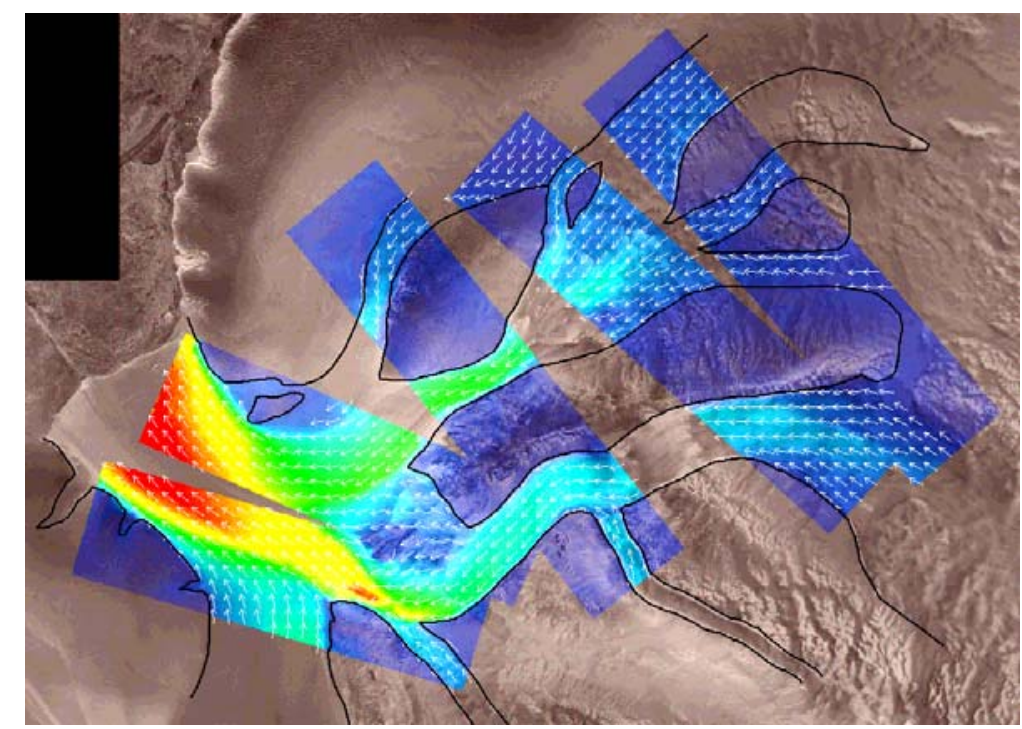

Figure 21. Surface velocities of Coates Land Ice Streams (Zhao, 2001).

\subsubsection{MAMM velocity data}

The MAMM velocity product is shown in Plate 9. The data capture the major features of ice sheet outflow. Details of the flow are illustrated in figure 22 which shows the velocity field of the Lambert Glacier and Amery Ice shelf on a logarithmic scale. The complexity of the drainage field is probably a consequence of irregular basal topography.

A second example of local flow is shown in figure 23 which depicts the David Glacier and the Drygalski Ice Tongue. The David Glacier drains a portion of Northern Victoria. Ice is funneled through a narrow, deep channel cut through the Transantarctic Mountains. The flow eventually extends out onto the Ross Sea in the form of the ice tongue. 


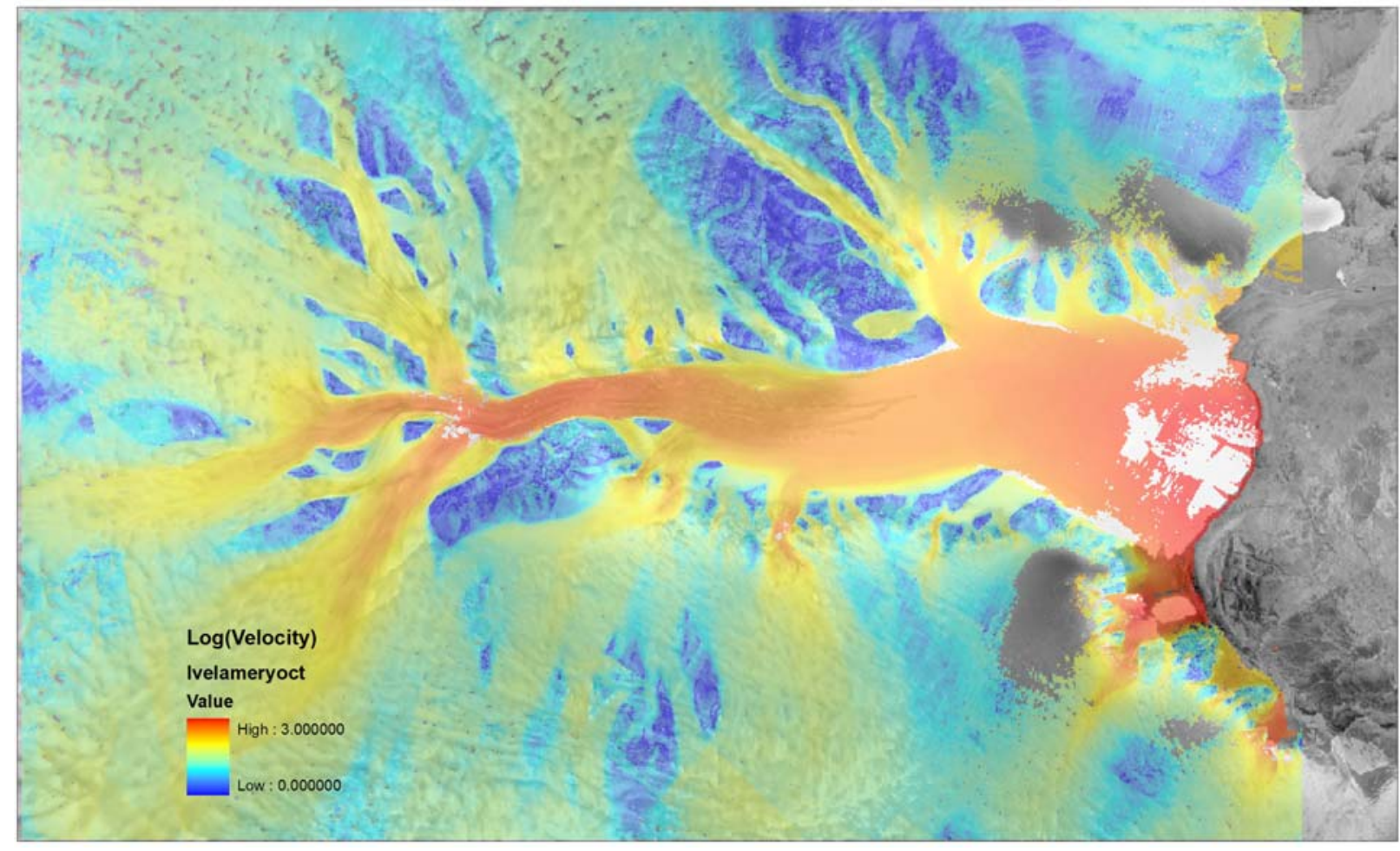

Figure 22. MAMM velocity measurement of the Amery Ice Shelf and Lambert Glacier depicted using a logarithmic scale.

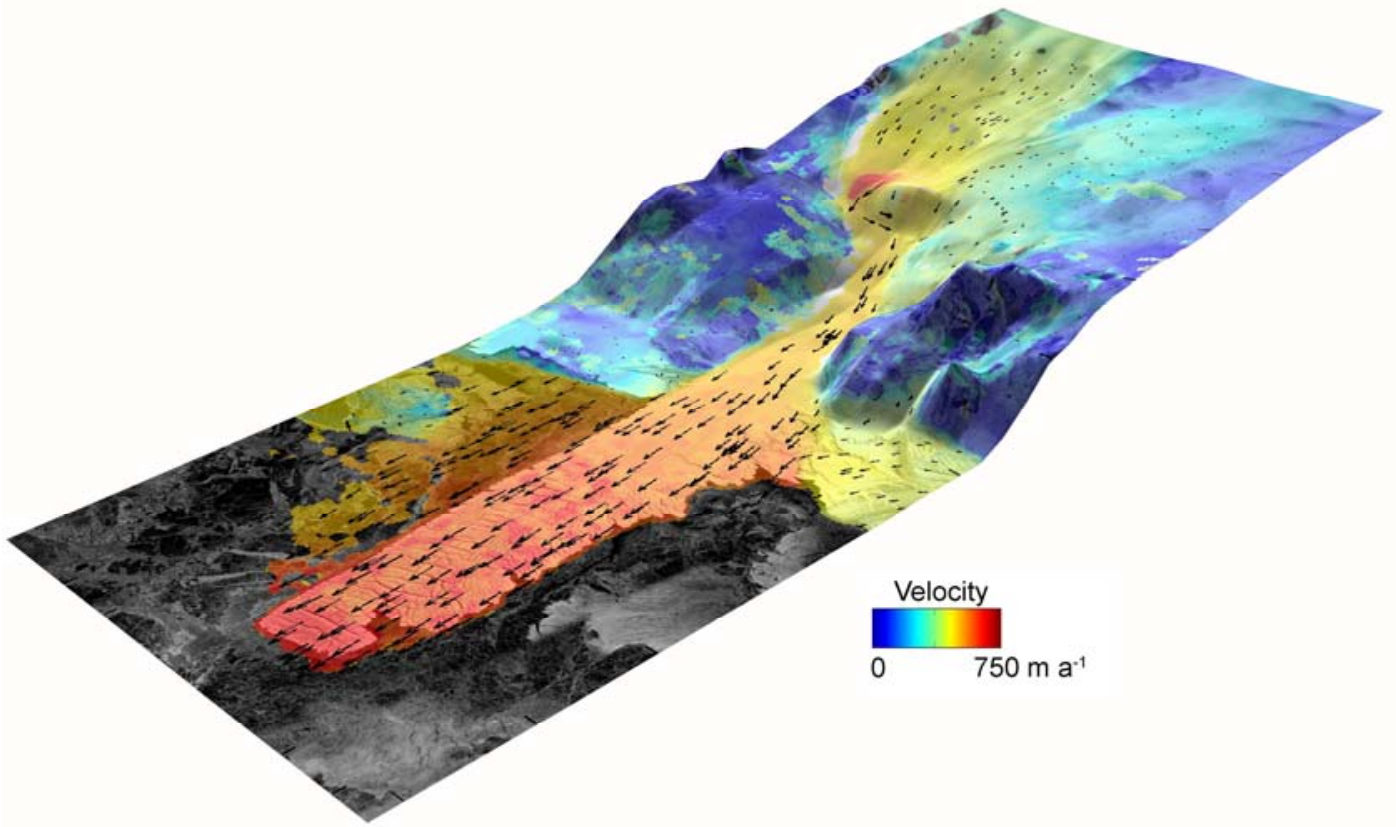

Figure 23. MAMM measurements of surface velocity on the David Glacier and Drygalski Ice Tongue (Wuite, 2006).

MAMM velocities have been computed using InSAR phase and speckle retracking techniques. It is also possible to use the AMM-1 and MAMM data to estimate feature retracking velocities. Figure 24 shows the InSAR and 3-year average feature retracking velocities for Stancomb Wills 
Glacier. The good correlation between the two estimates suggests there has been little recent change. Comparison with flow stripes indicates that changes did occur in the past.

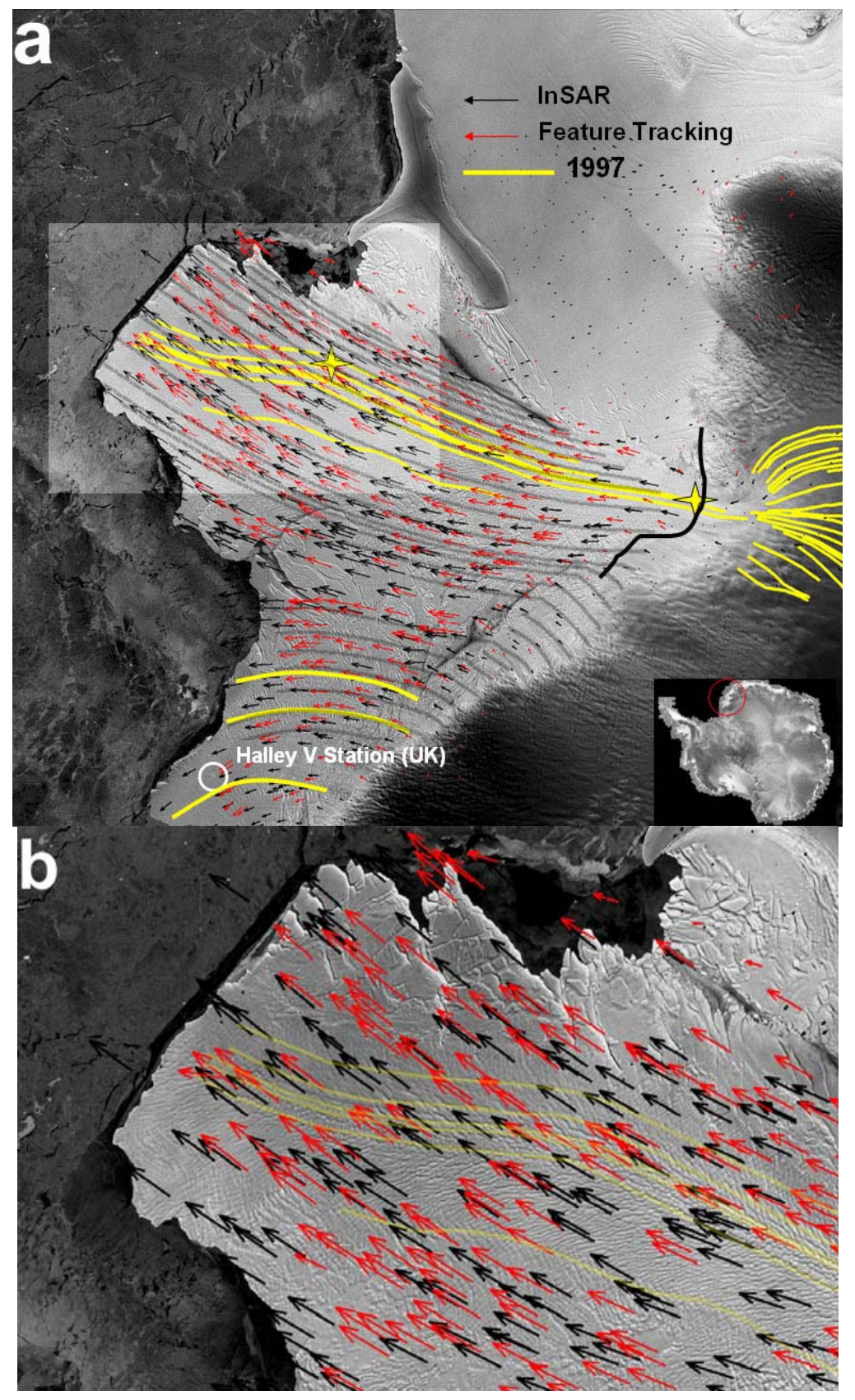

Figure 24. a) RADARSAT-1 image of BIS and SWIT showing flow lines inferred from the velocity field (grey), traced flow stripes (yellow), feature tracking (red) and InSAR (black) velocity vectors. The solid black line indicates the approximate location of the grounding line (adapted from Rignot, 2002). Stars mark beginning and end of velocity profile that is used to estimate the timing of the perturbation. Highlighted square shows area of enlargement in $b . b$ ) Close up of the front of SWIT showing clearly the divergence between relict flow stripes and current velocity vectors (Wuite, 2006). 


\section{RAMP Digital Elevation Model}

All mapping and velocity calculations used the OSU Antarctic Digital Elevation Model (figure 25) during the orthorectification process (Liu and others, 1999; Jezek and others, 2000). While this model has been superceded in many ways by the more recent ICEsat data set, it represents a common datum for the RAMP products.

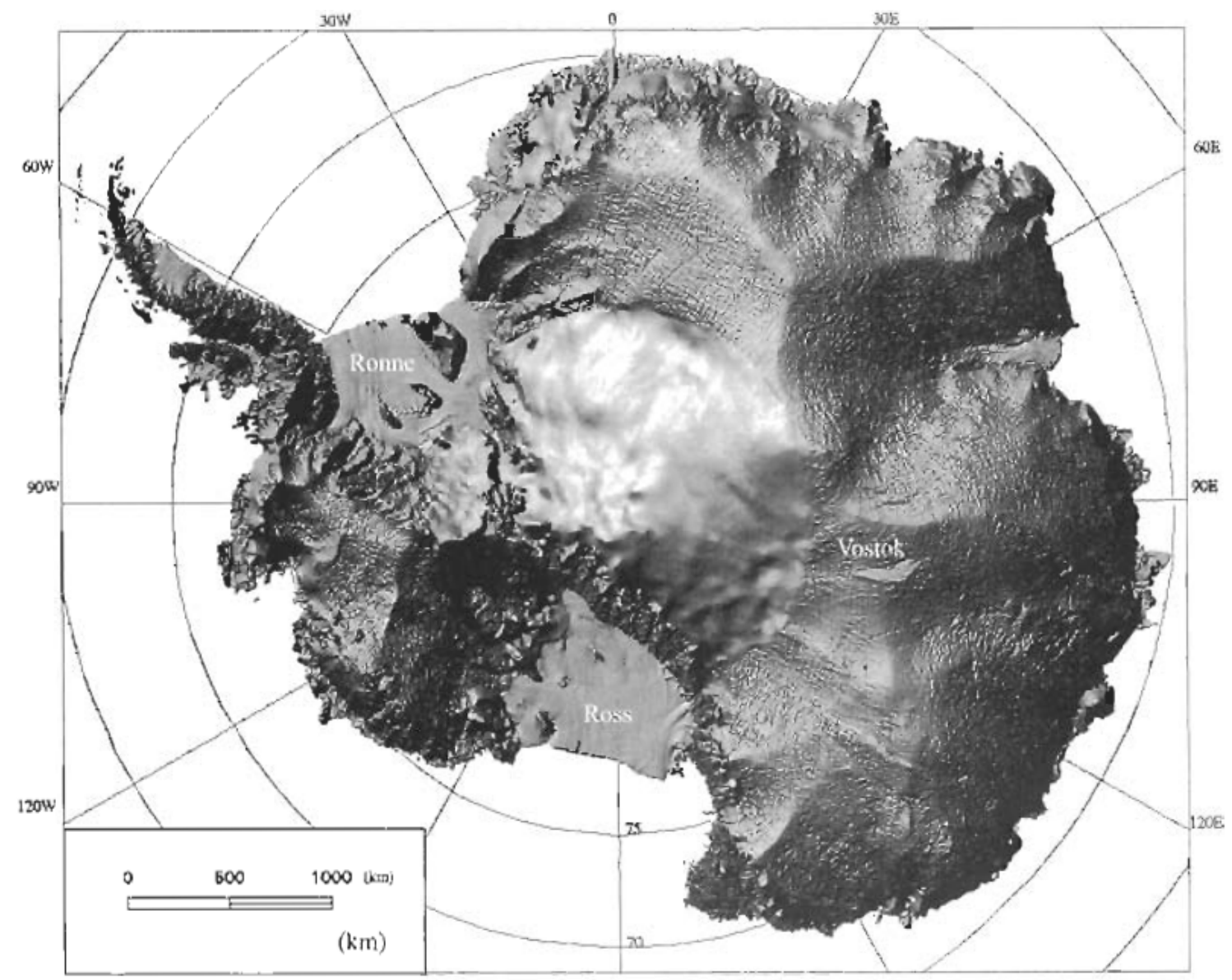

Figure 25. RAMP DEM used in all calculations.

\section{Summary}

We conclude with a brief summary of the combined RAMP products. 


\subsection{Physical Properties of the Antarctic Ice Sheet}

The following figures summarize derived products from the RAMP data set. Figure 26 shows the AMM-1 mosaic upon which is overlain the MAMM 2000 coastline and flow stripes for fast glaciers interpreted from the AMM-1 mosaic. Notice the difference in ice front position along the Ross Ice Shelf made evident by the comparison between the 1997 image mosaic and 2000 derived coastline.

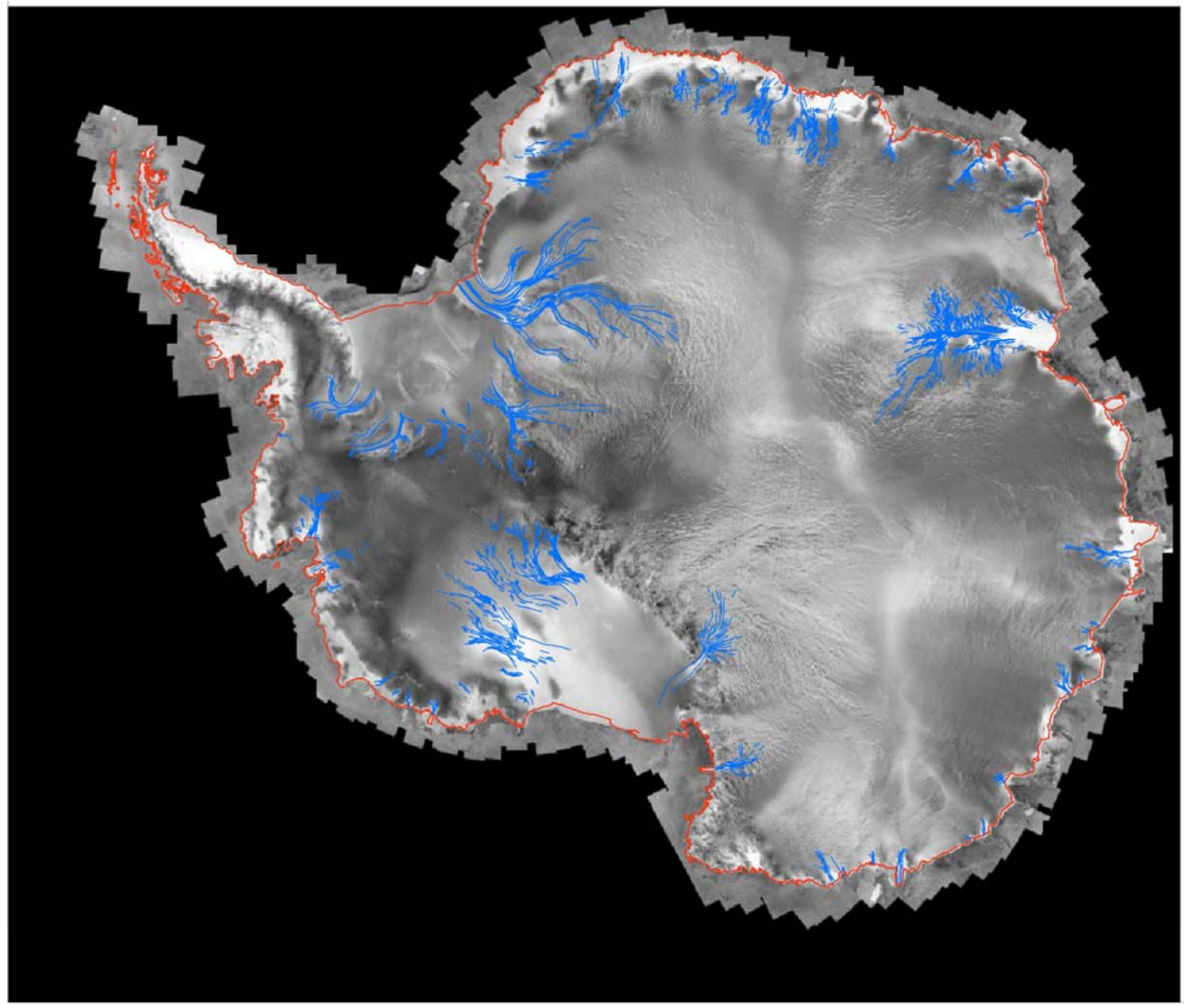

Figure 26. MAMM 2000 coastline (red), flow stripes for fast glaciers (blue) overlain on the AMM-1 mosaic.

Figure 27 shows the RAMP DEM overlain on the AMM-1 mosaic. Note again the general correspondence between the locations of ice divides especially in East Antarctica and high radar backscatter. 


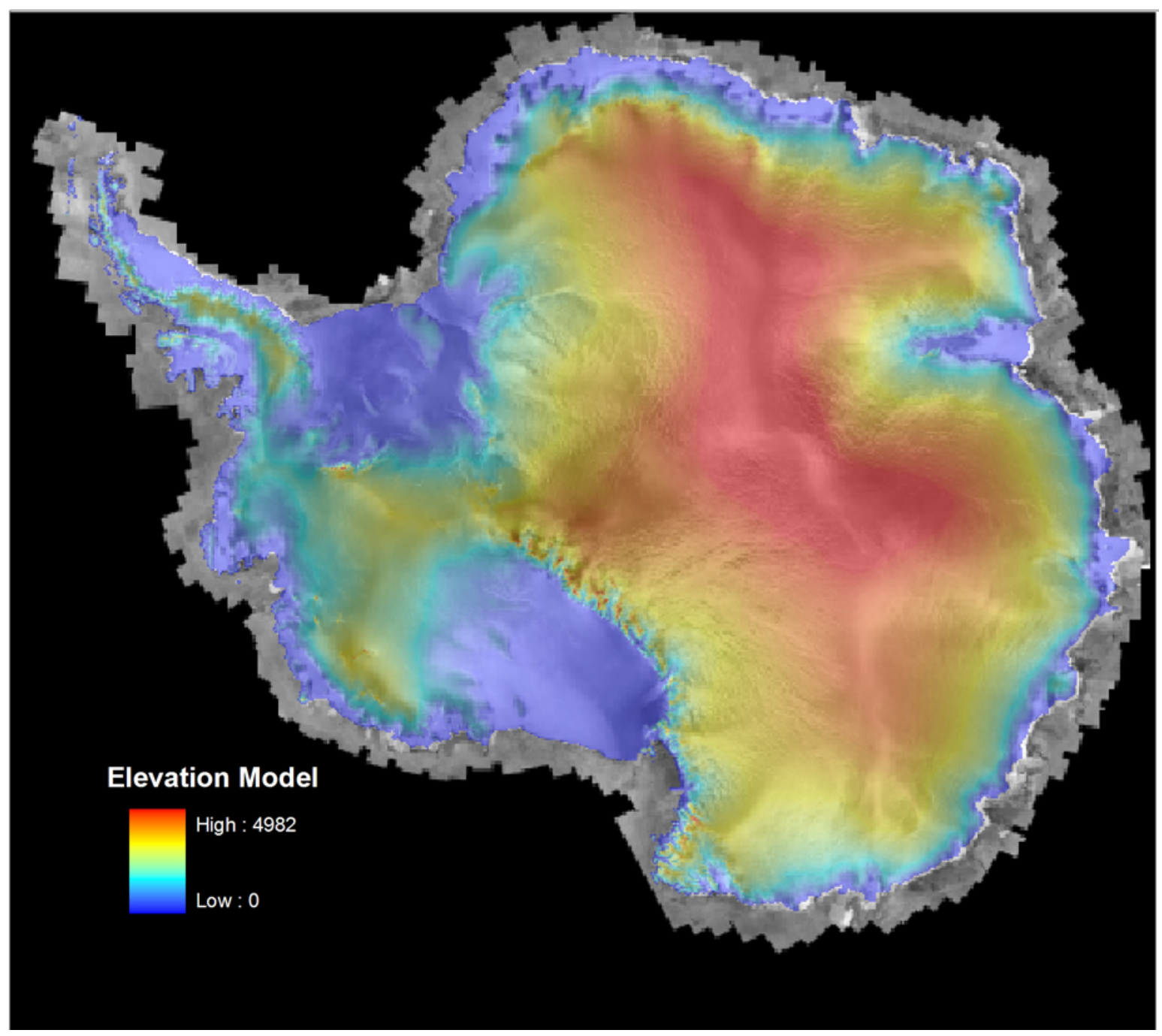

Figure 27. RAMP DEM overlain on the AMM-1 mosaic.

A resulting model of the ice-sheet surface-velocity field is shown in figure 28. AMM-1 and MAMM velocities estimated by the project using interferometric, speckle retracking, and feature retracking techniques are the primary input to the model. Where no RAMP measurements are available, balance velocities are used to supplement the results. 


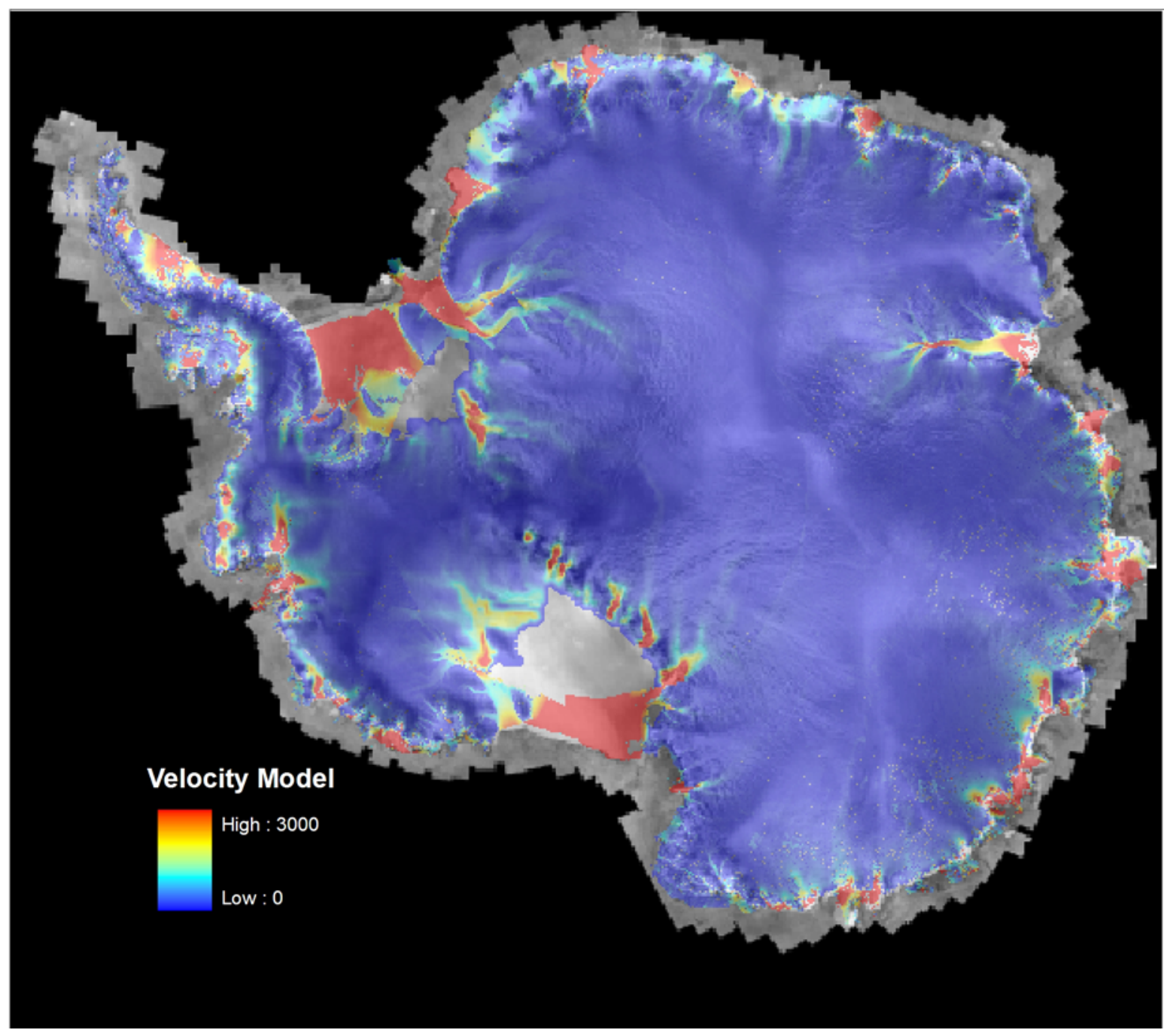

Figure 28. RAMP ice sheet surface velocity model.

\subsection{RAMP Team}

The success of the RADARSAT-1 program in general and the achievements of the RAMP project in particular are the successes of the many people committed to the venture. Some of those individuals are shown in the photos below (figures 29, 30, 31) and most are listed in Appendix 3. As of this writing and through the efforts of many of those pictured, RADARSAT1 continues to provide exceptional scientific data about the Earth from pole-to-pole. 


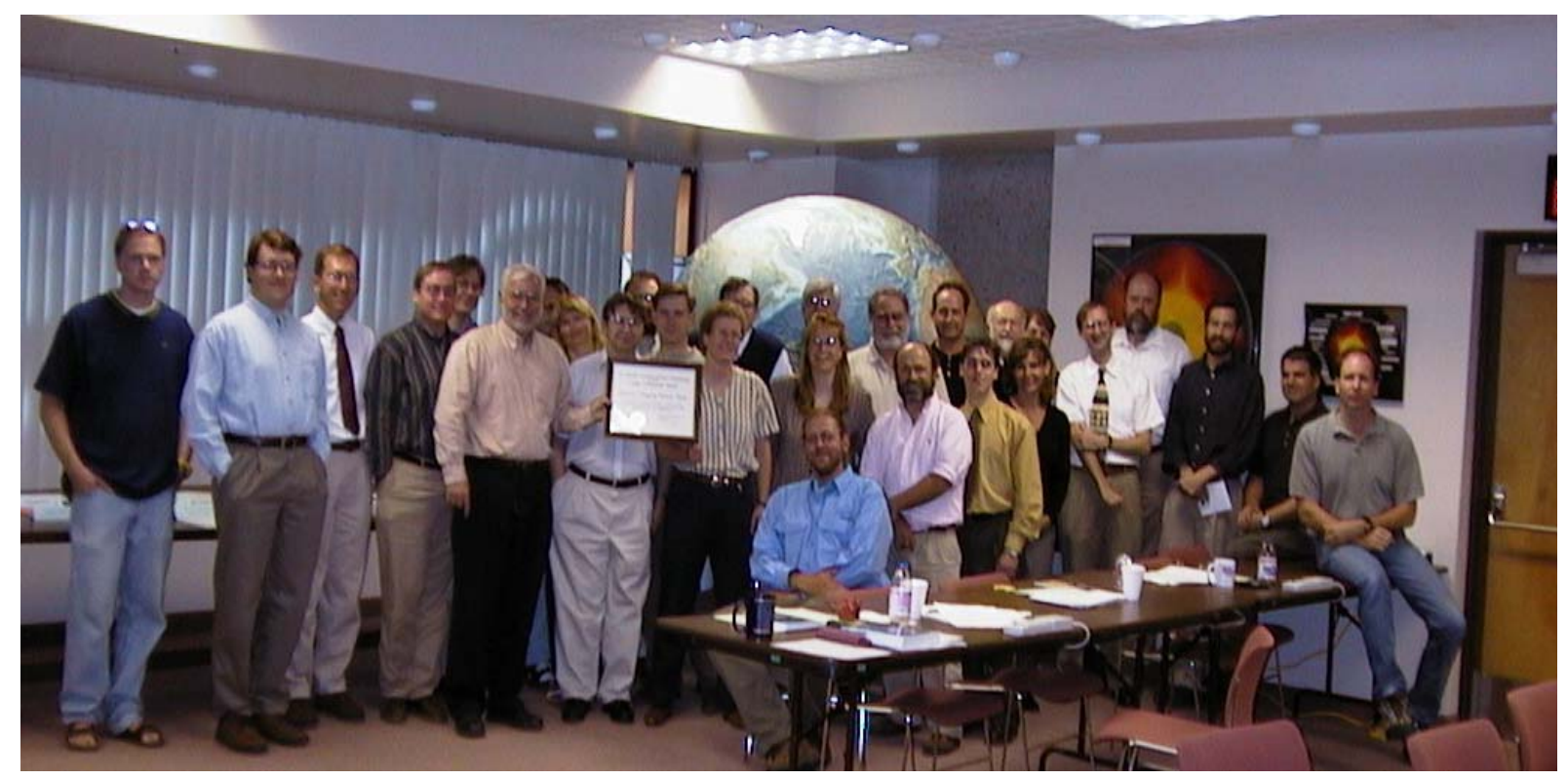

Figure 29. RAMP team at ASF.

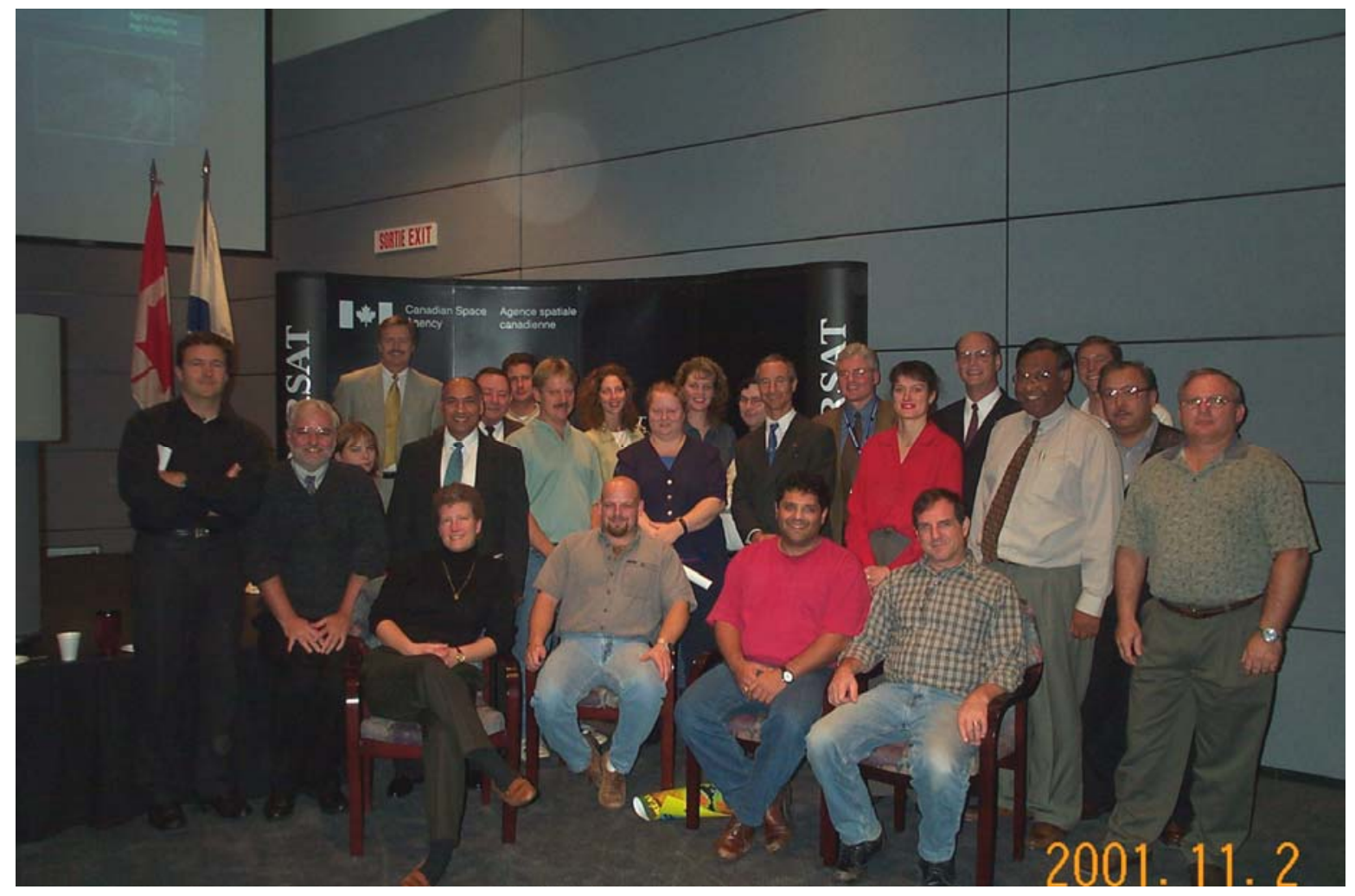

Figure 30. RAMP team at CSA. 


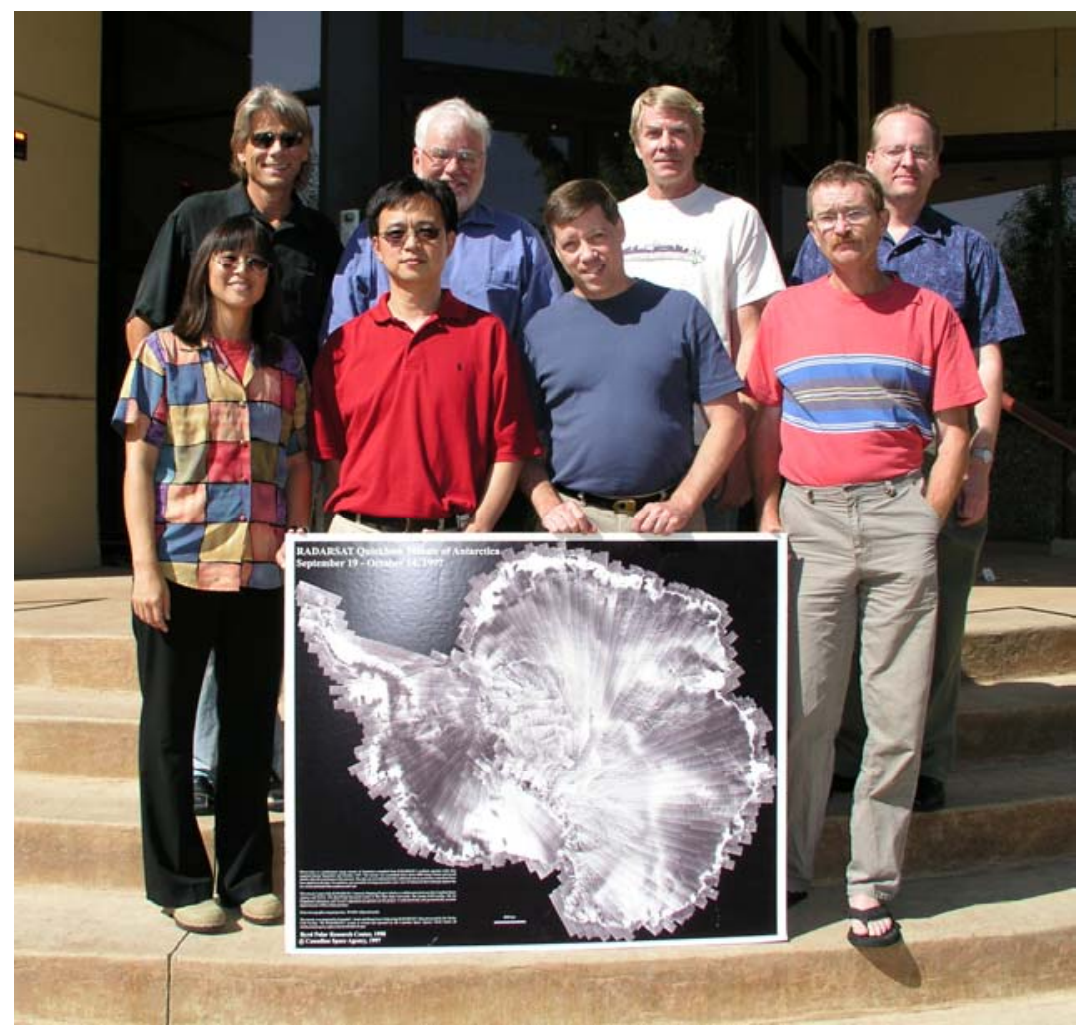

Figure 31. RAMP team at Vexcel.

\section{References and RAMP Bibliography ${ }^{1,2}$}

ASF Prelaunch Science Working Team, 1989. Science plan for the ASF program. Jet Propulsion Laboratory Publication 89-14, 87 pages.

Carande, R., D. Fatland, K. Jezek, J. Miller and X. Wu, 2002. Interferometric mapping of Antarctica using Radarsat. Proceedings EUSAR 2002, Cologne, Germany, p. 129-132.

Carsey, F. and B. Holt, 1985. Mapping Antarctica and Greenland with Shuttle Imaging Radar. Informal White Paper, Jet Propulsion Laboratory, 18 pages.

Carsey, F., K. Jezek, J. Miller, G. Weller and W. Weeks, 1987. The Alaskan Synthetic Aperture Radar Facility Project. EOS, 68(25), 596.

Forster, R.R., K.C. Jezek, H.G. Sohn, A.L. Gray and K.E. Matter, 1998. Analysis of glacier flow dynamics from preliminary RADARSAT InSAR data of the Antarctic Mapping Mission. Geoscience and Remote Sensing Symposium Proceedings, IGARSS '98, v. 4, 2225-2227.

Forster, R.R., K.C. Jezek, L. Koenig and E. Deeb, 2003. Measurement of glacier geophysical properties from InSAR wrapped phase. IEEE Transactions on Geoscience and Remote Sensing, 41(11), 2595-2604.

Gray, A.L., N. Short, K. Mattar and K.C. Jezek, 2001. Velocities and flux of the Filchner ice shelf and its tributaries determined from speckle tracking interferometry. Canadian Journal of Remote Sensing, 27(3), 193-205. 
Gray, L., I. Joughin, S. Tulazcyk, V. Spikes, R. Bindschadler and K. Jezek, 2005. Evidence for subglacial water transport in the West Antarctica Ice Sheet through three dimensional satellite radar interferometry. Geophysical Research Letters, 32, L03501.

Gray. L., K. Mattar, P. Vachon, R. Bindschadler, K. Jezek, R. Forster and J. Crawford, 1998. InSAR results from the Radarsat Antarctic Mapping Mission data: estimation of glacier motion using a simple registration procedure. Geoscience and Remote Sensing Symposium Proceedings, IGARSS '98, v. 3, 1638-1640.

Gray, L., N. Short, K. Jezek and Z. Zhao, 2001. Radarsat reveals Antarctic ice dynamics. Newsletter for Canadian Antarctic Research Network, 12, 1-3.

Jezek, K., 2003. Observing the Antarctic Ice Sheet using the RADARSAT-1 synthetic aperture radar. Polar Geography, 27(3), 197-209.

Jezek, K., R. Carande, N. Labelle-Hamer, K. Noltimier and X. Wu, 2003. RADARSAT-1 synthetic aperture radar observations of Antarctica: Modified Antarctic Mapping Mission 2001. Radio Science, 38(4), 8067-8073.

Jezek, K. and F. Carsey (eds.), 1991. McMurdo SAR Facility: Report of the Ad Hoc Science Working Team. BPRC Technical Report 91-01, 32 pages.

Jezek, K.C., 1998. Flow variation of the Antarctic Ice Sheet from comparison of modern and historical satellite data. Geoscience and Remote Sensing Symposium Proceedings, IGARSS '98, v. 4, 2240-2242.

Jezek, K.C., 1998. Radarsat Antarctic Mapping Project, 1998. BPRC Report No. 17, 40 pages.

Jezek, K.C., 1999. Glaciologic properties of the Antarctic Ice Sheet from spaceborne synthetic aperture radar observations. Annals of Glaciology, 29, 286-290.

Jezek, K.C., 2002. RADARSAT-1 Antarctic Mapping Project: change detection and surface velocity campaign. Annals of Glaciology, 34, 263-268.

Jezek, K.C., 2004. Building an integrated view of Antarctica. Alaska SAR Facility News and Notes, 1(5), 2-3.

Jezek, K.C., 2007. Antarctica: a continent revealed. In: Our Changing Planet: The View from Space, M. King, C Parkinson, K. Partington, and R. Williams (eds.), Cambridge University Press, Cambridge, 209-213.

Jezek, K.C. and F.D. Carsey (eds.), 1993. RADARSAT: The Antarctic Mapping Project. BPRC Report No. 6, 24 pages.

Jezek, K.C., J. Curlander, L. Norikane, F. Carsey, J. Crawford, C. Wales and J. Muller, 1996. RADARSAT: The Antarctic Mapping Project. Geoscience and Remote Sensing Symposium Proceedings, IGARSS '96, v. 3, 1775-1776.

Jezek, K.C. and L. Everett (eds.), 1995. Managing the Antarctic Environment: From Observations to Policy. BPRC Report 12, 42 pages.

Jezek, K.C. and H. Liu, 2005. Structure of Eastern Antarctic Peninsula ice shelves and ice tongues from synthetic aperture radar imagery. Journal of Glaciology, 51(174), 373-376.

Jezek, K.C., H. Liu, Z. Zhao and B. Li, 1999. Improving a digital elevation model of Antarctica using radar remote sensing data and GIS techniques. Polar Geography, 23(3), 185-200.

Jezek, K.C. and R.G. Onstott, 1999. The role of remote sensing in the environmental monitoring of Antarctica. Polar Geography, 23(1), 55-70.

Jezek, K.C., H.G. Sohn and K.F. Noltimier, 1998. The RADARSAT Antarctic Mapping Project. Geoscience and Remote Sensing Symposium Proceedings, IGARSS ’98, v. 5, 2462-2464.

Jezek, K.C. and 10 others, 1998. Snapshots of Antarctica from RADARSAT-1. Geoscience and Remote Sensing Symposium Proceedings, IGARSS '98, v. 3, 1428-1430. 
Kim, K., 1999. Application of Time Series Satellite Data to Earth Science Problems. M.S. Thesis, The Ohio State University, 69 pages.

Kim, K., 2004. Satellite Mapping and Automated Feature Extraction: Geographic Information System-based Change Detection of the Antarctic Coast. Ph.D. Dissertation, The Ohio State University, 157 pages.

Kim, K., K. Jezek and H. Liu, 2007. Decadal-scale variations in the extent of Antarctic Ice Shelves. Journal of Geophysical Research (Oceans), in revision.

Kim, K., K. Jezek and H. Liu, 2007. Orthorectified image mosaic of the Antarctic coast compiled from 1963 Argon satellite photography. International Journal of Remote Sensing, 28(23-24), 5357-5373.

Kim, K., K.C. Jezek and H. Sohn, 2001. Ice shelf advance and retreat rates along the coast of Queen Maud Land, Antarctica. Journal of Geophysical Research, 106(C4), 7097-7106.

Lazzara, M.A., K.C. Jezek, T.A. Scambos, D.R. MacAyeal and C.J. van der Veen, 1999. On the recent calving of icebergs from the Ross Ice Shelf. Polar Geography, 23(3), 201-212.

Liu, H., 1999. Development of an Antarctic Digital Elevation Model. BPRC Report 19, 157 pages.

Liu, H., 1999. Generation and Refinement of a Continental Scale Digital Elevation Model by Integrating Cartographic and Remotely Sensed Data: a GIS-Based Approach. Ph.D. Dissertation, The Ohio State University.

Liu, H. and K. Jezek, 2004. Automated extraction of coastline from satellite imagery by integrated Canny edge detection and locally adaptive thresholding methods. International Journal of Remote Sensing, 25(5), 937-958.

Liu, H. and K. Jezek, 2004. A complete high-resolution coastline of Antarctica extracted from orthorectified Radarsat SAR imagery. Photogrammetric Engineering and Remote Sensing, 70(5), 605-616.

Liu, H., L. Wang and K. Jezek, 2005. Delineation of dry and melt snow zones in Antarctica using active and passive microwave observations from space. Geoscience and Remote Sensing Symposium, IGARSS '05, v. 8, 5452-5455.

Liu, H., L. Wang and K. Jezek, 2006. Delineation of dry and melt snow zones using active and passive microwave observations from space. IEEE Transactions on Geoscience and Remote Sensing, 44(8), 2152-2163.

Liu, H., J. Yu, Z. Zhao and K. Jezek, 2007. Calibrating and mosaicking surface velocity measurements from interferometric SAR data with simultaneous least-squares adjustment approach. International Journal of Remote Sensing, 28(6), 1217-1230.

Liu, H., Z. Zhao and K. Jezek, 2004. Correction of positional errors and geometric distortions in topographical maps and DEMs using rigorous SAR simulation technique. Photogrammetric Engineering and Remote Sensing, 70(9), 1031-1042.

Liu, H., Z. Zhao and K. Jezek, 2007. Synergistic fusion of interferometric and speckle-tracking methods for deriving surface velocity from interferometric SAR data. IEEE Geoscience and Remote Sensing Letters, 4(1), 102-106.

Liu, J., K.C. Jezek and B. Li, 1999. Development of Antarctic digital elevation model by integrating cartographic and remotely sensed data: A GIS-based approach. Journal of Geophysical Research, 104(B10), 23,199-23,213.

Mahmood, A., J.P. Crawford, R. Michaud and K. Jezek, 1998. RADARSAT-1 background mission - mapping the world. EOS, 79(2), 17 and 23. 
Mahmood, A., K. Jezek, S. Parashar and L. Giugni, 2003. Snapshots from space of the world's continents. Geotimes, 48(11), 18-19.

National Research Council (NRC), 1989. Prospects and Concerns for Satellite Remote Sensing of Snow and Ice. National Academy Press, Washington, DC, 44 pages.

Noltimier, K., K. Jezek, H. Sohn, B. Li, H. Liu, F. Baumgartner, V. Kaupp, J. Curlander, B. Wilson and R. Onstott, 1999. RADARSAT Antarctic Mapping Project - mosaic construction. Geoscience and Remote Sensing Symposium Proceedings, IGARSS '99, v. 5, 2349-2351.

Noltimier, K. and 7 others, 1997. Antarctic Mapping Mission Planning Aids. BPRC Technical Report 97-01, 138 pages.

Noltimier, K.F. and K.C. Jezek, 1995. Variations in Radar Backscatter across the Great Ice Sheets. BPRC Technical Report 95-04, 35 pages.

Noltimier, K.F. and K.C. Jezek, 1996. Variations in radar backscatter across the great ice sheets. Geoscience and Remote Sensing Symposium Proceedings, IGARSS '96, v. 1, 142-144.

Noltimier, K.F., H. Sohn and K.C. Jezek, 1996. Derived Backscatter Values from JERS-1 Digital Number Distributions over Ross Island Antarctica. BPRC Technical Note 96-01, 12 pages.

Norikane, L., B. Wilson and K.C. Jezek, 1996. RADARSAT Antarctica mapping system: system overview. Geoscience and Remote Sensing Symposium Proceedings, IGARSS '96, v. 3, 1772-1774.

Norikane, L., B. Wilson and K. Jezek, 1998. RADARSAT Antarctic Mapping System: system overview - an update. Geoscience and Remote Sensing Symposium Proceedings, IGARSS '98, v. 1, 265-267.

Rignot, E. 2002. Mass balance of East Antarctic glaciers and ice shelves from satellite data. Annals of Glaciology, 34, 217-227.

Sohn, H., K. Jezek, F. Baumgartner, R. Forster and E. Mosley-Thompson, 1999. Radar backscatter measurements from RADARSAT SAR imagery of South Pole Station, Antarctica. Geoscience and Remote Sensing Symposium Proceedings, IGARSS '99, v. 5, 2360-2362.

Stearns, L., 2002. The Dynamic State of Whillans Ice Stream, West Antarctica. M.S. Thesis, The Ohio State University, 88 pages.

Stearns, L., K. Jezek and C. J. Van der Veen, 2005. Decadal scale variations in ice flow along Whillans Ice Stream and its tributaries, West Antarctica. Journal of Glaciology, 51(172), 147-157.

Van der Veen, C., K. Jezek and L. Stearns, 2007. Shear measurements across the northern margin of Whillans Ice Stream. Journal of Glaciology, 53(180), 17-29.

Wen, J., K. Jezek, B. Csatho, U. Herzfeld, K. Farness and P. Huybrechts, 2007. Mass budgets of the Lambert, Mellor and Fisher Glaciers and basal fluxes beneath their flowbands on Amery Ice Shelf. Science in China Series D: Earth Sciences, 50(11), 1693-1706.

Wen, J. and K. Jezek. A. Monaghan, B. Sun, J. Ren and P. Huybrechts, 2006. Accumulation variability and mass budgets of the Lambert Glacier-Amery Ice shelf system at high elevations. Annals of Glaciology, 43, 351-360.

Wu, X., 2002. Estimating Balance Velocities Using GIS-based Techniques. M.S. Thesis, The Ohio State University, 68 pages.

$\mathrm{Wu}, \mathrm{X}$. and K. Jezek, 2005. Antarctic Ice Sheet balance velocities from merged point and vector data. Journal of Glaciology, 50(169), 219-230. 
Wuite, J., 2006. Spatial and Temporal Dynamics of Three East Antarctic Outlet Glaciers and Their Floating Ice Tongues. Ph.D. Dissertation, The Ohio State University, 249 pages.

Wuite, J. and K. Jezek, 2007. Evidence of past fluctuations on Stancomb-Wills ice tongue, Antarctica, preserved by relict flow stripes. Journal of Glaciology, submitted.

Wuite, J., K. Jezek, X. Wu, K. Farness and R. Carande, 2007. The velocity field and flow regime of David Glacier and Drygalski Ice Tongue, Antarctica. Polar Geography, submitted.

Zhao, Z., 2001. Surface Velocities of the East Antarctic Ice Streams from Radarsat-1 Interferometric Synthetic Aperture Radar Data. Ph.D. Dissertation, The Ohio State University, 180 pages.

${ }^{1}$ Project documentation including calibration and validation reports, planning reports, requirements documents and similar materials are not listed here. All available reports are included with the data files provided to ASF and these are listed in Appendix 2. .

${ }^{2}$ Publications by the project are included here. As intended, other authors have used RAMP data and data products. Publications outside of the project are not listed here. 


\section{Appendix 1 Plates}

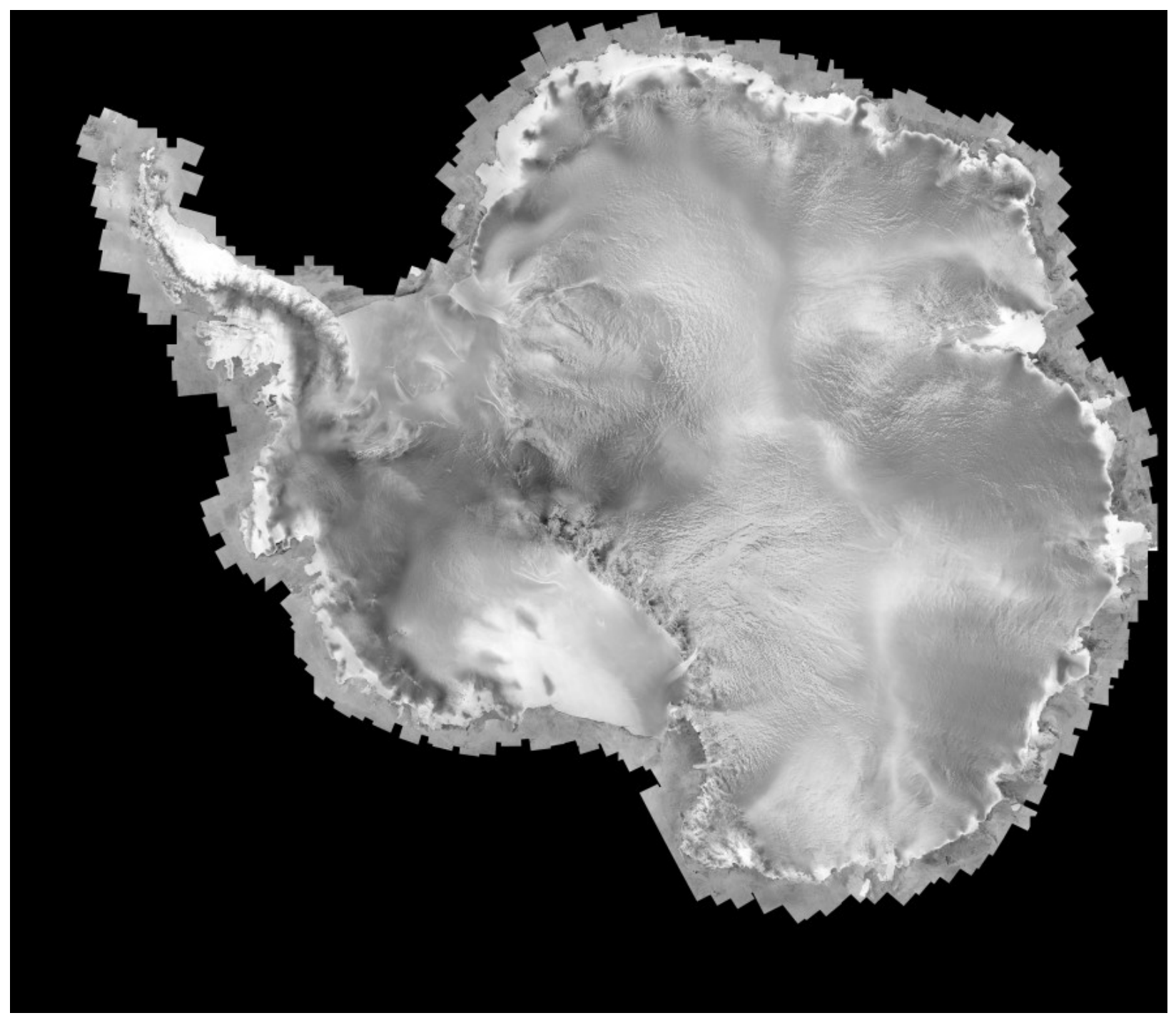

Plate 1. AMM-1 radiometrically balanced mosaic (log scale). 


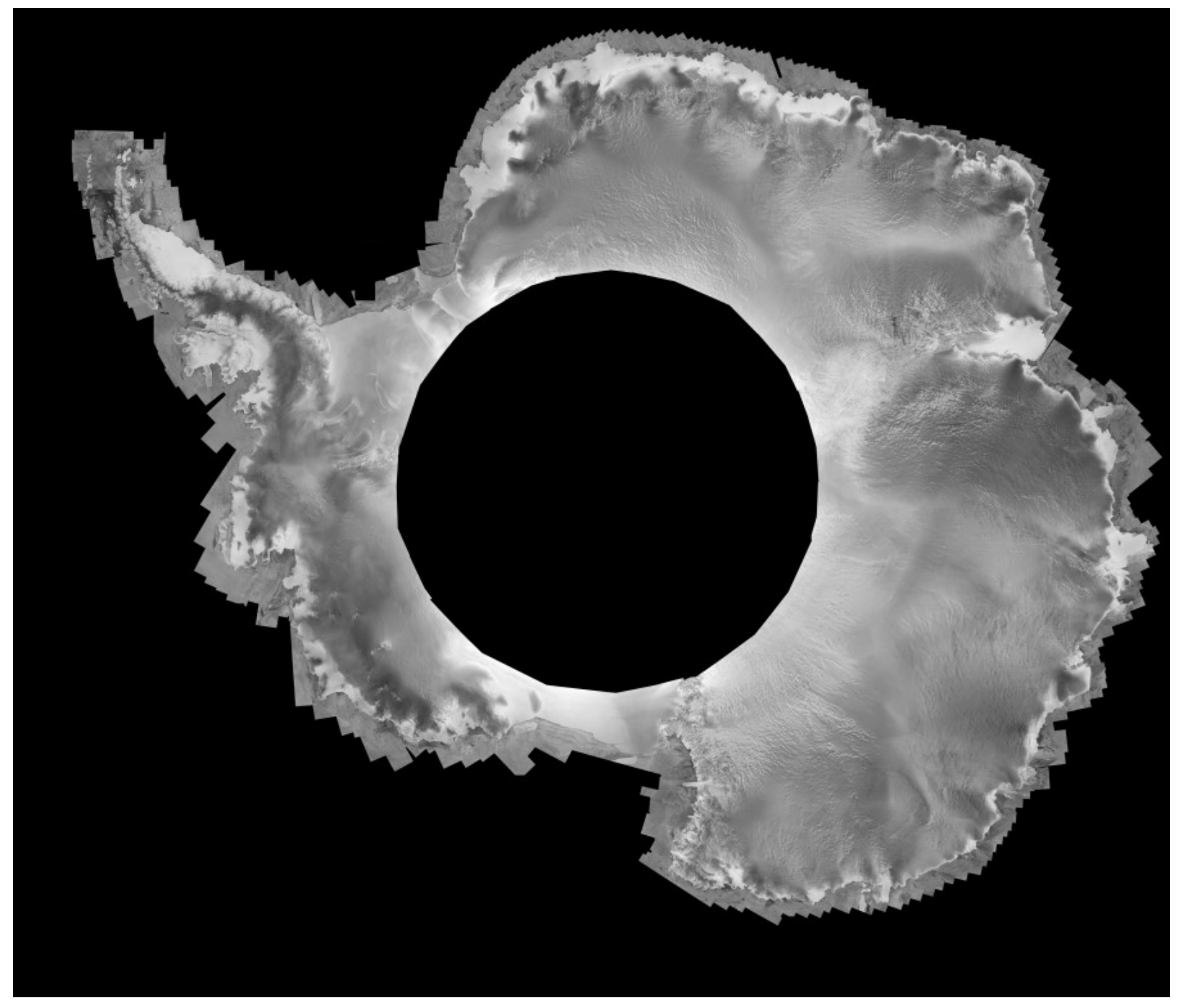

Plate 2. MAMM 2000 ascending radiometrically balanced mosaic (log scale). 


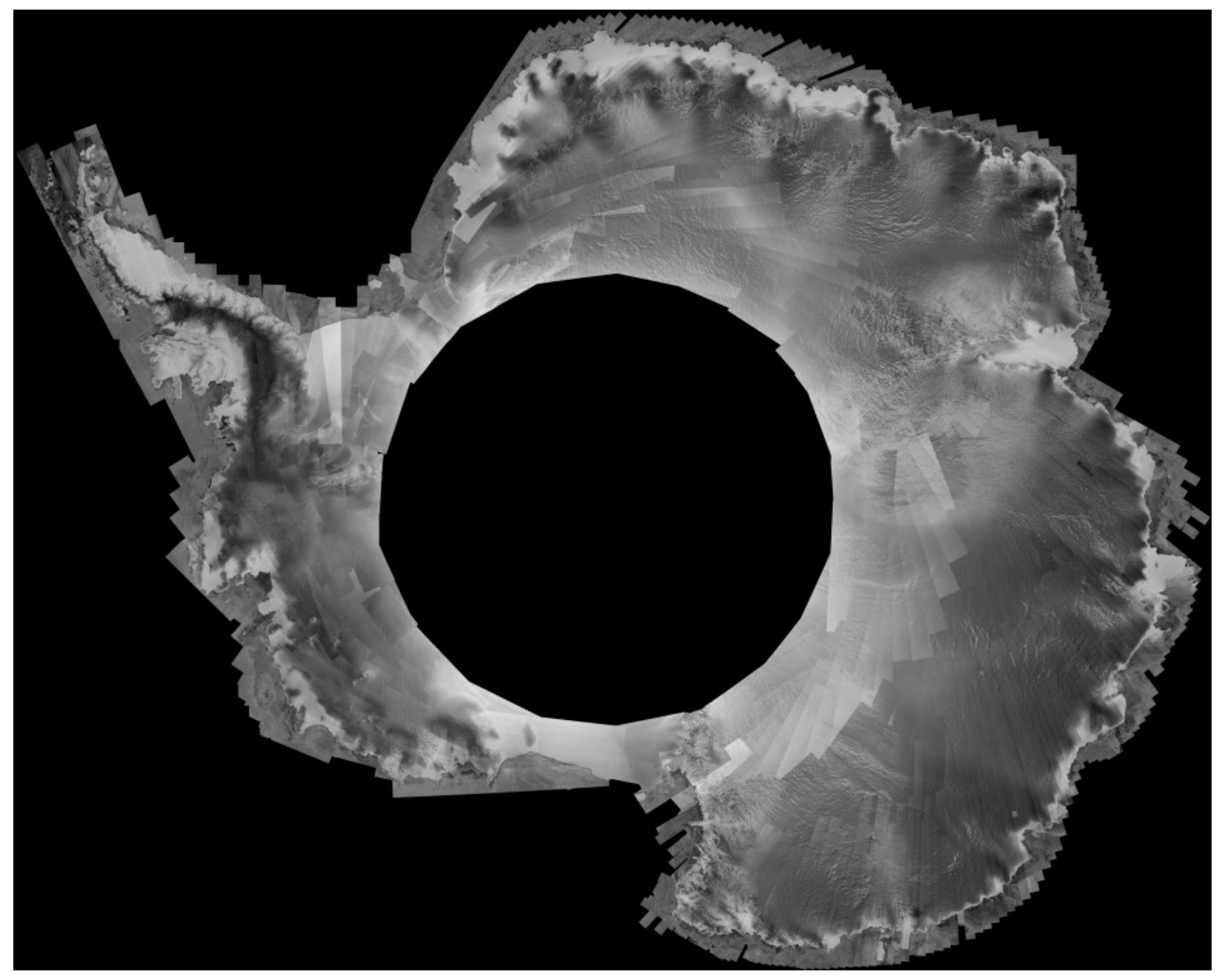

Plate 3. MAMM 2000 descending mosaic. No radiometric balancing applied (log scale). 


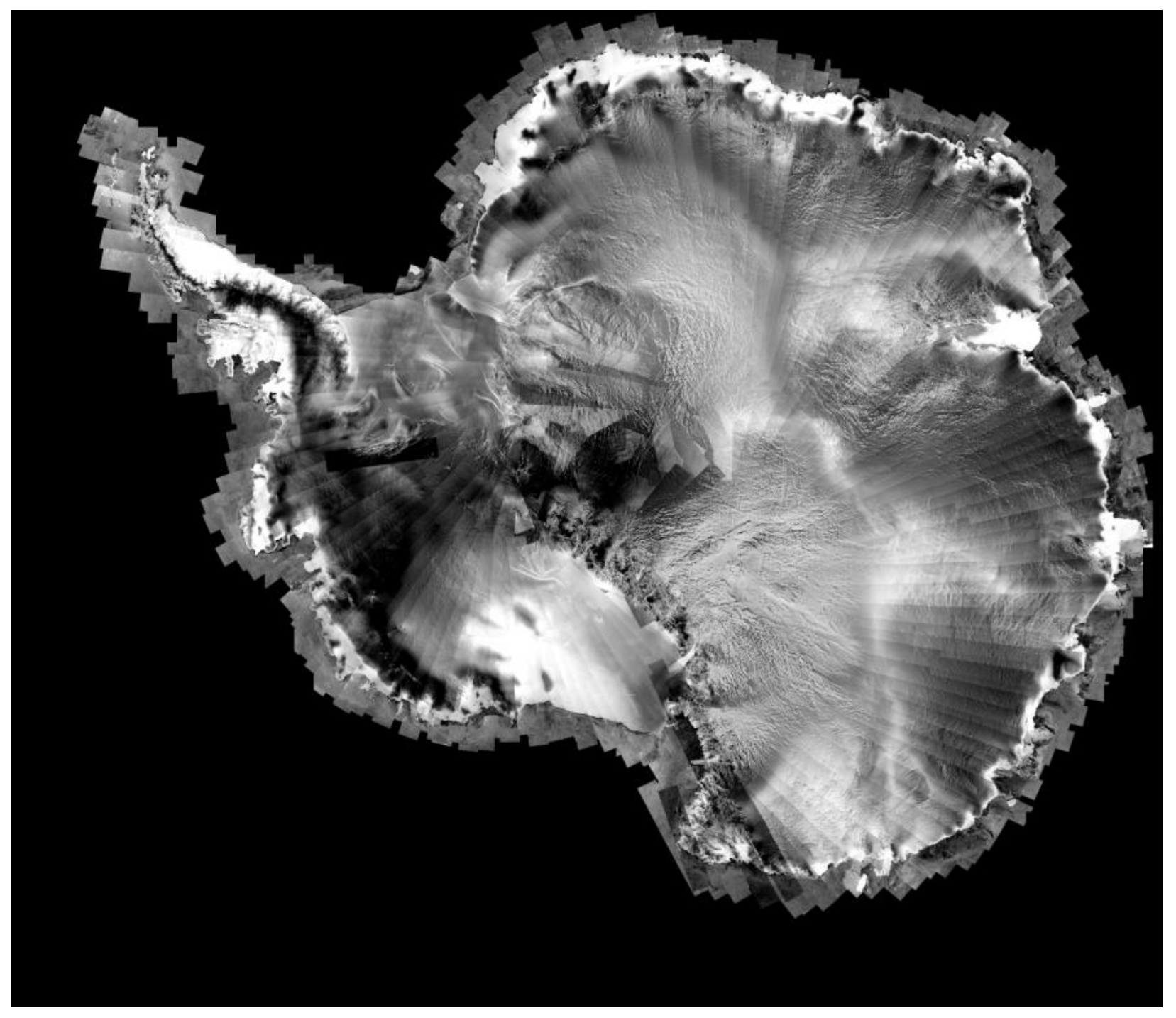

Plate 4. AMM backscatter coefficient. 


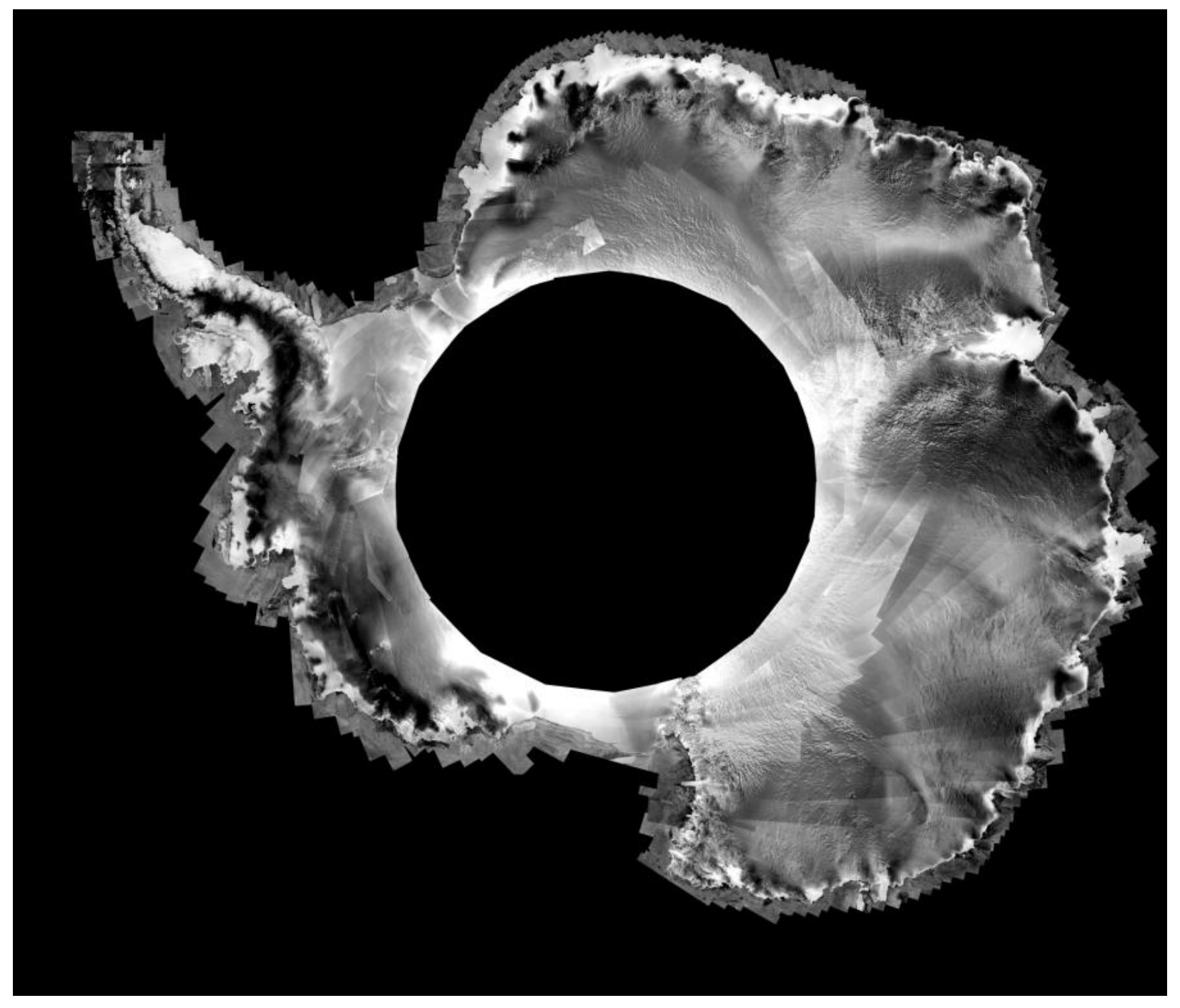

Plate 5. MAMM ascending backscatter coefficient. 


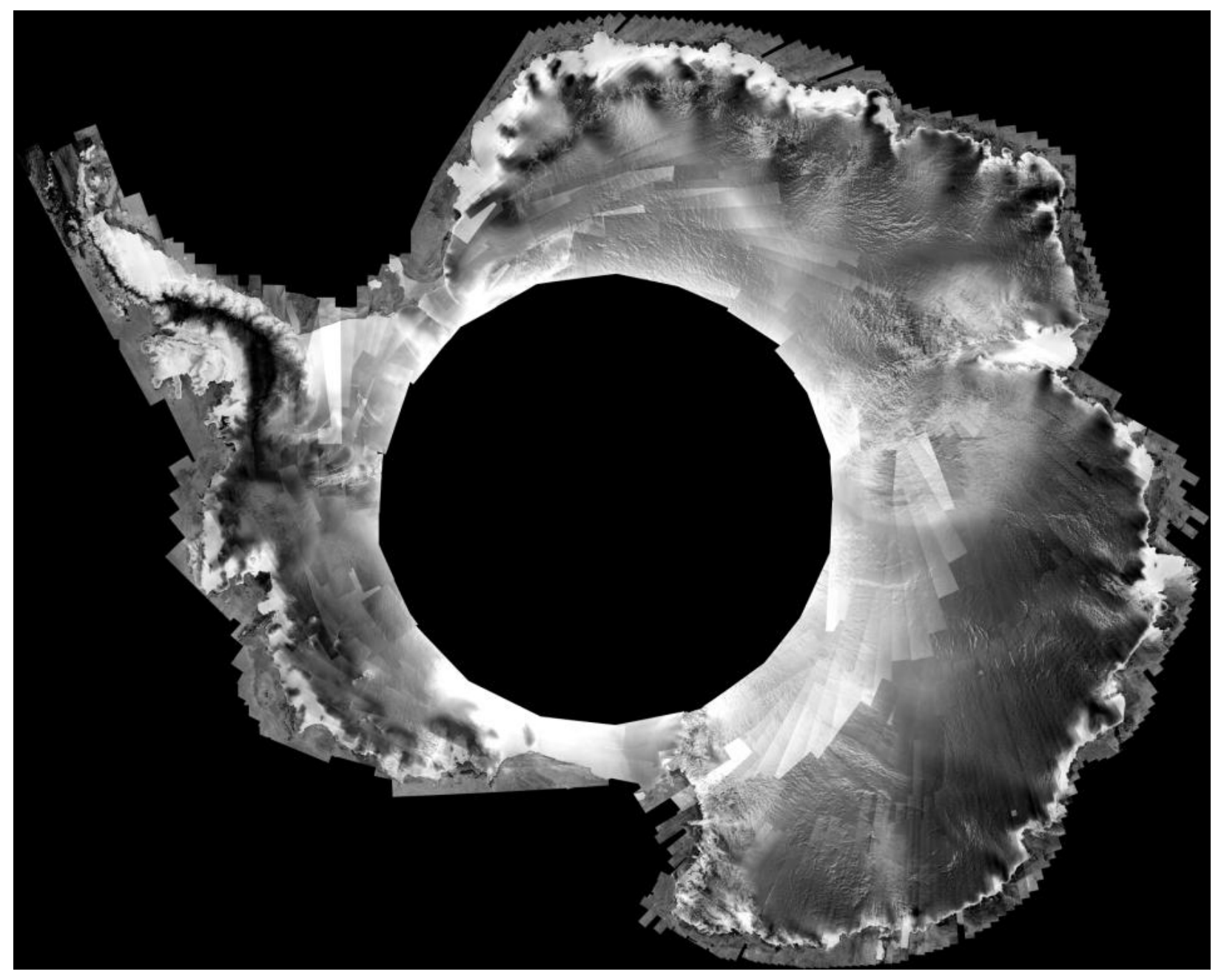

Plate 6. MAMM descending backscatter coefficient. 


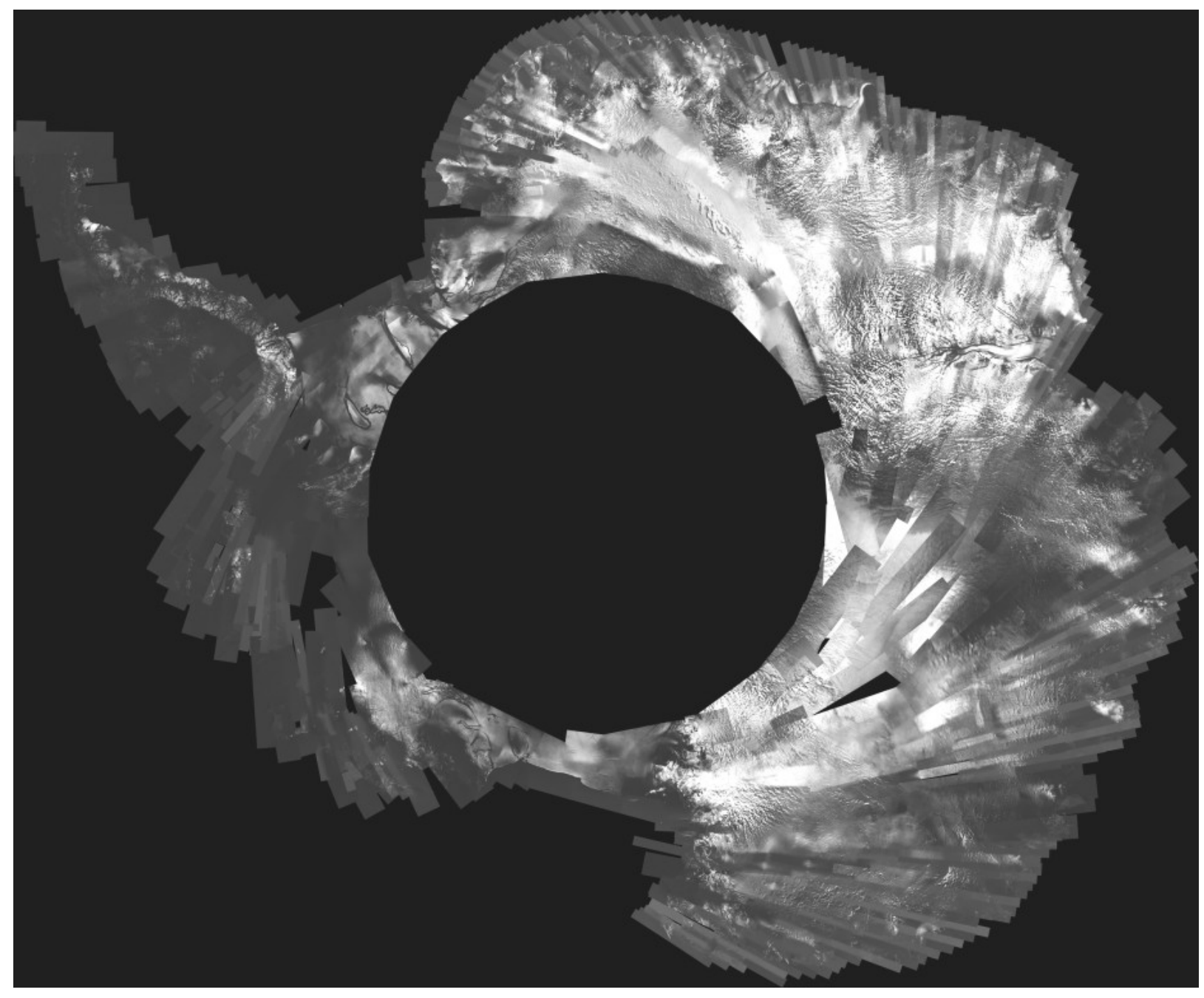

Plate 7. MAMM ascending coherence mosaic (smoothed). 


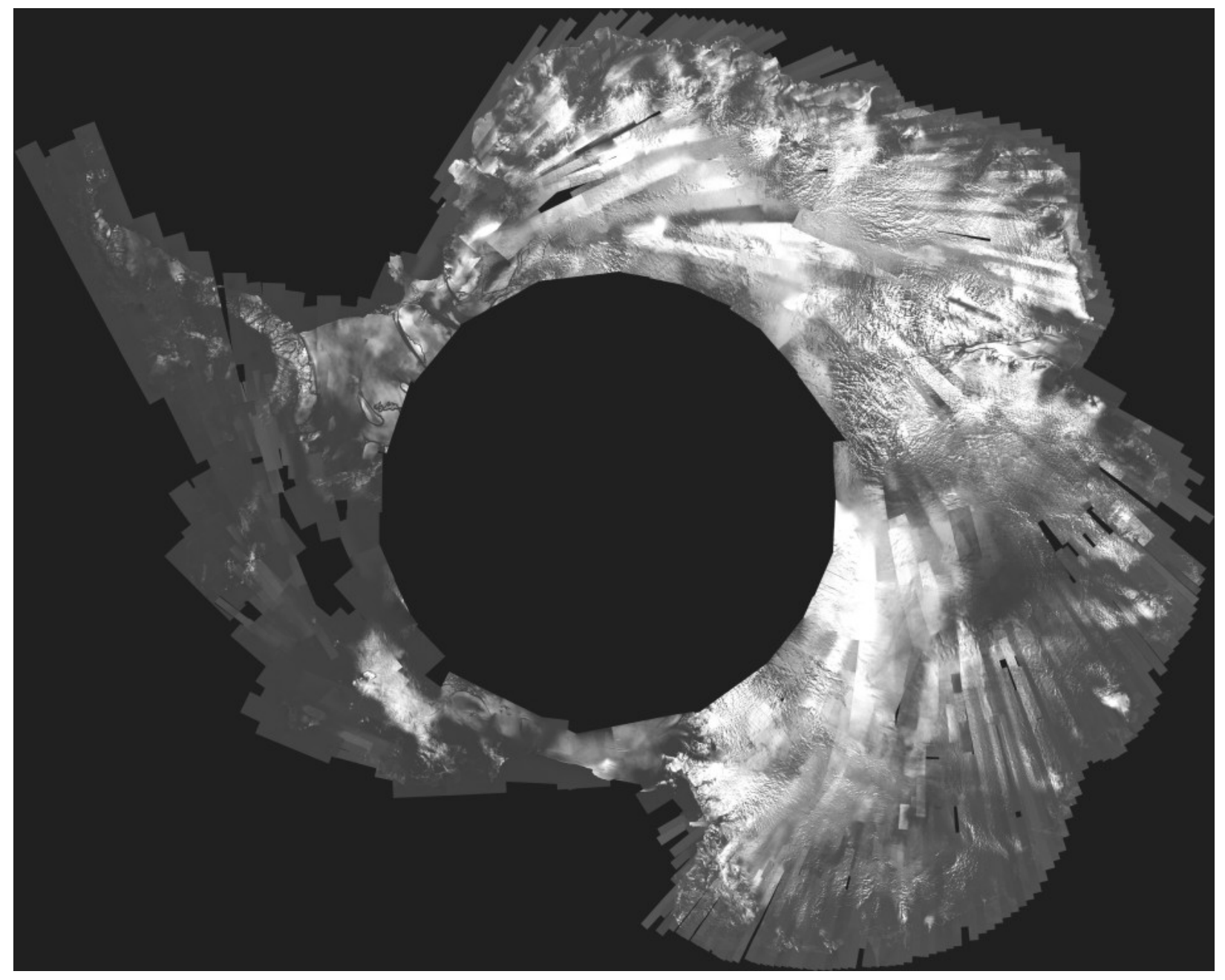

Plate 8. MAMM descending coherence mosaic (smoothed). 


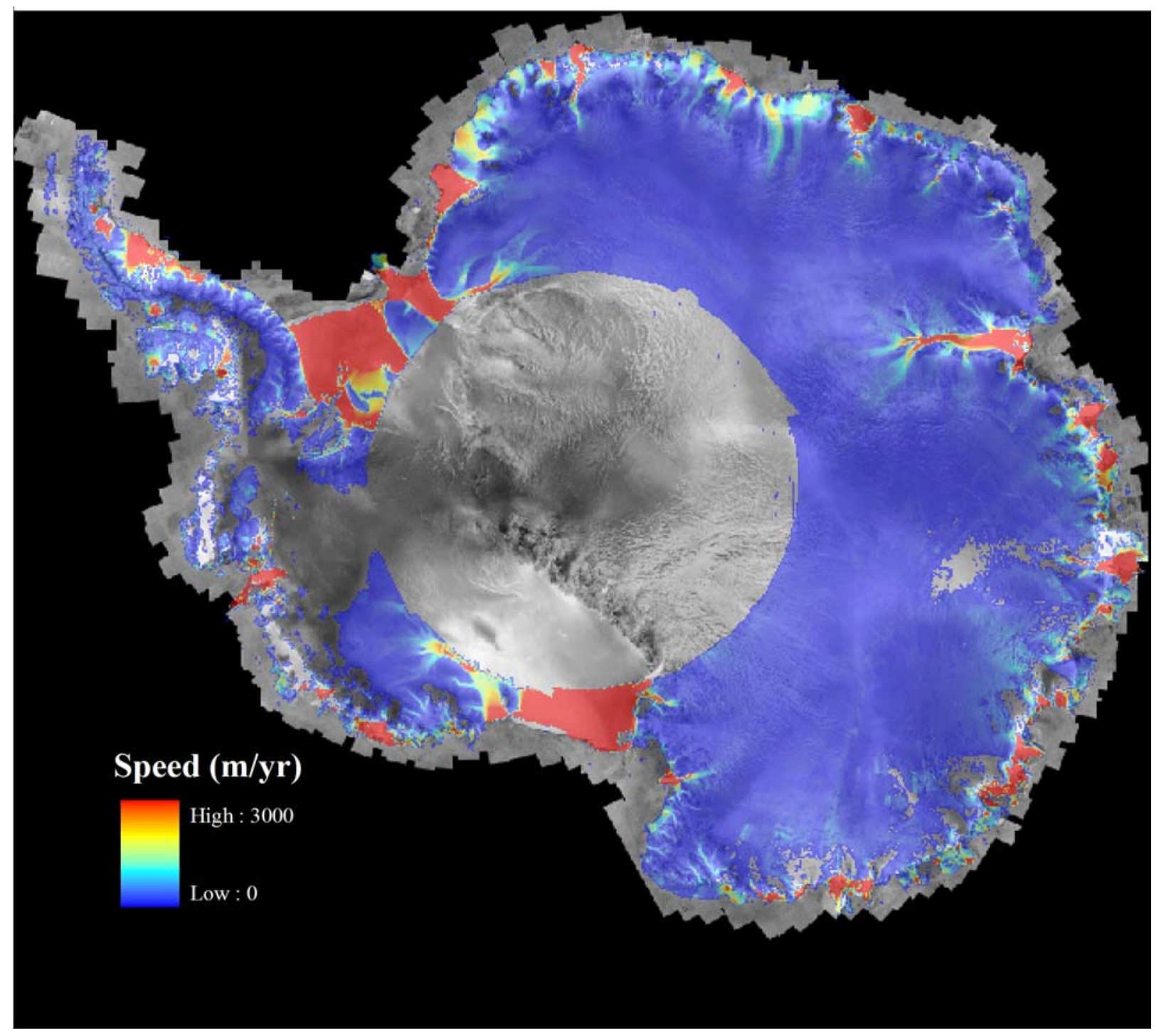

Plate 9. MAMM velocity mosaic. 


\section{Appendix 2 Product Spreadsheet}

All of the RAMP project and research products are compiled onto a pair of 750 GB hard disks. Copies of the disks were sent to the ASF DAAC and to several of our international partners for data distribution. A summary of the data products is given in the first table. The final table lists groups and individuals who have received the data disks and who have agreed to help with data distribution.

Note that many of the individual products are not unique. During the course of processing, we often found it convenient to prepare results at different resolutions or in different formats. We choose to retain the different combinations believing that others may find these useful.

Individuals interested in the data set are encouraged to either contact the Alaska Satellite Facility DAAC or one of the other major polar centers listed in the table. 


\begin{tabular}{|c|c|c|c|}
\hline \multicolumn{4}{|l|}{ RAMP Wrap up } \\
\hline Deliverables & $\begin{array}{l}\text { Directory structure on distributed } \\
\text { disks }\end{array}$ & File name & page \\
\hline \multicolumn{4}{|l|}{ AMM-1 Deliverables } \\
\hline $25 \mathrm{~m}$ Final Tiles & amm_v2/TILES & AMM-1 Final Tile Product & 48 \\
\hline $25 \mathrm{~m}$ Tile Overviews & amm_v2/TILES_OV & AMM-1 Overviews & 48 \\
\hline \multicolumn{4}{|l|}{ Balanced mosaics (8-bit) } \\
\hline $100 \mathrm{~m}$ & amm_v2/MOSAICS & amm1mos_100m & 48 \\
\hline $200 \mathrm{~m}$ & amm_v2/MOSAICS & amm1mos_200m & \\
\hline $400 \mathrm{~m}$ & amm_v2/MOSAICS & amm1mos_400m & \\
\hline $800 \mathrm{~m}$ & amm_v2/MOSAICS & amm1mos_800m & \\
\hline \multicolumn{4}{|l|}{ AMM-1 Research Products } \\
\hline \multicolumn{4}{|l|}{ Scaled dB Unit Mosaics (16 bit) } \\
\hline $100 \mathrm{~m}$ & amm_v2/MOSAICS & amm1sig0_100m & 51 \\
\hline $200 \mathrm{~m}$ & amm_v2/MOSAICS & amm1sig0_200m & \\
\hline $400 \mathrm{~m}$ & amm_v2/MOSAICS & amm1sig0_400m & \\
\hline $800 \mathrm{~m}$ & amm_v2/MOSAICS & amm1sig0_800m & \\
\hline \multicolumn{4}{|l|}{ dB Units Mosaics (32 bit) } \\
\hline $100 \mathrm{~m}$ & amm_v2/MOSAICS & amm1sig0_100m32bit & 51 \\
\hline $200 \mathrm{~m}$ & amm_v2/MOSAICS & amm1sig0_200m32bit & \\
\hline $400 \mathrm{~m}$ & amm_v2/MOSAICS & amm1sig0_400m32bit & \\
\hline $800 \mathrm{~m}$ & amm_v2/MOSAICS & amm1sig0_800m32bit & \\
\hline Scaled dB units $25 \mathrm{~m}$ Tiles (16 bit) & amm_v2/TILES_dB & "TILENAME"sig0amm1 & 51 \\
\hline Incidence Angle Mosaic & amm_v2/MOSAICS & amm1_v2_angles & 20 \\
\hline Quicklook Mosaic (1km) & amm_v2/MOSAICS & amm1_qlook_1km & \\
\hline DEM & amm_v2/DEM & vexcel200m.dem & 38,40 \\
\hline AMM-1 Coastline & amm_v2/COASTLINE & after_isl_ll & 15,39 \\
\hline Flowlines & amm_v2/COASTLINE & flowlines.e00 & 16,39 \\
\hline \multicolumn{4}{|l|}{ CONTROL POINTS } \\
\hline location gifs & amm_v2/CONTROL_POINTS & Project ground control pts & 13 \\
\hline summary & amm_v2/CONTROL_POINTS & & \\
\hline source data & amm_v2/CONTROL_POINTS & & \\
\hline \multicolumn{4}{|l|}{ EAST ANTARCTIC VELOCITY } \\
\hline griddata & amm_v2/EAST_ANTARCTIC & InSAR Work done by Z. & 35 \\
\hline imaginefiles & amm_v2/EAST_ANTARCTIC & Zhao on the East Antarctic & \\
\hline linecoverage & amm_v2/EAST_ANTARCTIC & Ice Streams using AMM-1 & \\
\hline otherdata & amm_v2/EAST_ANTARCTIC & repeat pass data & \\
\hline \multicolumn{4}{|l|}{ DOCUMENTATION } \\
\hline 8-bit_conversion_equations.pdf & amm_v2/DOCS & & \\
\hline AMM1_ASF_Calibration.pdf & amm_v2/DOCS & & \\
\hline AMM1_Noise_Recalibration_Sum.xls & amm_v2/DOCS & & \\
\hline AMM1_Radar_Caliber_Deployment.pdf & amm_v2/DOCS & & \\
\hline AMM1_radiometry.pdf & amm_v2/DOCS & & \\
\hline AMM1_Sci_Requirements.pdf & amm_v2/DOCS & & \\
\hline AMM1_Sig0_evalr4.pdf & amm_v2/DOCS & & \\
\hline AMM1_sig0_tiers evaluation.pdf & amm_v2/DOCS & & \\
\hline Amplitude.pdf & amm_v2/DOCS & & \\
\hline FinaTileValidation.pdf & amm_v2/DOCS & & \\
\hline RAMP_Description.pdf & amm_v2/DOCS & & \\
\hline Sigma0_comparison.pdf & amm_v2/DOCS & & \\
\hline
\end{tabular}




\begin{tabular}{|c|c|c|c|}
\hline \multicolumn{4}{|l|}{ MISSION_PLANS } \\
\hline AMM_file.txt & amm_v2/MISSION_PLANS & Mission planning data for & 8,10 \\
\hline AMM_final & amm_v2/MISSION_PLANS & the AMM-1 mission & \\
\hline SPA_AMM & amm_v2/MISSION_PLANS & & \\
\hline insar & amm_v2/MISSION_PLANS & & \\
\hline nom_c1 & amm_v2/MISSION_PLANS & & \\
\hline \multicolumn{4}{|l|}{ MAMM Deliverables } \\
\hline Velocity Product & mamm/VELOCITY & MAMM Velocity Product & 41,56 \\
\hline \multicolumn{4}{|l|}{ ASCENDING (ASC) } \\
\hline Asc 25 m Final Tiles (Tile Product) & mamm/ASCENDING/TILES & MAMM Final Tile Product & 49 \\
\hline Asc $25 \mathrm{~m}$ Tile overviews & mamm/ASCENDING/TILES_OV & MAMM Coh Overviews & 49 \\
\hline Asc 200m Final Coherence Product & mamm/ASCENDING/COHERENCE_PROD & MAMM Coh Overiews & 33,54 \\
\hline Asc 200m Coherence overviews & mamm/ASCENDING/COHERENCE_OV & MAMM Coh Overviews & 33,54 \\
\hline $10 \mathrm{~m}$ mini-mosaics & mamm/ASCENDING/MOSAICS & MAMM Mini-Mosaics & 17 \\
\hline \multicolumn{4}{|l|}{ Balanced Asc Mosaic (8 bit) } \\
\hline $100 \mathrm{~m}$ & mamm/ASCENDING/MOSAICS & mamm_asc_lin100m.bin & 49 \\
\hline $100 \mathrm{~m}$ & mamm/ASCENDING/MOSAICS & mamm_asc_log $100 \mathrm{~m}$.bin & \\
\hline $125 \mathrm{~m}$ & mamm/ASCENDING/MOSAICS & mamm_asc_lin125m.bin & \\
\hline $125 \mathrm{~m}$ & mamm/ASCENDING/MOSAICS & mamm_asc_log125m.bin & \\
\hline $200 \mathrm{~m}$ & mamm/ASCENDING/MOSAICS & mamm_asc_lin200m.bin & \\
\hline $200 \mathrm{~m}$ & mamm/ASCENDING/MOSAICS & mamm_asc_log200m.bin & \\
\hline $400 \mathrm{~m}$ & mamm/ASCENDING/MOSAICS & mamm_asc_lin400m.bin & \\
\hline $400 \mathrm{~m}$ & mamm/ASCENDING/MOSAICS & mamm_asc_log $400 \mathrm{~m}$.bin & \\
\hline $800 \mathrm{~m}$ & mamm/ASCENDING/MOSAICS & mamm_asc_lin800m.bin & \\
\hline $800 \mathrm{~m}$ & mamm/ASCENDING/MOSAICS & mamm_asc_log800m.bin & \\
\hline Asc Coherence Mosaic 200m (8 bit) & mamm/ASCENDING/MOSAICS & $\begin{array}{l}\text { coh_asc_arc \& } \\
\text { coh_asc_block }\end{array}$ & 33,54 \\
\hline Asc Coherence Mosaic 200m (32 bit) & mamm/ASCENDING/MOSAICS & coh_asc_block32bit & 33,54 \\
\hline \multicolumn{4}{|l|}{ DESCENDING (DESC) } \\
\hline Desc 25m Block Overviews (16 bit) & mamm/DESCENDING/BLOCK_OV & blk_\#\#_Ov_\#\#\# & \\
\hline Desc 200m Final Coherence Product & mamm/DESCENDNG/COHERENCE_PROD & MAMM Coh Overviews & 33,55 \\
\hline Des 200m Coherence overviews & mamm/DESCENDING/COHERENCE_OV & MAMM Coh Overviews & 33,55 \\
\hline \multicolumn{4}{|l|}{ Desc Mosaic (8 bit, no radiometry) } \\
\hline $100 \mathrm{~m}$ & mamm/DESCENDING/MOSAICS & mamm_desc_100m_log & 50 \\
\hline $200 \mathrm{~m}$ & mamm/DESCENDING/MOSAICS & mamm_desc_200m_log & \\
\hline $400 \mathrm{~m}$ & mamm/DESCENDING/MOSAICS & mamm_desc_400m_log & \\
\hline $800 \mathrm{~m}$ & mamm/DESCENDING/MOSAICS & mamm_desc_800m_log & \\
\hline Desc Coherence Mosaic 200m (8 bit) & mamm/DESCENDING/MOSAICS & $\begin{array}{l}\text { coh_desc_arc \& } \\
\text { coh_des_block }\end{array}$ & 33,55 \\
\hline Desc Coherence Mosaic 200m (32 bit) & mamm/DESCENDING/MOSAICS & coh_desc_block32bit & 33,55 \\
\hline \multicolumn{4}{|l|}{ MAMM Research Products } \\
\hline Balance Velocity Map & mamm/VEL_BAL & balvel_10k, balvel_20k & 31 \\
\hline \multicolumn{4}{|l|}{ ASCENDING (ASC) } \\
\hline MAMM Coastline & mamm/ASCENDING/COASTLINE & cst2000line & \\
\hline \multicolumn{4}{|l|}{ Scaled dB Asc Mosaic (16-bit) } \\
\hline $100 \mathrm{~m}$ & mamm/ASCENDING/MOSAICS & mammsig0_asc_100m & 52 \\
\hline $200 \mathrm{~m}$ & mamm/ASCENDING/MOSAICS & mammsig0_asc_200m & \\
\hline
\end{tabular}




\begin{tabular}{|c|c|c|c|}
\hline $400 \mathrm{~m}$ & mamm/ASCENDING/MOSAICS & mammsig0_asc_400m & \\
\hline $800 \mathrm{~m}$ & mamm/ASCENDING/MOSAICS & mammsig0_asc_800m & \\
\hline \multicolumn{4}{|l|}{ dB Asc Mosaic (32-bit) } \\
\hline $100 \mathrm{~m}$ & mamm/ASCENDING/MOSAICS & mammsig0_asc_100m32bit & 52 \\
\hline $200 \mathrm{~m}$ & mamm/ASCENDING/MOSAICS & mammsig0_asc_200m32bit & \\
\hline $400 \mathrm{~m}$ & mamm/ASCENDING/MOSAICS & mammsig0_asc_400m32bit & \\
\hline $800 \mathrm{~m}$ & mamm/ASCENDING/MOSAICS & mammsig0_asc_800m32bit & \\
\hline Scaled dB Asc 25m Tile Overviews (16-bit) & mamm/ASCENDING/TILES_dB & "TILENAME"sig0mamm & 52 \\
\hline Asc Swath Coherence Mosaic (8 bit) & mamm/ASCENDING/MOSAICS & coh_asc_arc & \\
\hline Asc Swath Coherence Mosaic (32-bit) & mamm/ASCENDING/MOSAICS & coh_asc_arc32bit & \\
\hline Asc Coherence Blocks 200m (8 bit) & mamm/ASCENDING/COHERENCE_OV & blk_\#\# & \\
\hline Smoothed Asc Coherence Mosaic (8 bit) & mamm/ASCENDING/MOSAICS & coh_asc_smooth & 54 \\
\hline Incidence Angle Mosaic & mamm/ASCENDING/MOSAICS & mamm_asc_angles & 20 \\
\hline \multicolumn{4}{|l|}{ DESCENDING (DESC) } \\
\hline \multicolumn{4}{|l|}{ Scaled dB Desc Mosaic (16-bit) } \\
\hline $100 \mathrm{~m}$ & mamm/DESCENDING/MOSAICS & mammsig0_desc_100m & 52 \\
\hline $200 \mathrm{~m}$ & mamm/DESCENDING/MOSAICS & mammsig0_desc_200m & \\
\hline $400 \mathrm{~m}$ & mamm/DESCENDING/MOSAICS & mammsig0_desc_400m & \\
\hline $800 \mathrm{~m}$ & mamm/DESCENDING/MOSAICS & mammsig0_desc_800m & \\
\hline \multicolumn{4}{|l|}{ dB Desc Mosaic (32-bit) } \\
\hline $100 \mathrm{~m}$ & mamm/DESCENDING/MOSAICS & mammsig0_des_100m32bit & 52 \\
\hline $200 \mathrm{~m}$ & mamm/DESCENDING/MOSAICS & mammsig0_des_200m32bit & \\
\hline $400 \mathrm{~m}$ & mamm/DESCENDING/MOSAICS & mammsig0_des_400m32bit & \\
\hline $800 \mathrm{~m}$ & mamm/DESCENDING/MOSAICS & mammsig0_des_800m32bit & \\
\hline Scaled dB Desc 25 m Blk overvu (16-bit) & mamm/DESCENDING/BLOCKS_dB & "BlockName"sig0mamm & 52 \\
\hline Desc Swath Coherence Mosaic (8 bit) & mamm/DESCENDING/MOSAICS & coh_desc_arc & \\
\hline Desc Swath Coherence Mosaic (32 bit) & mamm/DESCENDING/MOSAICS & coh_desc_32bit & \\
\hline Desc Coherence Blocks 200m (8 bit) & mamm/DESCENDING/BLOCKS_OV & & \\
\hline Smoothed Desc Coherence Mosaic (8 bit) & mamm/DESCENDING/MOSAICS & coh_desc_smooth & 55 \\
\hline Incidence Angle Mosaic & mamm/DESCENDING/MOSAICS & mamm_desc_angles & \\
\hline \multicolumn{4}{|l|}{ VELOCITY CONTROL POINTS } \\
\hline location gifs & mamm/CONTROL_POINTS & Project velocity control & 30 \\
\hline summary & mamm/CONTROL_POINTS & points & \\
\hline source data & mamm/CONTROL_POINTS & & \\
\hline \multicolumn{4}{|l|}{ MISSION_PLANS } \\
\hline Fianl_MAMMM_Plans & mamm/MISSION_PLANS & Mission planning data for & 9,10 \\
\hline MAMM_SPA_export & mamm/MISSION_PLANS & the MAMM mission & \\
\hline Presentations & mamm/MISSION_PLANS & & \\
\hline SPA_MAMM & mamm/MISSION_PLANS & & \\
\hline various documents & mamm/MISSION_PLANS & & \\
\hline \multicolumn{4}{|l|}{ DOCUMENTATION } \\
\hline 8-bit_conversion_equations.pdf & mamm/DOCS & & \\
\hline 8-bit_conversion_equations_desc.pdf & mamm/DOCS & & \\
\hline Amplitude.pdf & mamm/DOCS & & \\
\hline Asc_Bandwidth_Along_Track.pdf & $\mathrm{mamm} / \mathrm{DOCS}$ & & \\
\hline Asc_Baseline_Perpendicular.pdf & mamm/DOCS & & \\
\hline Asc_Coastal_25m.pdf & mamm/DOCS & & \\
\hline Asc_Coastline_100m.pdf & mamm/DOCS & & \\
\hline Asc_Geo_Rad.pdf & $\mathrm{mamm} / \mathrm{DOCS}$ & & \\
\hline Asc_Interior_100m.pdf & mamm/DOCS & & \\
\hline
\end{tabular}




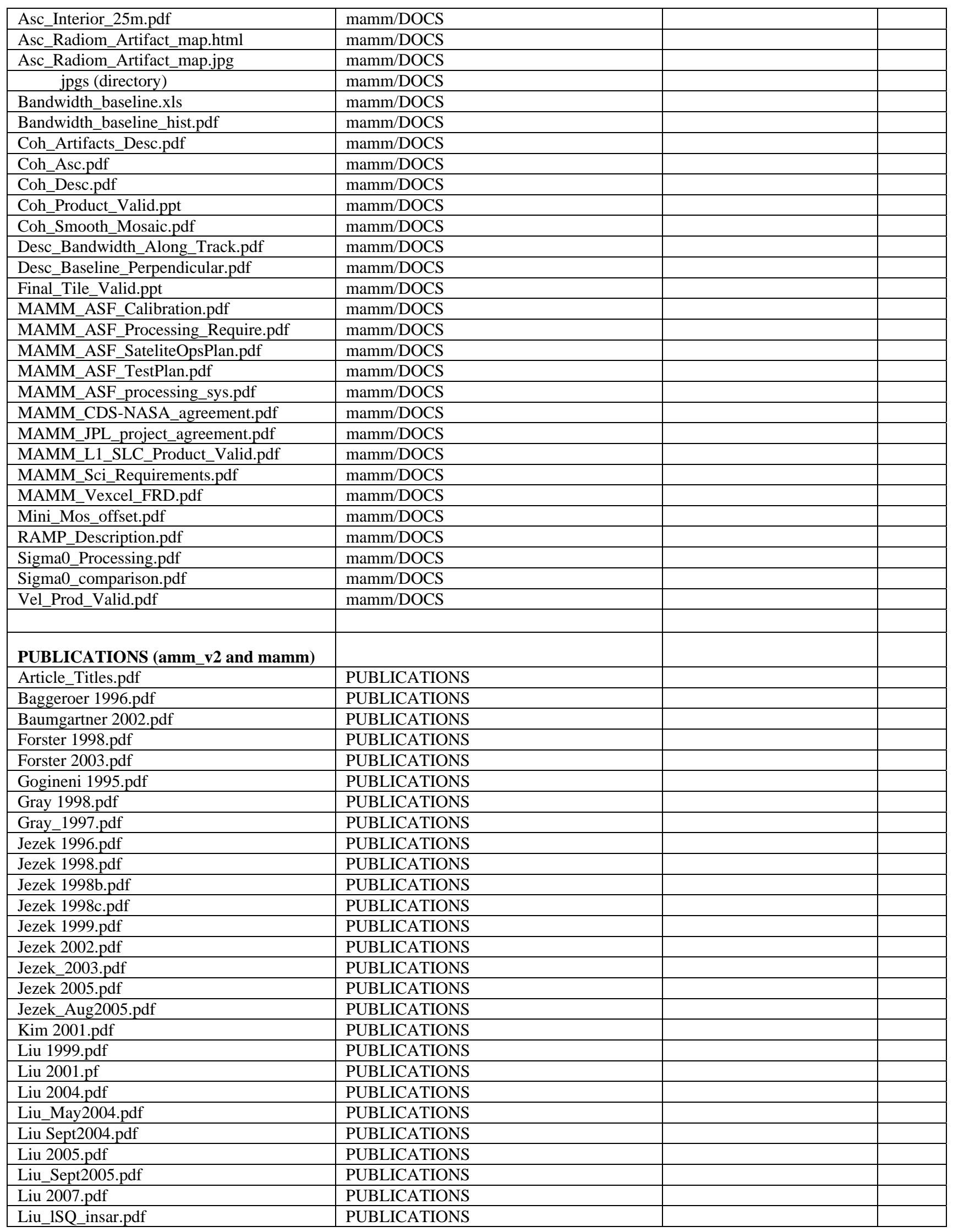




\begin{tabular}{|l|l|l|l|}
\hline Noltimier 1996.pdf & PUBLICATIONS & & \\
\hline Noltimier 1998.pdf & PUBLICATIONS & & \\
\hline Noltimier 1999.pdf & PUBLICATIONS & & \\
\hline Noltimier 2000.pdf & PUBLICATIONS & & \\
\hline Paden 2005.pdf & PUBLICATIONS & & \\
\hline Sterns 2005.pdf & PUBLICATIONS & & \\
\hline VanDerVeen_2007.pdf & PUBLICATIONS & & \\
\hline Wen_2006.pdf & PUBLICATIONS & & \\
\hline Wen_Amery_MassBudget.pdf & PUBLICATIONS & & \\
\hline Wu_Balance_Velocities.pdf & PUBLICATIONS & & \\
\hline & & & \\
\hline THESIS (amm_v2 and mamm) & & & \\
\hline kim_Dissertation.pdf & & & \\
\hline kim_ms_thesis.pdf & PUBLICATIONS/THESIS & \\
\hline liu_Dissertation.pdf & PUBLICATIONS/THESIS & & \\
\hline sterns_thesis.pdf & PUBLICATIONS/THESIS & & \\
\hline wuite_Dissertation.pdf & PUBLICATIONS/THESIS & & \\
\hline wu_thesis.pdf & PUBLICATIONS/THESIS & & \\
\hline zhao_dissertation.pdf & PUBLICATIONS/THESIS & & \\
\hline & PUBLICATIONS/THESIS & & \\
\hline FUn_STUFF (amm_v2 and mamm) & & & \\
\hline Movies & & & \\
\hline Stills & FUN_STUFF & & \\
\hline
\end{tabular}




\section{Data Distribution Contact Information}

Nettie La Belle-Hamer

Alaska Satellite Facility

903 Koyukuk Dr

Fairbanks, AK 99775

Waleed Abdalati

NASA Goddard Space Flight

Center

Code 614.1, Bld 33, Room A205

Greenbelt, MD 20771

Xiaoqing Wu, James Miller

Vexcel Corp

1690 38th Street

Boulder, CO 80301

John Crawford

Jet Propulsion Lab

Mail Stop 301-170S

4800 Oak Grove Drive

Pasadena, CA 91109

Prasad Gogenini

University of Kansas

CReSIS

339 Nichols Hall

2335 Irving Hill Rd

Lawrence, KS 66045

Yves Crevier

CSA Headquarters

6767 Route de l'Aeroport

Longueuil, Quebec J3Y 8Y9
Norbert Ott

Alfred Wagener Institute

Van-Ronzelen - Strabe 2

Bremerhaven, Germany

D-27568

\section{A. Paul R. Cooper}

British Antarctic Survey

Madingley Rd

Cambridge, England CB3 0ET

Ursula Ryan

Australian Antarctic Data Centre

Australian Antarctic Division

203 Channel Highway

Kingston, Tasmania 7050

\section{Hongxing Liu}

University of Texas

Dept. of Geography

814 C O\&M Building

College Station, TX 77845

Frederique Remy

Equipe Glaciologie - Legos

Observatoire Midi-Pyrenees

14, Avenue Edourad Belin

Toulouse, France 31400

Ole Morton Olsen

Norsk Polarinstitutt

Polarmiljosenteret

9296 Tromso, Norway 


\section{Appendix 3 RAMP Team Members}

\begin{tabular}{|c|c|c|}
\hline OSU & Marc Forbes & ERIM \\
\hline Kenneth Jezek & Jamie Marshner & Robert Onstott \\
\hline Katy Farness & Jeremy Nicholl & \\
\hline Hong Xing Liu & Paul Brown & CCRS \\
\hline Hong Gyoo Sohn & Dave Fluetsch & Lawrence Gray \\
\hline Zhiyuan Zhao & Richard Marlin & Kevin Adams \\
\hline Biyan Li & Brett Delana & Doug Banks \\
\hline Steve Mather & Ruth Duerr & \\
\hline Xiaolan Wu & Barb Severin & RSI \\
\hline Jan Wuite & Cindy Wilson & Bill Jeffries \\
\hline Ed Oshel & Tom George & \\
\hline Rick Forster & Martha Mason & NASA HQ \\
\hline Jens Munk & Rudi Gens & Martha Maiden \\
\hline Everett Fortner & Carel Lane & Richard Monson \\
\hline Tom Kassabaum & & Robert Thomas \\
\hline Ada Chan & JPL & Prasad Gogineni \\
\hline Bradon Love & John Crawford & Kim Partington \\
\hline \multirow[t]{2}{*}{ Carrie Dratwa } & Frank Carsey & Stan Wilson \\
\hline & Ben Holt & Bill Townsend \\
\hline Vexcel Corporation & Tom Bicknell & \\
\hline John Curlander & Dick Harding & NASA GSFC \\
\hline Richard Carande & Pat Liggett & Paul Ondrus \\
\hline Lynn Norikane & Dave Cuddy & Bill Potter \\
\hline Bob Wilson & Rick Austin & Vanessa Griffin \\
\hline James Miller & Ian Joughin & \\
\hline Xiaoqing Wu & Ramachand Bhat & NSF \\
\hline Tom Fetterer & Sue Digby & Pat Smith \\
\hline Peter Nagy & Kon Leung & Erick Chiang \\
\hline Dave Aparicio & Dave Nichols & \\
\hline \multicolumn{3}{|l|}{ Rob Fatland } \\
\hline Chris Lesher & CSA & \\
\hline Craig Oberg & Ken Lord & \\
\hline Dan Cronin & Surendra Parashar & \\
\hline \multirow[t]{2}{*}{ Tom Baltzer } & Ed Langham & \\
\hline & Rolf Mamen & \\
\hline Alaska Satellite Facility & Don Showalter & \\
\hline Carl Wales & Ken Ashworth & \\
\hline Verne Kaupp & Satish Srivastiva & \\
\hline Nettie Labelle-Hamer & Stephanie Ruel & \\
\hline Vicky Wolf & Greg Hammel & \\
\hline Michelle Harbin & George Harris & \\
\hline Rick Guritz & Rejean Michou & \\
\hline Greta Reynolds & Jean Muller & \\
\hline
\end{tabular}

